Portland State University

PDXScholar

\title{
Transit-Oriented Development and Equity in Latino Neighborhoods: A Comparative Case Study of MacArthur Park (Los Angeles) and Fruitvale (Oakland)
}

Gerardo Francisco Sandoval

University of Oregon

Roanel Herrera

University of Oregon

Follow this and additional works at: https://pdxscholar.library.pdx.edu/trec_reports

Part of the Transportation Commons, and the Urban Studies and Planning Commons Let us know how access to this document benefits you.

\section{Recommended Citation}

Gerardo Francisco Sandoval \& Herrera, R. Transit-Oriented Development and Equity in Latino Neighborhoods: A Comparative Case Study of MacArthur Park (Los Angeles) and Fruitvale (Oakland). NITC-RR-544. Portland, OR: Transportation Research and Education Center (TREC), 2015. http://dx.doi.org/10.15760/trec.58

This Report is brought to you for free and open access. It has been accepted for inclusion in TREC Final Reports by an authorized administrator of PDXScholar. Please contact us if we can make this document more accessible: pdxscholar@pdx.edu. 

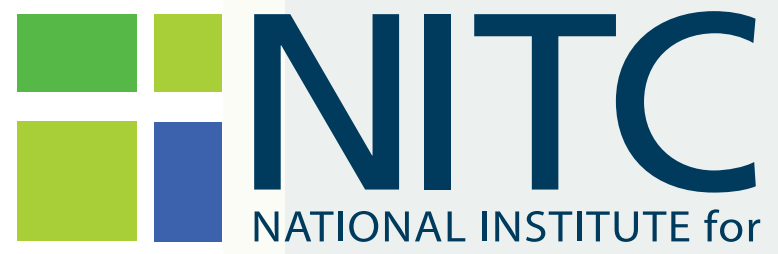

TRANSPORTATION and COMMUNITIES

\section{FINAL REPORT}

Transit-Oriented Development and Equity in Latino Neighborhoods:

\section{A Comparative Case Study of Macarthur Park (Los Angeles) and Fruitvale (Oakland)}

NITC-RR-544 April 2015

NITC is the U.S. Department of Transportation's national university transportation center for livable communities.

H:" TREC 


\section{TRANSIT-ORIENTED DEVELOPMENT AND EQUITY IN LATINO NEIGHBORHOODS:}

\section{A COMPARATIVE CASE STUDY OF MACARTHUR PARK (LOS ANGELES) AND FRUITVALE (OAKLAND)}

\section{Final Report}

NITC-RR-544

by

Gerardo Francisco Sandoval, PhD

Roanel Herrera, MCRP

University of Oregon

Department of Planning, Public Policy \& Management

for

National Institute for Transportation and Communities (NITC)

P.O. Box 751

Portland, OR 97207
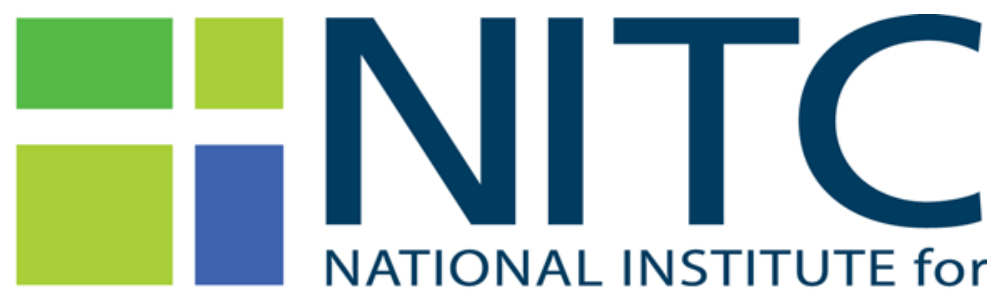

TRANSPORTATION and COMMUNITIES

April 2015 



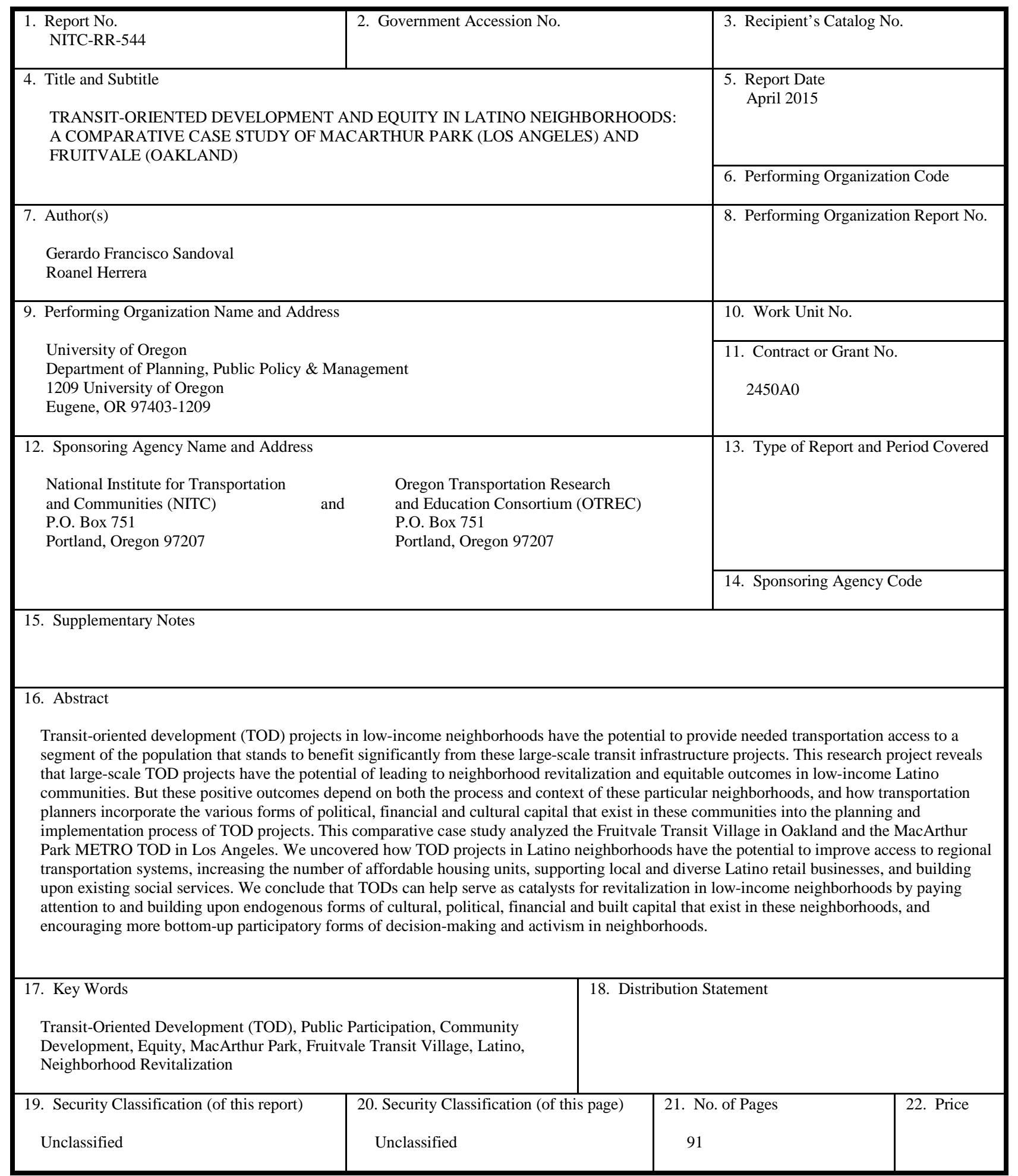




\section{ACKNOWLEDGEMENTS}

This project was made possible with funding from the Oregon Transportation Research and Education Consortium (OTREC).

\section{DISCLAIMER}

The contents of this report reflect the views of the authors, who are solely responsible for the facts and the accuracy of the material and information presented herein. This document is disseminated under the sponsorship of the U.S. Department of Transportation University Transportation Centers Program and OTREC in the interest of information exchange. The U.S. Government and the sponsoring parties assume no liability for the contents or use thereof. The contents do not necessarily reflect the official views of the U.S. Government or OTREC. This report does not constitute a standard, specification, or regulation. 


\section{TABLE OF CONTENTS}

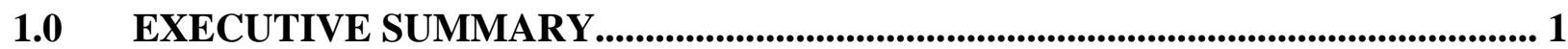

2.0 INTRODUCTION \& BACKGROUND.............................................................................. 5

2.1 PURPOSE AND OBJECTIVES OF RESEARCH PROJECT.......................................... 6

2.2 THEORETICAL FRAMING AND CASE STUDY METHOD......................................... 7

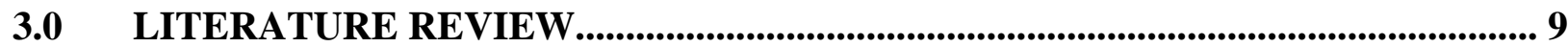

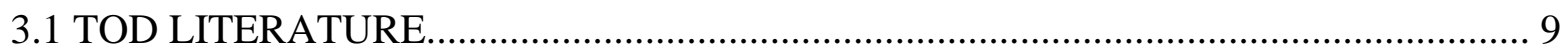

3.1.1 Defining Transit-Oriented Development............................................................ 10

3.1.2 Limitations of Current Data Collection Practices.................................................. 12

3.2 HISTORY OF FEDERAL TRANSPORTATION POLICY RELATED TO COMMUNITIES OF COLOR ………………………............................................ 13

3.3 TRANSPORTATION JUSTICE AND TOD EQUITY CONCERNS................. 15

3.4 DEBATES ON TOD EQUITY IN LOW-INCOME POPULATIONS.................. 16

3.4.1 Building Support for Equity in Transit-Oriented Development .......................... 16

3.4.2 Unintended Consequences? TODs and Gentrification......................................... 17

3.4.2.1 Government-Forced

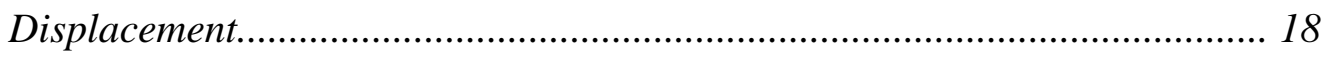

3.4.2.2 Market-Driven Displacement: Gentrification................................................ 19

4.0 THEORETICAL FRAMING \& METHODS................................................................. 21

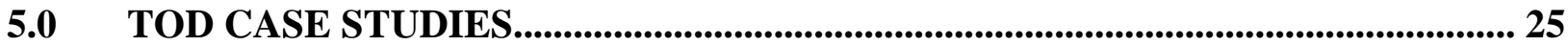

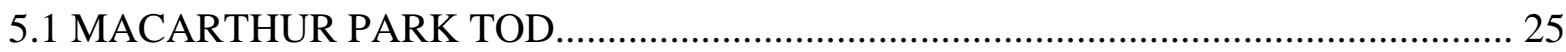

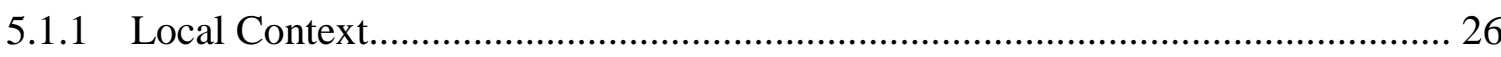

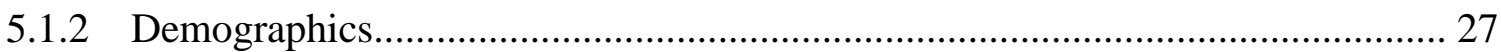

5.1.3 Story of Project.............................................................................................. 32

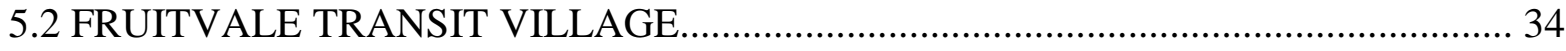

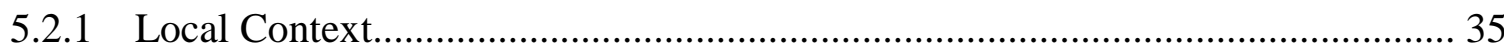

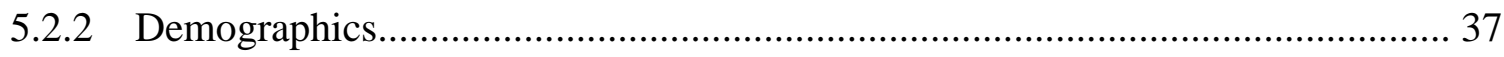

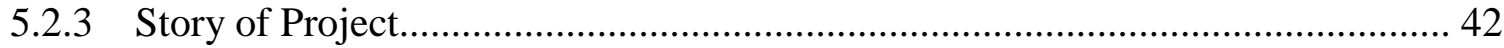

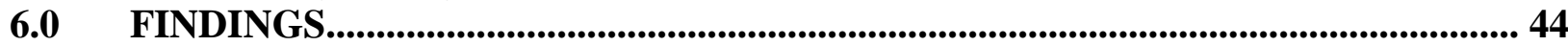

6.1 POLITICAL, FINANCIAL AND CULTURAL FORMS OF CAPITAL IN THE

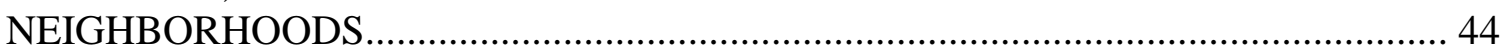

6.1.1 Role CBOs Played in Transforming TOD Projects............................................... 44

6.1.2 Local Latino Politicians as Champions.................................................................. 48

6.1.3 Supporting Latino Small Businesses in Revitalization Efforts.............................. 51

6.1.4 Latino Placemaking as Community Anchor........................................................... 55

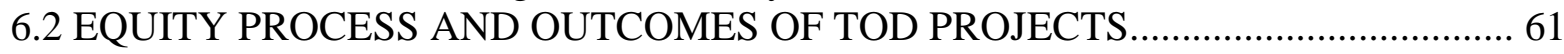

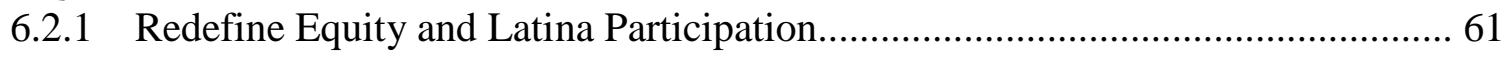

6.2.2 Equity Outcomes in the Neighborhood.................................................................6 63

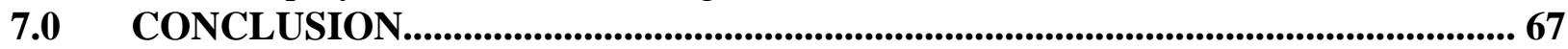

7.1 CATALYSTS FOR TRANSFORMING AND IMPROVING LOW-INCOME, LATINO COMMUNITIES.

7.1.1 Support Endogenous Forms of Cultural, Political, Financial and Built Capital that

Exist in these Neighborhoods

7.1.2 Encourage More Authentic Bottom-Up Participatory Forms of Decision-Making 


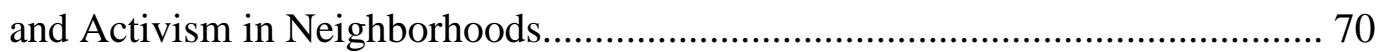

7.1.3 Support Increased Access to Equity Outcomes.................................................. 72

7.2 FUTURE RESEARCH ON TODs IN LATINO NEIGHBORHOODS........................ 73

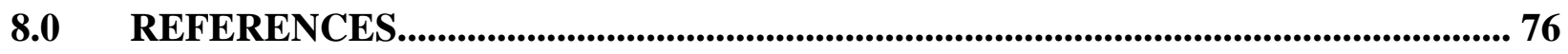

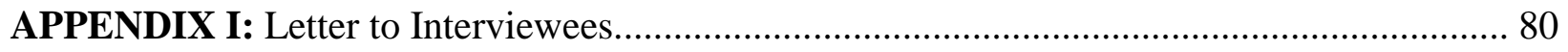

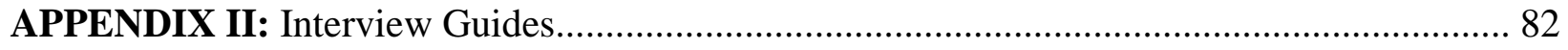




\section{LIST OF TABLES}

Table 1: Total Population for MacArthur Park and the City of Los Angeles............................. 28

Table 2: Total Population for Fruitvale and the City of Oakland........................................... 38 


\section{LIST OF FIGURES}

Figure 1: The TOD is Located Across the Street from MacArthur Park, a Regional Public Space

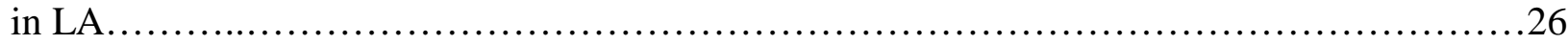
Figure 2: Hispanic or Latino by Race-Percentages of Population for MacArthur Park and the

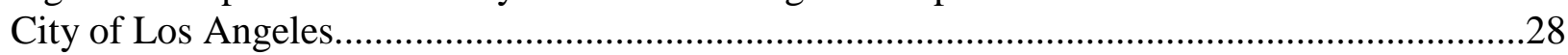

Figure 3: Income Disparities between MacArthur Park and the City of Los Angeles.................. 29 Figure 4: Percentages of the Population Above and Below Poverty Level for MacArthur Park

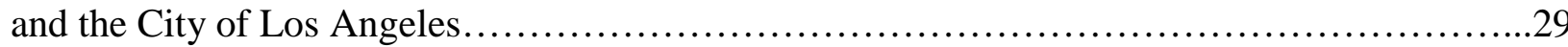
Figure 5: Percentages of U.S. Native and Foreign-Born Residents in MacArthur Park and the City of Los Angeles. .................................................................. 30 Figure 6: The Years of Arrival in the U.S. of Immigrants in MacArthur Park and the City of Los Angeles. 30

Figure 7: Affordability of Rents in MacArthur Park, Compared with the Entire City of Los Angeles. 31

Figure 8: Distribution in Rents Between MacArthur Park and the City of Los Angeles.............. 31

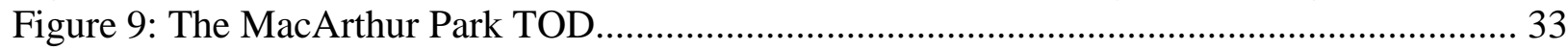

Figure 10: Fruitvale Transit Village Paseo (Pedestrian Way)........................................................ 35

Figure 11: The Fruitvale Transit Village..................................................................................... 37

Figure 12: Hispanic or Latino by Race-Percentages of Population for Fruitvale and the City of

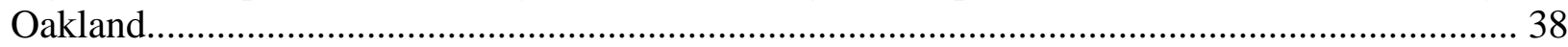

Figure 13: Income Disparities Between Fruitvale and the City of Oakland................................. 39 Figure 14: Percentages of the Population Above and Below Poverty Level for Fruitvale and the

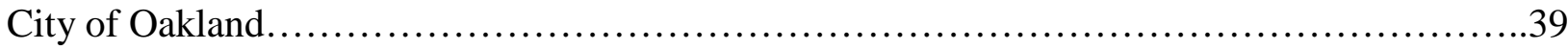
Figure 15: Percentages of U.S. Native and Foreign-Born Residents in Fruitvale and the City of

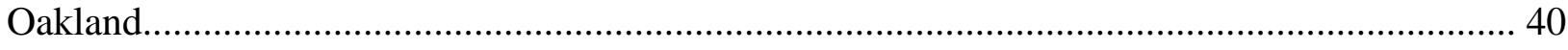

Figure 16: The Years of Arrival in the U.S. of Immigrants in Fruitvale and the City of Oakland

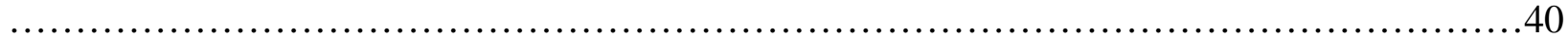

Figure 17: Affordability of Rents in Fruitvale, Compared with the Entire City of Oakland......... 41

Figure 18: Distribution in Rents between Fruitvale and the City of Oakland.............................. 41

Figure 19: International Blvd.'s Latino Small Businesses have Benefitted from the TOD......... 53

Figure 20: Located in the Center of the Image, this View of the Cathedral was Designed into the TOD (image was taken from BART's platform)........................................................................ 57

Figure 21: Youth Soccer Fields in MacArthur Park, Which as a Collective are Officially Considered a Meadow............................................................................................................ 59

Figure 22: The New Monsignor Oscar Romero Plaza Across the Street from the TOD............... 60 Figure 23: Arabella Martinez's Plaque at the Fruitvale TOD Site is a Reminder of her Leadership and Contribution to the Project. 63 


\subsection{EXECUTIVE SUMMARY}

Historically, large-scale transportation infrastructure projects have had devastating outcomes in low-income communities of color. This research project has examined whether contemporary transit-oriented development (TOD) projects in two low-income Latino neighborhoods have offered a different trajectory, and incorporated the neighborhood's dynamics within TOD plans to encourage more equitable outcomes in these projects. Planning equity debates around TODs in low-income communities of color center on whether these projects serve as catalysts for neighborhood redevelopment or as tools for displacement and/or gentrification. These TOD projects have the potential to provide needed public transportation access and community benefits linked to those transportation investments, but there are risks. The new investments in transportation may lead to changes in land use patterns and housing stock, and attracting new commercial investments can lead to neighborhood displacement and higher turnover rates. In this research project, we document the literature on transportation equity and present two in-depth case studies of large scale TODs in Latino neighborhoods. The two case studies are examples of large-scale TOD projects transformed by community stakeholders into catalysts for more equitable neighborhood revitalization. These more equitable outcomes depend on both the process and context of these particular neighborhoods, and how planners incorporate the various forms of political, financial and cultural capital that exist in these communities into the planning and implementation process of TOD projects.

The literature review covers the emerging debates on TOD and equity within communities of color. We first discuss the difficulty in defining TOD. We then focus on transportation justice issues as they relate to TOD equity concerns. We review the history of federal transportation policy and how certain policies have created inequities in low-income communities of color. Lastly, the scholarly debates regarding the relationship between TODs, low-income populations and equity is presented. Debates such as the links between TOD and neighborhood displacement and/or gentrification are analyzed. Researchers, for example, are increasingly concerned with providing guidance to city planners across the country who are interested in learning how they can ensure that TOD projects are inclusive, equitable, and better serve the needs of diverse populations.

The case studies reveal how TOD projects in Latino neighborhoods have the potential to open up access to regional transportation systems; increase the number of affordable housing units in a neighborhood; support local and diverse Latino retail businesses; and build upon existing social services such as medical and educational services. The research also reveals the important role bottom-up participatory processes play in promoting endogenous forms of capital in these 
neighborhoods. The analysis was conducted by comparing and contrasting the equity effects of two large TOD projects in low-income, Latino immigrant communities, which revealed how, under what circumstances, and through what mechanisms TOD impacted equity outcomes in those neighborhoods. Our ultimate aim is to provide a thick description of these two TOD projects to help transportation planners better understand the possibilities that TOD has in revitalizing low-income, Latino immigrant communities without widespread displacement and community disruption.

The research engaged the Community Capitals Framework (CCF), which helped provide an understanding of the endogenous forms of capital that exist in these Latino low-income neighborhoods and how these forms of capital influenced the TOD projects. Via this framework, we studied the cultural, financial, political and built forms of capital that exist in the neighborhoods. Analyzing these forms of capital helped to answer how the institutional, sociocultural and political context of these low-income, Latino immigrant communities allowed residents to reshape large-scale redevelopment projects in a more equitable and generative fashion.

We used a replicable case study design focused on two neighborhoods: Fruitvale in Oakland, CA, and MacArthur Park in Los Angeles. We built off of the theoretical findings from a past narrative case study of MacArthur Park, which was conducted by Dr. Gerardo Sandoval (2010). By using a qualitative in-depth case study approach, the research answered the following key question(s):

How might low-income Latino communities benefit from large-scale TOD projects? What are the risks to these neighborhoods if TODs are linked to neighborhood revitalization? And what are the neighborhood characteristics that exist within Latino communities that can help mitigate those risks and create more equitable outcomes?

By answering these research questions and understanding both the process and outcomes that contributed to community revitalization, this research contributes to the emerging literature on transit equity. The report also contributes to a better understanding of how TODs revitalize marginalized neighborhoods, and we provide concrete recommendations for creating TODs that may potentially lead to more equitable outcomes in low-income communities of color.

According to the former secretary of the U.S. Department of Housing and Urban Development (Shaun Donovan), MacArthur Park METRO is considered a national example of linking affordable housing to public transportation via TOD. This TOD project is comprised of new high-density housing and retail. It is located in one of the most densely populated neighborhoods in Los Angeles. The majority of residents are recent immigrants from Central America and Mexico, who have significantly lower incomes and rely heavily on public transportation. Initially, the top-down redevelopment project did not take the local community into consideration, and actually aimed to change the demographics in the neighborhood by bringing in luxury condos and higher-end retail (Sandoval, 2010). Community leaders, with the help of 
local Latino politicians, were able to create a more bottom-up TOD project that has contributed to community benefits.

The Fruitvale Transit Village emerged in 2004 as a \$100 million mixed-use project. It is adjacently located to the Bay Area Rapid Transit's (BART) Fruitvale Station. The Fruitvale Transit Village is located in the Fruitvale District (pop. 51,000). The project was a top-down, community-oriented project that had strong Latino leadership. The TOD project was designed as a social service-oriented TOD. However, the development also contains affordable housing and retail space. Fruitvale is home to many recent Latino immigrants. Over half of all families in the area speak a language other than English at home. One-fifth of the community's households live under the poverty line, which is why the service providers located at the TOD site are an important community resource.

In analyzing both the process and outcomes of these two case studies, we find that large-scale TOD projects have the potential of contributing to equity outcomes and generative urban revitalization in low-income, Latino immigrant communities. But this very much depends on the neighborhood context, the various forms of political, financial and cultural capital that exist in these communities, and how these capitals are incorporated into the planning process.

Community-based organizations (CBOs) played an important role in developing each project because they had a significant amount of political capital (from the top-down political model the Unity Council used to the more bottom-up networked approach CBOs used in MacArthur Park). Local Latino politicians also served as champions for the TOD projects by using their political capital to make sure the projects were implemented. The financial forms of capital within the neighborhoods included Latino small businesses that were very active in the neighborhood's revitalization efforts. In Fruitvale, Latino small businesses along International Boulevard greatly benefitted from the new physical connection the TOD provided between International Boulevard and the BART station. The Fruitvale TOD project created a paseo that served as a nicely designed pedestrian way that brought both spaces (International Boulevard and the BART station) together in a synergistic fashion. In MacArthur Park, the TOD project forced city officials to address issues related to the informal businesses in the neighborhood. As a result, hundreds of street vendors surrounding the TOD site were formalized through an innovative street vendors district.

Cultural capital also played a key role in how the TOD project transformed the neighborhood. The community's Latino placemaking efforts, for example, were instrumental in fueling local opposition to METRO's original top-down transportation plans. In Fruitvale, these placemaking efforts are seen via both the TOD project's culturally appropriate design and the cultural celebrations that take place in the paseo and plaza. MacArthur Park is also an important area in Los Angeles where Mexican and Central American immigrants express their cultural traits via placemaking (i.e., community celebrations such as Feria Agostina attract thousands of Central Americans to the park).

This research reveals the importance of providing authentic public participation opportunities in designing and implementing TOD projects. Both of our cases involved substantive participation 
from Latina women leaders who had a strong leadership style, an activist background, and decision-making power throughout the TOD project's development process. The various forms of capital within the neighborhood created an authentic public participation climate where community concerns were taken seriously during decision-making processes. The two largescale TOD projects contributed to equity outcomes in the neighborhood by providing increased access to regional public transportation and affordable housing; encouraging diverse local small businesses; and improving social services in the neighborhood, such as medical and educational services.

Hence, our overall findings conclude that large-scale TODs can serve as catalysts for lowincome neighborhoods by paying attention to and building upon three important factors in these neighborhoods:

1) Supporting the endogenous forms of cultural, political, financial and built capital that exist in these neighborhoods.

2) Encouraging more bottom-up participatory forms of decision-making and activism in neighborhoods.

3) Incorporating and supporting increased access to:

a. Regional public transportation

b. Affordable housing

c. Supporting a diverse local small business base

d. Social services provisions like medical and educational facilities

e. Authentic public participation

The Fruitvale Transit Village and MacArthur Park METRO TOD projects serve as important examples of how large-scale transportation projects can improve and provide community benefits for low-income Latino communities. The cases highlight the importance of working within the context of a neighborhood, and the important role neighborhood dynamics play in creating more equitable-based outcomes. These two cases also shed light on the important role transportation planners play in supporting more equitable outcomes by building on the endogenous forms of capital that exist in these neighborhoods, and by creating opportunities for authentic public participation. 


\subsection{INTRODUCTION \& BACKGROUND}

Transportation equity has been gaining attention from both transit academics and practitioners. The concept is still being defined as transportation planners grapple with debates related to increasing access to transit systems; decision-making on transit investments; and the detrimental, disproportional, negative effects of transit systems on low-income communities of color. In more recent years, TOD, or the creation of compact, livable and walkable communities near mass transit facilities, has become a promising trend in sustainable development planning. There are no clearly agreed upon definitions of TOD; hence we define TOD in a broad way as the distance people are willing to walk to public transit and the development that occurs because of that connection between walking and a transit node (Dittman and Ohrland, 2004). TOD has the potential of connecting workers to employment centers, creating jobs, and spurring investments in areas that have suffered neglect and economic disinvestment. TOD projects in low-income communities also have the potential to create new models of community development, as these large-scale transportation systems serve as catalysts for capital investment in these neighborhoods. They could potentially improve regional transportation connectivity, and reduce the social and economic isolation that many low-income communities face.

Historically, large infrastructural transportation projects have had devastating outcomes in lowincome communities of color. During urban renewal, communities of color were forcefully displaced, and their neighborhoods were destroyed to make way for large-scale transportation systems (Mohl, 2008). The construction of freeways, for example, many times ran through lowincome communities and cut them off from job opportunities, displaced residents from homes and neighborhoods, and physically/spatially separated neighborhoods. Logan Heights in San Diego is a prime example of how freeways served to separate Latino neighborhoods, as well as many cases in East Los Angeles. Today's large-scale transportation projects also similarly have the potential of disrupting low-income communities of color as they are linked to land use and commercial development projects that aim to change existing neighborhoods. However, now most of this disruption comes in the form of market-driven displacement (gentrification).

Even though this dark history of interventions exits within the transportation field, one cannot deny or underestimate the importance transportation investments play in potentially revitalizing low-income neighborhoods. However, most of the literature on the topic justly traces the detrimental consequences of large-scale transportation projects in communities of color. There is just not enough known regarding transportation infrastructure projects (like TOD) that have actually served to improve low-income communities of color. There are serious risks associated with building TOD projects in low-income communities of color because changes in land use patterns, the housing stock, and commercial investments can lead to neighborhood displacement and/or gentrification.

In some cases, TOD can price low-income residents out of their neighborhoods and push them farther away from jobs and transit because successful TODs generally raise surrounding land and housing costs. When this happens, instead of benefitting low-income residents, TOD projects can have the opposite effect, dramatically disrupting low-income neighborhoods and contributing to 
the negative history associated with transportation infrastructure projects in low-income communities of color.

As Latino immigrants continue to settle in U.S. urban areas, it is imperative that transit investments driven by smart-growth ideals do not spur gentrification, displacement and the disruption of local communities. In fact, considering that newly arrived Latino immigrants have a tendency to live lifestyles that are compatible with compact cities, TOD should be promoted as an economic and community development tool that holds tremendous promise for these communities. For example, newly arrived Latino immigrants generally occupy fewer housing units relative to their population size (larger average household size), and regularly live in multifamily rental units (apartments) (Myers, 2007). They also have a propensity for compact commuting because they are more likely to travel to work by public transit, bicycle or walking.

The housing and commuting behaviors among newly arrived immigrants (as well as native Latinos) suggest that the growing U.S. Latino population can become a key element in helping planners create compact cities through TOD. In order to achieve this, however, TOD projects linked to redevelopment plans need to assess how redevelopment proposals impact the lives of current vulnerable residents.

We find that the TOD projects in both these low-income Latino communities contributed to neighborhood revitalization and equitable outcomes. But these interesting outcomes occurred because each project was characterized by a unique process and developed within the context of these particular neighborhoods. Further, transportation planners incorporated the various forms of sociopolitical, financial and cultural capital that exists in these communities into the planning and implementation of the projects.

Through two case studies of large-scale TOD projects in low-income Latino communities, this report examines how TOD projects have the potential to connect low-income Latino immigrant communities to important local resources and create more equitable outcomes. It analyzes how TOD projects in Latino neighborhoods have the potential to open up access to a regional transportation system; increase the number of affordable housing units; support local diverse retail businesses; and build upon existing social services, such as medical and educational services. It also reveals the important role bottom-up participatory processes play in promoting endogenous forms of capital in these neighborhoods.

\subsection{PURPOSE AND OBJECTIVES OF RESEARCH PROJECT}

We know very little of the benefits TOD brings to low-income communities of color. Hence, the purpose of the study was to better understand how TOD shaped the revitalization efforts occurring in two low-income Latino communities where TOD was a major factor in revitalization efforts. We were particularly interested in the relationship between TOD and neighborhood revitalization related to equity concerns. This relationship was investigated by comparing and contrasting the equity effects of the two projects by revealing how, under what 
circumstances, and through what mechanisms TODs contribute toward equitable impacts in lowincome neighborhoods. The two TOD projects selected were the MacArthur Park METRO, a new subway station in Los Angeles, and the Fruitvale Transit Village, a mixed-use development project adjacent to a Bay Area Rapid Transit District (BART) station in Oakland.

We were also interested in describing the difficulty and complexity of revitalizing neighborhoods where TODs serve as catalysts for neighborhood change. Hence, we focused on understanding how planners need to build on already existing community resources and dynamic neighborhood characteristics commonly found in these communities. Ultimately, our aim was to provide a comprehensive description of these two projects to help transportation planners better understand the possibilities that TOD has in revitalizing low-income, Latino immigrant communities without widespread displacement.

\subsection{THEORETICAL FRAMING AND CASE STUDY METHOD}

To understand the potential role TODs play in urban revitalization and the community changes they contribute towards, we used a Community Capitals Framework (CCF) to understand both the process and the outcomes related to equity. Conceptually, we were trying to understand how TOD projects could contribute to equity outcomes and generative urban revitalization in lowincome, Latino immigrant communities by incorporating the various forms of political, financial and cultural capital that exists in these communities into the planning and implementation of those TOD projects. The CCF (Flora and Flora, 2013) helped us understand the endogenous forms of capital that exists in these Latino low-income neighborhoods and how these forms of capital influenced the TOD projects. Analyzing the cultural, financial, political and built forms of capital helped answer how the institutional and sociocultural political context within Latino lowincome, immigrant communities help them reshape large-scale redevelopment projects in a more equitable and generative fashion.

The research team adopted a comparative case study approach to assess whether TOD projects can facilitate generative urban revitalization in low-income, Latino immigrant communities. With comparative case studies, the primary research goal is to uncover a significant finding from one case study and then replicate this finding by conducting a second, third and even more case studies. In other words, "replication” logic, not sampling logic, is used to investigate multiple case studies. A literal replication predicts similar results, while a theoretical replication predicts contrasting results but for predictable reasons. Dr. Sandoval has written a book on MacArthur Park's generative revitalization, and now has updated his study and compared and contrasted the revitalization that took place in Oakland's Fruitvale district to the TOD project in MacArthur Park. Hence, conceptually he was able to build upon the framing and findings from his previous study by updating his MacArthur Park research (now with a direct focus on TOD) to investigate similar and contrasting results related to the new Fruitvale case.

An important step in all of these replication procedures is the development of a rich theoretical framework. In Case Study Research: Design and Methods, Robert Yin discusses that a 
"framework needs to state the conditions under which a particular phenomenon is likely to be found (a literal replication) as well as the conditions when it is not likely to be found (a theoretical replication).” The theoretical framework later becomes the vehicle for generalizing to new cases, similar to the role played in cross-experiment designs. We used this replicable case study design, building on some of the theoretical findings from the MacArthur Park case to answer the following key research question that linked both cases:

How might low-income Latino communities benefit from large-scale TOD projects? What are the risks to these neighborhoods if TODs are linked to neighborhood revitalization? And what are the neighborhood characteristics that exist within Latino communities that can help mitigate those risks and create more equitable outcomes?

Further, a rich theoretical framework that relies on qualitative information is especially important when it is difficult to produce reliable quantitative data. For example, relying on U.S. Census data to create a Housing Affordability Index for these types of communities would not yield a statistically reliable index because, upon arrival, a typical immigrant household consists of more than one family. Hence, establishing quantitative metrics does not capture the dynamism and complexity of immigrant neighborhoods where a lot of relationships are intended to remain hidden and in the shadows. This limits our understanding of the potential impacts of TOD in low-income, Latino immigrant communities. Further research, based on an ethnographic approach designed to tap into the social networks in immigrant neighborhoods, could provide valuable survey data and insight. 


\subsection{LITERATURE REVIEW}

The literature review covers the emerging debates on TOD and equity within communities of color. We first discuss the difficulty in defining TOD. TOD is now considered an important component of sustainable development. Over the years, various competing terms have surfaced to convey the idea of TOD, which is one of the reasons data collection practices are limited. We review the history of federal transportation policy and how certain policies have created inequities in low-income communities of color. We then focus on transportation justice issues as they relate to TOD equity concerns. Lastly, the scholarly debates regarding the relationship between TODs, low-income populations and equity is presented. Debates such as the links between TOD and neighborhood displacement and/or gentrification are examined.

\subsection{TOD LITERATURE}

TOD has recently become a popular tool to promote smart growth because moderate-to-higher density development projects have the ability to integrate land use and transportation planning (Calthorpe, 1993; Cervero, 1998; Newman and Kenworthy, 1999; Renne and Newman, 2002; Renne and Wells, 2004). In TCRP Report 102: Transit-Oriented Development in the United States: Experiences, Challenges, and Prospects (2004), Cervero et al. maintain that "TOD has gained currency in the United States as a means of promoting smart growth, injecting vitality into declining inner-city settings, and expanding lifestyle choices.”

Across the United States, sustainable transportation advocates are encouraging TODs, not only because it may lead to higher levels of transit ridership but also because it is believed to encourage economic development, environmental conservation (due to the density in housing and transition to public transit), and increased social diversity (in terms of mixing incomes and ethnic groups both at the local/community scale and across the region). TOD advocates also argue that by increasing access to transportation, TODs help improve the quality of life in areas related to health, employment and education. With the ability to travel within and across cities, for example, individuals have access to resources necessary for empowerment, societal engagement and productivity (Wellman, 2012; 518). Hence, transit agencies and TODs are “primed to become urban areas' most active community developers since there are few societal needs as basic as mobility needs which transit providers are already concerned about and actively seeking to assist,” (Wellman, 2012; 525).

In What Does 'Smart Growth' Mean for Community Development, Daniels discusses the importance of linking smart-growth policies to community development to further equity concerns. He argues that smart-growth programs designed to promote more compact development will result in less sprawl, higher-density development, greater use of mass transit, a pedestrian orientation, more close-knit communities, and a higher quality of life. Daniels maintains, however, that smart growth will succeed only if these programs "build the capacity of community residents to undertake land use planning and solve community problems,” (20). 
Hence, TOD advocates need to also consider the pressures, impacts and unintended consequences of building TOD projects in low-income communities of color.

\subsubsection{Defining Transit-Oriented Development}

Different terms have been used over the years to convey the idea of TOD, such as "transit villages," "transit-supportive development," "transit-friendly design," (Cervero et al., 2002) and "transit-related development" (Dittmar and Ohrland, 2004). TOD is the most commonly used term, however, and is therefore what we will adopt for this report. Some authors use the term TOD quite liberally to discuss any form of “transit-oriented development," including bus- and rail-oriented development as well as development along freeways (Lefaver, 1997). Dittman and Ohrland propose a broad yet helpful definition of TOD as the distance people are willing to walk to public transit and the development that occurs because of that connection between walking and a transit node (2004). Yet in much of the literature, TOD has taken a narrower definition. For example, it is referred to as development near or oriented to mass-transit facilities. Therefore, most definitions of TOD share common traits.

A TOD research report written by Robert Cervero, Christopher Ferrell and Steven Murphy provides a sample of TOD definitions found in the literature:

- The practice of developing or intensifying residential land use near rail stations (Boarnet and Crane, 1998A).

- Development within a specified geographical area around a transit station with a variety of land uses and a multiplicity of landowners (Salvensen, 1996).

- A mixed-use community that encourages people to live near transit services and to decrease their dependence on driving (Still, 2002).

- A compact, mixed-use community, centered on a transit station that, by design, invites residents, workers and shoppers to drive their cars less and ride mass transit more. The transit village extends roughly a quarter mile from a transit station, a distance that can be covered in about five minutes by foot. The centerpiece of the transit village is the transit station itself and the civic and public spaces that surround it. The transit station is what connects village residents to the rest of the region. The surrounding public space serves the important function of being a community gathering spot, a site for special events, and a place for celebrations-a modern-day version of the Greek agora (Bernick and Cervero, 1997).

- Moderate- to higher-density development located within an easy walk of a major transit stop, generally with a mix of residential, employment and shopping opportunities designed for pedestrians without excluding the auto. TOD can be new construction or 
redevelopment of one or more buildings whose design and orientation facilitate transit use (California Department of Transportation, 2001).

- A place of relatively higher density that includes a mixture of residential, employment, shopping and civic uses located within an easy walk of a bus or rail transit center. The development design gives preference to pedestrians and bicyclists, and may be accessed by automobiles (Maryland Department of Transportation, 2000).

- A mix of residential, retail and office uses and a supporting network of roads, bicycle and pedestrian ways focused on a major transit stop designed to support a high level of transit use. The key features of TOD include (a) a mixed-use center at the transit stop, oriented principally to transit riders and pedestrian and bicycle travel from the surrounding area; (b) high density of residential development proximate to the transit stop sufficient to support transit operations and neighborhood commercial uses within the TOD; and (c) a network of roads, and bicycle and pedestrian paths to support high levels of pedestrian access within the TOD and high levels of transit use (Oregon Revised Statutes, Section 307-600-1: www.leg.state.or.us/95reg/measures/hb3100.dir/hb3133.en.html).

Cervero et al. (2002) argue that while such definitions vary in scope and specificity, most TOD definitions share a few common principles:

- Mixed-use development

- Development that is close to and well-served by transit

- Development that is conducive to transit riding

And while these next traits are less universally subscribed to, they are also found in some definitions of TOD:

- Compactness

- Pedestrian- and cycle-friendly infrastructure

- Public and civic spaces near stations

- Stations as community hubs

Some authors argue that because of the various TOD definitions in much of the literature, practices that encourage development in and around transit stations are increasingly referred to in abstract terms so much that even new terms have emerged such as "transit-adjacent development," or TAD (Cervero et al., 2002). However, for the purpose of our analysis of the two inner-city Latino neighborhoods now served by rail, we consider TOD to be conceptualized in general terms as public transportation investments linked to heavy rail (subway stations) that aim to encourage neighborhood revitalization by increasing commercial/retail development, increasing density in housing surrounding the transit station, and investing in public amenities adjacent to the station. 


\subsubsection{Limitations of Current Data Collection Practices}

Since the definitions of TOD are debated and contested, so are the methods for evaluating their impacts. While there have been many claims for the various benefits of TOD, few studies agree on a specific method to evaluate their impact. As Cervero et al. state, "Relatively little empirical research has been conducted documenting the benefits of TOD beyond studies showing that developments near rail stations boost ridership and increase land values,” (2004).

Reviewing a few ways researchers have operationalized an evaluative TOD framework is useful to demonstrate the diversity in approaches. In Transit-Oriented Development: Developing a Strategy to Measure Success, Renne et al. propose a number of quantitative indicators that could more effectively monitor TOD outcomes and success. Based on a survey of transit professionals, the authors identified that the following top nine measurements could serve as the foundation for a TOD evaluation program:

- Transit ridership

- Density—population/housing

- Quality of streetscape design

- Quantity of mixed-use structures

- Pedestrian activity/pedestrian safety

- Increase in property value/tax revenue

- Public perception—resident and merchant surveys

- Mode connections at the transit station

- Parking configuration-for commuters, for residents, and shared

The results of their survey also revealed that the collection of data for many of these indicators is not straightforward. For example, pedestrian activity counts, public perception surveys, determination of economic outcomes, and quality of design require more involved effort, expertise and expense, which make these types of evaluations difficult.

Due to the federal reporting requirements that call for transit agencies to link financial assistance to improved performance, the overwhelming majority of transit performance measures found in the literature consist of productivity measurements (Hartman et al., 1994; Benn, 1995; Furth, 2000; Gleason, 1982; Nakanishi, 1997). The reporting requirements of the National Transit Database (NTD), for example, have caused transit agencies to focus primarily on ridership and financial performance, leaving the measurement of other aspects of transit such as quality of service and accessibility underrepresented (Kittelson, 2003; Levinson, 2004). Further, the data routinely collected outside of the NTD requirements varies among agencies because performance measures are tailored to address the specific goals of each different agency. As a result, a uniform standard of data collection does not exist outside the NTD's reporting requirements.

If the top-down monitoring approaches of national reporting systems such as the NTD are not extended to include indicators that reflect a more holistic understanding of livability and 
sustainability, transit officials interested in measuring TOD performance will continue to lack a uniform standard of data collection techniques. Hence, we conclude with Dittman et al., that "there is no clear definition of TOD or agreement on desired outcomes, and hence no way of ensuring that a project delivers these outcomes." (Dittman and Ohland, 2004: 9).

However, an expansion of top-down, data-driven approaches can be improved by assessing short- and long-term success through bottom-up qualitative methods that pay particular attention to the context of specific neighborhood changes. For example, transit officials could organize community stakeholder meetings with local residents, business owners, community advocates, government officials, and others to establish short- and long-term goals for each TOD project. Long-term success could then be assessed on the combination of these goals, and top-down goals established by regulatory agencies that measure the success of TODs by incorporating the community needs of these diverse stakeholders. For example, measures like the increase of affordable housing in the neighborhood linked to the TOD or the general housing affordability could be tracked. Further, bottom-up approaches could provide transit agencies with an opportunity to educate the general public regarding the benefits of TOD for livability and sustainability. Also, by not taking a one-size-fits-all approach to TOD, transit officials will have the opportunity to connect with local communities and become more receptive to their needs.

\subsection{HISTORY OF FEDERAL TRANSPORTATION POLICY RELATED TO COMMUNITIES OF COLOR}

An analysis of TOD's equity impacts cannot be fully understood without placing today's largescale transportation projects within the context of a longer history of transportation inequality in low-income communities of color. Beginning in the 1950s and 1960s, it was common practice to build major highways through low-income and communities of color (Mohl, 2008). Federal transportation policy mostly consisted of allocating large amounts of money to build interstate highway construction projects. These types of transportation policies and practices, which were also linked to racialized urban renewal policies that targeted low-income communities of color, led to the destruction of thriving neighborhoods and large-scale displacement (Avila, 2014). In 1961, Los Angeles Assembly Member Edward F. Elliot recognized the economic and physical impacts freeways were having on eastside LA, and decried the way in which the downtown area "had become encircled, cut up, and glutted by freeways." Since property values in those areas were significantly lower than in the suburbs, East and South Central Los Angeles became prime locations for massive freeway interchanges that consumed large amounts of property (Avila, 1998). In LA's Boyle Heights, for example, freeways displaced one-tenth of the local population. East Los Angeles became the national example of how freeways could dissect neighborhoods and create segregated communities (Avila, 2014).

It was not until the 1990s that the civil rights implications of transportation policies began to be examined. The Intermodal Surface Transportation Efficiency Act (ISTEA), the primary federal transportation funding law, changed the way funding was allocated and began to shift away from long-standing practices. The legislation became the first major federal transportation policy to 
evaluate the health, economic and social effects of transportation policy on minority and lowincome communities. In addition, ISTEA significantly altered the way transportation projects were planned in metropolitan areas, giving important additional powers and funding to metropolitan planning organizations (MPOs). For example, ISTEA required MPOs to develop 20-year regional plans outlining the priorities, policies and strategies for the region's transportation system. ${ }^{1}$

When ISTEA expired in 1998, Congress passed the Transportation Equity Act for the $21^{\text {st }}$ Century (TEA-21). From 1998 to 2005, the act played an important role in making transportation planning and implementation more responsive to equity and environmental justice concerns as well as mandating increased public involvement in state and regional transportation planning. TEA-21 was designed to improve transportation mobility in low-income communities by ensuring that public transportation provided by different agencies and through various modes were integrated to ensure "connections between people and jobs, goods and markets, and neighborhoods” (Bullard, 1996). The legislation also established grant programs to help serve the transportation needs of minority and low-income communities. The Job Access and Reverse Commute grant program, for instance, provided new and expanded transportation services to help welfare recipients and eligible low-income individuals get to jobs and employment-related services such as education, training and child care.

TEA-21 was followed by the Safe, Accountable, Flexible, Efficient Transportation Equity Act: A Legacy for Users (SAFETEA-LU) in 2005. The law increased funding for environmental programs of TEA-21, and provided some of the most significant changes to environmental provisions affecting transportation in decades. Provisions ranged from "environmental streamlining” measures aimed at expediting the National Environmental Policy Act review process for transportation projects to better links between transportation and conservation planning. In addition, as part of the planning process, Section 6001 established that states and MPOs would “consult, as appropriate, with State and local agencies responsible for land use management, natural resources, environmental protection, conservation, and historic preservation concerning the development of a long-range transportation plan.”2

On July 6, 2012, President Obama signed into law a new two-year transportation reauthorization bill, the Moving Ahead for Progress in the 21st Century Act (MAP-21). Although the bill includes several provisions unrelated to transportation planning, it nevertheless provides lawmakers an opportunity to make even more policy improvements and address the continuing inequities that communities of color and low-income communities experience. In other words, MAP-21 continues to incorporate environmental justice principles into its existing activities, allowing it to build on and refine many of the highway, transit, bike, and pedestrian programs and policies established in $1991 .^{3}$

\footnotetext{
${ }^{1}$ Intermodal Surface Transportation Efficiency Act (Public Law 102-240; December 18, 1991)

2 Safe, Accountable, Flexible, Efficient Transportation Equity Act: A Legacy for Users (Public Law 109-59; August 10, 2005)

${ }^{3}$ Moving Ahead for Progress in the 21st Century Act (MAP-21): A Summary of Highway Provisions; Office of Policy and Governmental Affairs, July 17, 2012.
} 


\subsection{TRANSPORTATION JUSTICE AND TOD EQUITY CONCERNS}

It is important to acknowledge that the emerging transportation equity debates lie within the transportation justice literature, which has a rich history. In fact, in 1953 African Americans in Baton Rogue, LA, staged the nation's first successful bus boycott to protest their unequal treatment to whites on busses. In a way, struggles over transportation helped spark the modern civil rights movement as Rosa Parks refused to give up her seat to a white man in Montgomery, AL, in 1955. This was continued by the Freedom Riders campaign in the early 1960s, which were protests by African Americans who were exercising their constitutional rights to interstate travel (Bullard and Johnson, 1997). Hence, the transportation field has a rich, conflicted history in justice issues related to civil rights and equity concerns related to providing access, equal treatment, and transportation resources to communities of color.

Bullard and Johnson provide a useful framing for understanding transportation justice debates. They relate justice (mainly racial justice) to the allocation of transportation resources and inequality in three spheres: 1 . Procedural inequality, where attention is given to processes by which transportation decisions take place; 2. Geographic inequality, which focuses on the distributive spatial impacts (positive and negative) of transportation investments (or disinvestments); 3. Social inequality, which are the distributional impacts of policies on various population groups related to transportation decisions. Hence, transportation justice deals with the distributional impacts of transportation decisions and the inequality that exists between transportation nodes that impact low-income communities and communities of color because of their marginalization.

Before reviewing the transportation equity debates, it is important to define transportation equity. While most transportation planning decisions focus primarily on the performance and cost of transportation, such as people's mobility levels and the accessibility of transportation to reach the most people, policies that focus on transportation equity seek to expand fairness in mobility and accessibility levels across race, class, gender and disability (Litman, 2002). Therefore, one key objective of transportation equity is related to access and mobility, specifically to build transportation systems that provide all groups equal access to education, employment and other public services.

When defining transportation equity, planners must also consider how justice and power influence the development of transportation policies and programs. Philosopher Iris Marion Young argues that equity is making institutional amends for historically discriminated groups (Young, 2011). This is achieved by providing historically discriminated groups (African Americans, Latinos, Asian-Americans, Native Americans and others) with increased access to decision-making power; for example, by providing access to power via public participation mechanisms. Hence, this is not a distributional paradigm on equity, but one based on representation and power. Incorporating a public participation framework based on making historical amends for past discrimination demands that the development of transportation 
projects and the allocation of transportation resources be analyzed in terms of equitable outcomes.

\subsection{DEBATES ON TOD EQUITY IN LOW-INCOME POPULATIONS}

Ever since Peter Calthorpe published “The New American Metropolis” in 1993, TOD has become a fixture of modern planning (Carlton, 2007). TOD has gained in popularity as a planning tool because advocates claim that it encourages people to live near transit services and to decrease their dependence on driving (Still, 2002). Beyond its definition as a model for integrating land use with transportation in the interest of smart growth (Calthorpe, 1993), TOD has also been viewed as a community design theory that promises to address a myriad of social issues (Carlton, 2007). Ditmarr and Ohland (2004), for example, argue that TODs have "the potential to provide residents with improved quality of life and reduced household transportation expense while providing the region with stable mixed-income neighborhoods that reduce environmental impacts and provide real alternatives to traffic congestion.” However, while these goals may be simply stated, the extent to which they are achievable is complex.

The TOD debate now goes beyond technical discussions of environmental impacts and increasingly relates to issues of equity. For example, new debates have emerged around issues related to "the political economy of how cities can be made to work in terms of accessibility, how environmental costs and benefits are distributed, and the concept of environmental justice" (Crane and Schweitzer, 2003). Policymakers are now asking questions regarding transportation choices linked to housing locations and how land-use policies affect transportation equity decisions. In order to comprehend how TOD can contribute towards sustainable development, it is "necessary to consider how different social groups using different modes of transport are related to the design of the built environment," (Crane and Schweitzer, 2003).

\subsubsection{Building Support for Equity in Transit-Oriented Development}

Today, conversations concerning TOD have been expanded to include questions of equity and community involvement. Soursourian (2010) discusses that since TOD is now a common part of the planning landscape, community development practitioners have increasingly become interested in replacing the "what if" of TOD visioning with the "how" of TOD execution. He explains that "Transit-Oriented Development drives us to creative solutions and forces us to work across sectors. It's not just housing issues, not just transportation, not just environmental. They all need to be dealt with holistically.”

Because of its holistic nature, many metropolitan areas struggling with how to accommodate future population growth are looking to TOD as a potential solution. But convincing some private developers to invest in inner cities and low-income communities of color is often very difficult. Many private developers are unwilling to invest because of perceived risks (LoukaitouSideris, 2000) and a lack of public initiative to begin development projects in disenfranchised 
communities (Wander, 2008). Yet, inner cities across the U.S. provide many advantages to private investors and public funding that do not exist in outlying suburban areas. As LoukaitouSideris (2000) describes, "inner city commercial strips often have an abundance of available commercial space, lower commercial rents and land values, and higher density that translates into a consumer market with sizeable purchasing power.” Inner cities, therefore, offer a very conducive setting for TOD.

The greatest obstacle facing TOD in the inner city, however, is improving economic development and transit infrastructure in urban neighborhoods without leading to their displacement. In Equipping Communities to Achieve Equitable Transit-Oriented Development, Soursourian (2010) discusses several tools and strategies that can maximize the benefits of TOD and minimize the negative impacts for low-income and communities of color. The author provides examples of anti-displacement tools and strategies that have been used in the past to help low-income residents remain in their neighborhoods and enjoy the benefits of TOD. The article examines three types of strategies communities can rely on to ensure that equity concerns are included in TOD. It explores "the advantages and challenges of utilizing TOD funds, nonprofit developers, and community-benefit agreements as tools to promote equitable TOD.”

Some argue that building support for TOD also has to come from local residents. In some cases, NIMBYism (Not-In-My-Backyard) is a significant barrier to building TOD projects. In Why Are There NIMBYs?, Fischel (2001) discusses that most NIMBY sentiments are linked to fears of the unknown, the desire to preserve the status quo, and a feeling of resentment against planning processes that seem to be out of one's control. People's common concerns and myths about TOD include "lowered property values, higher traffic volumes, overcrowding because of higher densities, overburdened social infrastructure (like schools and police), unwanted people moving into the neighborhood, and a generally lowered quality of life,” (Machell et al., 2010). Therefore, Machell argues that planners must "sell” TOD as positive sustainable developments, and carry through with their promises by creating good plans for the community. Ironically, however, some of the people that would benefit the most from TODs in low-income communities of color oppose these projects because they rightly fear the new changes coming to their community (i.e., the possibility of displacement).

Accordingly, practitioners have developed successful strategies to both counter resistance and rally community support around projects. The case studies in this report and the recommendations we make to transportation planners directly speak to these issues.

\subsubsection{Unintended Consequences? TODs and Gentrification}

Displacement and gentrification are two examples of the negative impacts large-scale transportation projects can have on low-income neighborhoods. When freeway projects remove housing in communities or neighborhoods of color, for example, displaced residents may end up moving far away from their jobs and social networks because they have few alternative housing options. This problem can be especially burdensome for individuals who have limited transportation options. Therefore, an individual's residential location is crucial because it not 
only encompasses issues of displacement, but also of affordability, proximity to public schools, and access to public transportation.

\subsubsection{Government-Forced Displacement}

In a number of cases, freeway construction projects have destroyed thousands of residential units occupied by communities of color and low-income households. These projects are typically located in urban areas that have depressed property values, which generally coincide with the residential neighborhoods of inner-city communities of color. Powell and Graham (2002) argue that in some respects, "freeway locations in cities are the philosophical progeny of 'Negro removal' or 'urban renewal' programs, whose goal was to rid cities of neighborhoods that were 'blighted'." The identification of blight many times had racial undertones where findings of blight were associated with a certain percentage of non-white populations. These racist intervention policies lead to the destruction of many vibrant low-income communities of color through the mid-1950s and 1960s. Institutional racism and low levels of political power have historically prevented many of these communities from opposing government plans and creating more equitable solutions.

In some cases, however, community opposition has prevented large-scale displacement and other inequitable effects. For example, in 1972, individuals and organizations concerned about households that would be displaced by the proposed I-105 freeway construction in Los Angeles filed a lawsuit against state and federal government officials (Bullard and Johnson, 1997). In 1982, the Ninth Circuit Court of Appeals required that "the state and federal defendants provide freeway displacees with 3,700 units of decent, safe, and sanitary replenishment housing, either by rehabilitating existing structures or constructing new ones.”

A more contemporary example includes the proposed extension of the 710 Interstate freeway in California's South Pasadena. In 1994, the original proposal provided more mitigation measures to reduce the freeway's environmental impacts in the predominately white communities of South Pasadena and Pasadena than in the predominantly Latino neighborhood of El Sereno (Lee, 1997). The original plan called for a mostly below-grade freeway, which are expensive and labor-intensive to maintain, in Pasadena and South Pasadena, but not in El Sereno. In addition, it would have built five tunnel sections in Pasadena and South Pasadena to mitigate the perception of a divided neighborhood, but only one tunnel in El Sereno. Community-based organizations mobilized in El Sereno and objected to the original proposal and, through a lawsuit, were able to make the project more equitable.

In addition to dramatically disrupting thriving communities, some freeway construction has exposed communities of color and low-income individuals who live near them to physical hazards. For instance, in Miami-Dade County, FL, the expansion of Interstate 95 in the 1990s exacerbated the freeway's negative effects on local residents (Stolz, 2002). Not only had the community never recovered from the detrimental impacts the construction of I-95 had on its business district in the 1950s and 1960s, the highway was now located within several feet of residential homes. And the only barrier protecting families from noise, vibration and potentially 
dangerous accidents was a wire fence. Local residents reported, on several occasions, that cars, tires and other debris occasionally flew into their yards from the freeway, and many residents mentioned they were reluctant to spend time in their backyards for fear of their lives. To their credit, local government officials quickly pulled together enough financial resources to build a mitigation wall after residents raised concerns and allegations of discrimination (Stolz, 2002).

\subsubsection{Market-Driven Displacement: Gentrification}

Another housing-related impact of large-scale transportation policies and projects is gentrification. Gentrification is generally characterized as "the process by which higher income households displace lower income residents of a neighborhood, changing the essential character and flavor of that neighborhood” (Kennedy and Leonard, 2001). Gentrification is market-driven displacement of housing and retail businesses due to increased rents. Some of the most common reasons for gentrification are (1) an increased desirability of an area because of transportation investments such as extensions of commuter rail lines, (2) new or improved train service or stations, or (3) the addition of a highway ramp or exit. Recently, however, instances of gentrification are more closely related to residential relocation such as the "back to the city" flow patterns of suburban, middle-income residents relocating within metropolitan areas, which is also linked to expanding transit options for higher-income residents.

Gentrification occurs through reinvestment and by rehabilitating the deteriorated condition and appearance of both residential and commercial properties. The revitalization of low-income communities, unfortunately, many times leads to gentrification (Sandoval, 2010). Due to the perception that increased property values and improved neighborhood amenities signals community revitalization, middle-income residents generally upgrade their housing conditions for personal consumption (Kennedy and Leonard, 2001). While owner-occupied, single-family residences replace renter occupancy, businesses that target the demographic group of middleincome homeowners transform older commercial locations through reinvestment and renovation. Therefore, the gentrification process is generally associated with physical property improvements, property value increases, a demographic shift from low- to higher-income levels, and more young and professional households. There is also a racial aspect to gentrification, so demographic changes in a community are also important to consider when identifying areas of potential gentrification. While some gentrifying neighborhoods absorb vacant properties, others displace households that are no longer able to afford increased housing costs.

While some view property value increases occurring from gentrification as a positive, others have also criticized these changes because of their negative impact on the welfare of low-income communities of color. Those who support the latter position argue that increases in property values result in rent increases, which then drive households that are less able to pay out to other neighborhoods or to undesirable housing arrangements (Atkinson, 2002). In particular, some scholars argue that certain anti-sprawl land use policies that encourage more housing development in inner-city neighborhoods reduce housing affordability and limit housing choice, especially for low-income individuals (Blackwell, 2000). Hodge (1980) has also argued that gentrification should be avoided because it leads to homogenous neighborhoods that lack cultural 
and socioeconomic diversity. Currently, however, there is insufficient data to draw specific conclusions about the net social and economic impacts of transportation investments on gentrification and displacement. However, this is an extremely relevant topic because gentrification is particularly important when understanding the efforts of large-scale TOD projects in low-income communities of color. TOD projects have the potential of bringing in new investments, new housing and commercial services, and improving access to regional transit systems. Hence, these improvements at times attract higher-income populations that could potentially pave the way for gentrifying these revitalized neighborhoods.

TOD does not necessarily have to lead to displacement and/or gentrification. TOD also had the potential to lead to neighborhood revitalization and provide concrete benefits to low-income communities of color. Benefits include providing access to important community resources, regional mobility, and connectivity to other neighborhoods throughout the city. Historically, large transportation systems have done the opposite: cut off these marginalized neighborhoods from the rest of the city and at times their own neighborhoods! In other words, are TODs today connecting previously excluded and disenfranchised neighborhoods to resources? Are TODs providing increased access and opportunity to marginalized populations, and helping them both improve the quality of life in their communities and revitalize their neighborhoods? Hence, can TODs help contribute to more equitable outcomes in low-income communities of color (in our case, Latino low-income communities)?

The current literature on the benefits of TOD in low-income neighborhoods makes it difficult to assess how these large-scale projects are beneficial to these neighborhoods. There is just now enough known about the effects these projects have on low-income communities of color. This report contributes to that understanding by analyzing how two large-scale TODs were transformed by neighborhood interest to create outcomes that are more inclusive, generative and community-based. The research also contributes to the understanding of how the context of the community (in this case, immigrant, low-income Latinos) plays an important role in creating more equity-based outcomes. 


\subsection{THEORETICAL FRAMING \& METHODS}

The theoretical framing used in this study has been evolving since Dr. Sandoval's initial study of MacArthur Park (Sandoval, 2010). Qualitative research takes an inductive approach to developing theory by identifying empirical relationships from observations, developing themes that speak to those relationships, and conducting analysis that uses the emerging theory to explain the findings. Hence, the theory is developed simultaneously as the researcher grapples and explains the empirical findings. Dr. Sandoval's initial study of MacArthur Park revealed that the city's top-down revitalization efforts in the neighborhood contributed towards community benefits because the community was able to pressure local officials and planners into creating those benefits. They were mainly able to accomplish these community benefits as the endogenous characteristics in the neighborhood were strong enough to sustain the large-scale redevelopment project. These endogenous characteristics consisted of networked communitybased organizations, immigrant financial capital in the neighborhood, and support from local Latino politicians who did not want to see displacement. These endogenous neighborhood characteristics all helped sustain those community benefits, and transformed the redevelopment project into a revitalization effort that was more bottom-up.

Building upon this body of research and emerging literature on MacArthur Park (Sandoval, 2010; Main and Sandoval, 2014), as well as empirical observations that emerged from the Fruitvale Village case study, we turned to the Community Capitals Framework (CCF) to help us explain the positive equity outcomes related to TOD projects in both MacArthur Park and Fruitvale.

According to Flora and Flora, communities encompass various forms of capital, such as political, cultural, social, financial, human and built capital. These forms of capital help a community thrive and sustain a healthy community life. This concept is similar to the framework Dr. Sandoval developed through his initial case study of MacArthur Park, but it goes further in two important ways. One, it emphasizes the importance of cultural capital, and secondly it also incorporates a neighborhoods' built capital. These two forms of capital played an important role in creating positive TOD outcomes in MacArthur Park and Fruitvale. In defining these forms of capital, we can see how they relate to the case studies. Financial capital is the monetary resource invested in community capacity building, and in MacArthur Park and Fruitvale this is evident through the establishment and growth of local Latino small businesses.

Secondly, Flora and Flora argue that cultural capital is the heritages, values, generations, races and ethnicities in a community. Cultural capital played a key role in anchoring the generative revitalization in both areas because the neighborhoods are predominately Latino. Third, political capital is the influence on the distribution of resources, power, voice and connections in communities. In both areas, important community-based organizations were actively involved in the projects via their activism. Local Latino politicians also became involved and saw it in their best interest to support initiatives that would benefit the community. Lastly, built capital is the physical infrastructure that exists in a community. The study's TOD projects represent this built 
capital. As large infrastructure projects, they continue to serve as catalysts for community change and development.

Hence, the CCF is an appropriate analytical tool that helps explain some of the more important relationships that exist in both neighborhoods. The framework also helps us answer an important conceptual question:

How does the institutional, social, cultural and political context within Latino, lowincome, immigrant communities help them reshape large-scale redevelopment projects (such as TOD projects in low-income, inner-city neighborhoods) in a more equitable and generative fashion?

The research method consisted of a comparative case-study research designed to compare and contrast the community and equity impacts of the two large TOD projects in low-income, Latino, immigrant communities. We explored how and to what extent these communities were able to make large-scale TOD redevelopment projects benefit their communities. The research method employed in this study consisted of an in-depth, qualitative, case-study approach. According to Yin, multiple case studies are appropriate when a researcher has established a theoretical framing and wants to expand those findings to other situations by using more case studies. Multiple casestudy approaches use replication logic to understand under what conditions their previous findings will be similar or differ.

In this case, Dr. Sandoval has extensively researched MacArthur Park’s revitalization and, using this replication logic, picked the Fruitvale District as a logical expansion to this revitalization research. Dr. Sandoval's previous book, Immigrants and the Revitalization of Los Angeles, focused on MacArthur Park's revitalization efforts. In this research project, we investigated specifically the effects and outcomes of the TOD project in the neighborhood. Hence, this research was more targeted on trying to understand both the process and outcomes of the MacArthur Park TOD. The Fruitvale Transit Village was also chosen because it has received a significant amount of national attention as a large-scale TOD project in a low-income, Latino community that claimed to have community benefits and was also linked to a revitalization project. Both communities also have very similar demographic characteristics. Hence, our case studies are appropriate to answering the key research question(s):

How might low-income, Latino communities benefit from large-scale TOD projects? What are the risks to these neighborhoods if TODs are linked to neighborhood revitalization? And what are the neighborhood characteristics that exist within Latino communities that can help mitigate those risks and create more equitable outcomes?

By answering these research questions and understanding both the process and outcomes that contributed to community revitalization, this research contributes to the emerging literature on 
transit equity. The report also contributes to the literature on "community development" by studying how TODs revitalize marginalized neighborhoods.

The unit of analysis was the mechanisms that lead to equity outcomes related to the TOD development. The units of observation were participants in planning agencies and community organizations, and their interactions related to the TOD projects. Dependent variables were equity outcomes linked to TOD, and independent variables were the mechanisms that lead to equity outcomes (public participation, various forms of capital (political, financial, cultural and built)). In a qualitative study these variables are not measured in isolation, but are interpreted through a holistic approach that seeks interconnectedness of variables affecting outcomes, and provides more of a descriptive analysis and story of where these mechanisms can be identified interacting in specific ways.

In qualitative research, it helps to have sub-questions that will guide the analysis and help establish the specific questions investigators ask their subjects. We developed the following two sub-questions to guide the research:

1) How were the Latino, low-income, immigrant communities in both MacArthur Park and Fruitvale able to create more equitable outcomes from the top-down TOD projects in their community?

2) What were the mechanisms (both within the Latino community and the TOD institutions) underlying both the process and outcomes contributing to equity?

For each case study, the research team reviewed documents, research reports and published research. The team conducted interviews with approximately 60 key individuals, and specifically focused on individuals who were very well informed about the process and outcomes of the TOD projects in the neighborhood. The specific questions addressed topics such as the role public participation mechanisms played in the projects; how socio-economic, political, financial and cultural capital were also responsible for reshaping the projects (e.g., What mechanisms did community leaders use to reshape top-down TOD projects that were originally not culturally sensitive and threatened to undermine the neighborhood's local context?); and positive outcomes and benefits in the neighborhoods (e.g., affordable housing, community benefit agreements, social service provisions, regional public transportation).

The team also conducted site visits, which were designed to obtain detailed insights about the approach stakeholders and institutions both endogenous and exogenous to the community were required to develop in response to their culturally sensitive TOD projects. To understand the changing context in the area, descriptive demographic statistics of each neighborhood were conducted. These were complemented by conducting extensive observational trips into the neighborhood. Researchers spent about two weeks in each research site conducting interviews and observations (these were conducted via several separate trips into the neighborhoods). To understand the process and uncover mechanisms that lead to equity outcomes, in-depth semistructured interviews were conducted. Interviewees included metropolitan transportation staff 
directly involved with the TOD, redevelopment staff, city planning staff, local city councilmembers, politicians, leaders of community-based organizations, informal community leaders, neighborhood residents, and other users of the transportation systems. As we identified the equity outcomes and referenced them back to the literature, it became apparent that we needed to specifically focus on four key outcomes related to equity in the neighborhoods. And we had to answer how the TODs provided increased access to the following:

- Regional public transportation

- Affordable housing

- Diverse, local small businesses

- Social services (medical and education) 


\subsection{TOD CASE STUDIES}

Transit-oriented development (TOD) is not a new concept. When America's first cities were emerging at the turn of the $20^{\text {th }}$ century, decades before widespread car ownership had a profound impact on people's way of life, most cities were TODs since dense living quarters were located near retail businesses, services, and streets that were filled with pedestrians and streetcars. After the car changed the urban landscape, the concept of TOD aimed to change the development of land uses on transit investments. TODs are generally defined as compact, highdensity, mixed-use developments located within walking distance from a transit station, a distance that can be covered in approximately five minutes by foot. Also, the development design gives preference to pedestrians and bicyclists, while providing frequent, reliable and accessible transportation service.

This chapter provides brief overviews of the two case study areas to better understand the context in the neighborhoods. The two U.S. case study neighborhoods are located in Los Angeles and Oakland [see maps of the neighborhoods]. Additionally, a comparative demographic analysis between each neighborhood and its city helps provide context for detailed economic and social comparisons between the neighborhood scale and the city. Specifically, the percentages of U.S. native and foreign-born residents in each neighborhood highlight the fact that both sites are located in immigrant neighborhoods.

\subsection{MACARTHUR PARK TOD}

MacArthur Park Metro was proposed as a mixed-use TOD project comprised of new highdensity housing and retail uses. It is located in one of the most densely populated neighborhoods in the city. The majority of residents are recent immigrants from Central America and Mexico, who have significantly lower incomes and rely heavily on public transportation. Initially, the topdown redevelopment project did not take the local community into consideration and actually aimed to change the demographics in the neighborhood by bringing in luxury condos and higherend retail (Sandoval, 2010). Initially, plans called for taking four blocks in the neighborhood and building the new TOD development next to the subway station. The initial TOD project was opposed by community members, and they were able with the help of local Latino politicians to change that project into a more regenerative, community-supported TOD project.

Located above the METRO Redline Subway Station in Westlake/MacArthur Park, adjacent to one of the most significant public parks in Los Angeles, the two-phased TOD development has helped create a vibrant new component in downtown LA. The new TOD at MacArthur Park station includes 90 affordable apartments, 15,000 square feet of retail, 100 commuter car parking spaces, and 24 bicycle parking spaces. Also, a total of 82 affordable housing units are planned during the second phase of development. The two-phased development is located on 3.72 acres. This TOD project provides a model for future station-area development in the greater LA area. 


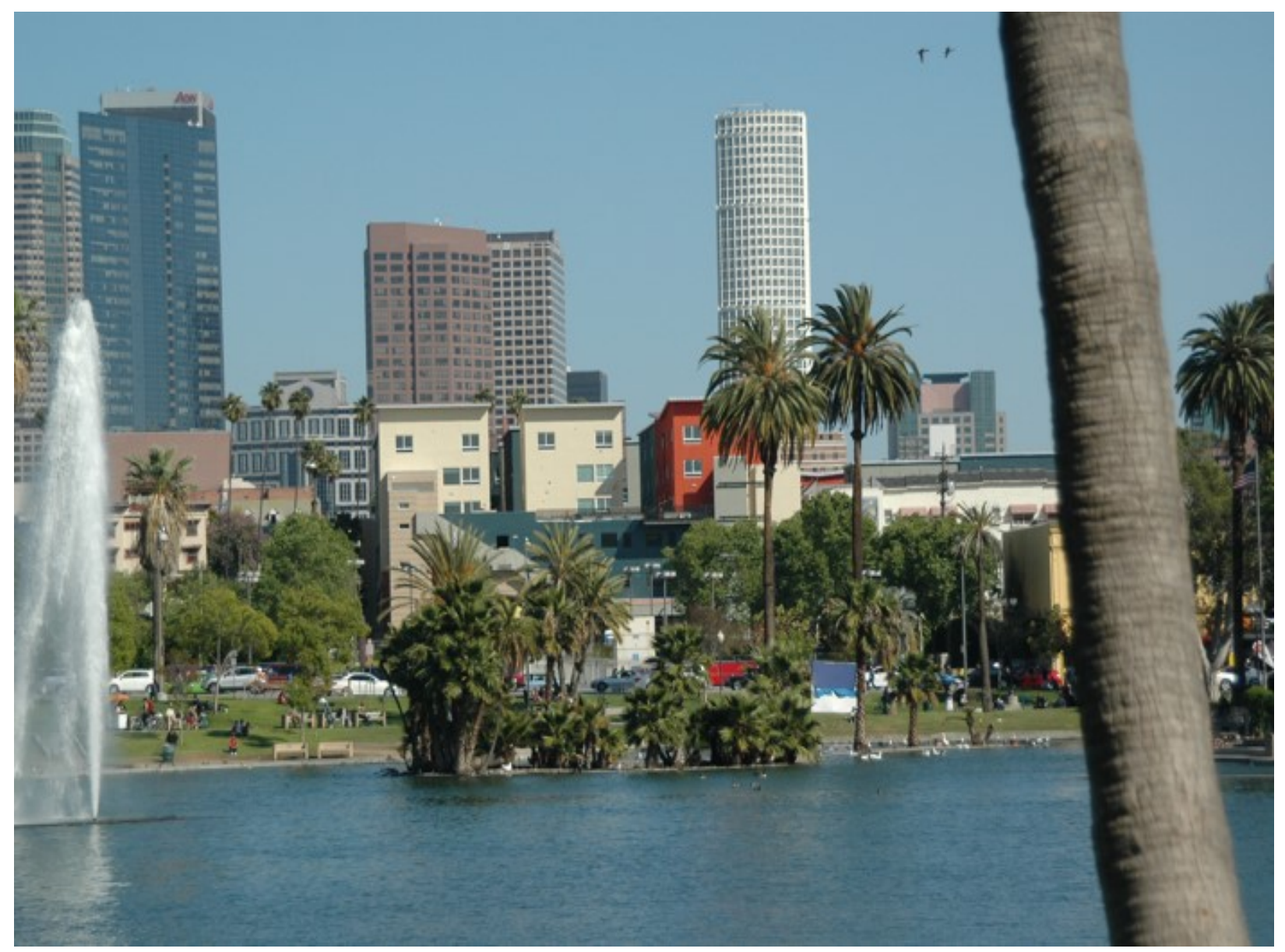

Figure 1: The TOD is Located Across the Street from MacArthur Park, a Regional Public Space in LA

\subsubsection{Local Context}

MacArthur Park's story really begins before World War II, when the area, then known as Westlake, was one of the premier residential areas of Los Angeles. At the time, the prestigious neighborhood had mainly well-to-do Jewish residents, a luxurious Victorian housing stock, theaters, and a spring-fed lake serving as its center. As Los Angeles expanded westward down Wilshire Boulevard, the residents of Westlake migrated toward LA's newer Westside to such places as Mid-Wilshire, La Brea, and Westwood, ultimately hitting the Pacific Ocean. That migration left a vacuum in the neighborhood, and in the late 1970s to early 1980s, its population changed to one composed mainly of elderly white retirees with smaller numbers of eastern European immigrants, Mexican-Americans, Cubans and immigrants from Central America.

Throughout the mid-1980s and the mid-1990s, the area was not just known for being a community of transition, but also as being one of the most dangerous areas of Los Angeles. It served as a hub for LA's drug trafficking market and had the city's largest concentration of 
illegal drug activities. It saw the emergence of violent street gangs (for example, MS-13) and had the city's most corrupt police station (the Rampart Division). The neighborhood had a reputation as a place with no regulations and lawlessness unprecedented in any other part of the city. Much of this criminal activity was carried out by people who did not reside in the neighborhood but used the lawlessness in the area to their criminal advantage. When newly appointed LAPD Chief William Bratton took a tour of the park in October 2002, he contended that, "This is the toughest police environment I have ever faced," even though he had formerly headed the New York City and Boston police departments.

Central American and Mexican immigrants kept coming because the area served their housing and access to labor needs, and represented one of LA's largest gateway immigrant communities. Another reason immigrants decided to locate in MacArthur Park was because they were not asked for documentation such as Social Security or formal ID cards. Most importantly, however, it emerged as a gateway immigrant community because people felt at home there. Most residents were not faced with a langurage barrier, for instance. By the late 1980s, the area had become a neighborhood mainly comprised of Mexicans and Central Americans. This occurred simultaneously with the long, dreadful and violent civil wars that plagued both Guatemala and El Salvador, as more Central Americans migrated to the U.S. to escape the wars. In fact, most of the Central American community-based organizations that emerged in MacArthur Park focused their work around issues related to amnesty, political asylum and human rights. Organizations such as El Rescate, the Central American Resource Center (CAREZEN), the Salvadoran American Legal and Education Fund (SALEF), Clinica Romero, and others emerged in MacArthur Park during that turbulent and violent time in Central America.

MacArthur Park in the mid-1990s reached a climatic point as its increasing density packed 35,000 people into a few blocks. Homicide rates peaked at 150 per year near the park. The Rampart police corruption scandal reached the front pages of Time Magazine (Cohen, 2000). The city councilor representing the area was arrested for buying cocaine in the park. A terrible fire exposed the housing code violations of absentee landlords. Rioting spread throughout the neighborhood following the Rodney King verdict. MacArthur Park in the early- to mid-1990s resembled Lawrence Veiler's descriptions of New York's immigrant slums at the turn of the 19th century. Hector Tobar's award winning novel, The Tattoed Soldier, takes place in MacArthur Park and demonstrates the chaotic environment that existed here throughout the 1990s and into the mid-2000s.

\subsubsection{Demographics}

The following section describes the demographic characteristics of the neighborhood. It paints a picture of an immigrant gateway community that is comprised of low-income Mexican and Central American residents. There seems to be rent increase pressures during the last 10 years that are similar to patterns seen throughout Los Angeles. In general, there has not been a lot of turnover in terms of the immigrant population, the ethnic composition, or percentage of resident poverty rates. 
Table 1: Total Population for MacArthur Park and the City of Los Angeles

\begin{tabular}{|lr|r|r|r|}
\hline & \multicolumn{2}{c|}{ MacArthur Park } & \multicolumn{2}{c|}{ Citywide } \\
\cline { 2 - 5 } & $\mathbf{2 0 0 0}$ & $\mathbf{2 0 1 0}$ & $\mathbf{2 0 0 0}$ & $\mathbf{2 0 1 0}$ \\
\hline White Alone & 1,662 & 1,805 & $1,099,188$ & $1,086,908$ \\
\hline Hispanic or Latino: & 24,592 & 24,402 & $1,719,073$ & $1,838,822$ \\
\hline $\begin{array}{l}\text { Alack or African American Alone } \\
\text { Alone }\end{array}$ & 1,458 & 1,317 & 401,986 & 347,380 \\
\hline Asian or Pacific Islander & 121 & 59 & 8,897 & 6,589 \\
\hline Other Race & 2,947 & 3,743 & 369,334 & 424,512 \\
\hline Total Population & 302 & 280 & 96,342 & 88,410 \\
\hline
\end{tabular}

Source: U.S. Census Bureau (2000) Social Explorer fact sheet - Table SE: T15; U.S. Census Bureau (2010) Social Explorer fact sheet - Table SE: T55 ${ }^{4}$

Figure 2: Hispanic or Latino by Race_-Percentages of Population for MacArthur Park and the City of Los Angeles

Hispanic or Latino by Race

MacArthur Park vs. City of Los Angeles, 2000 to 2010 Census

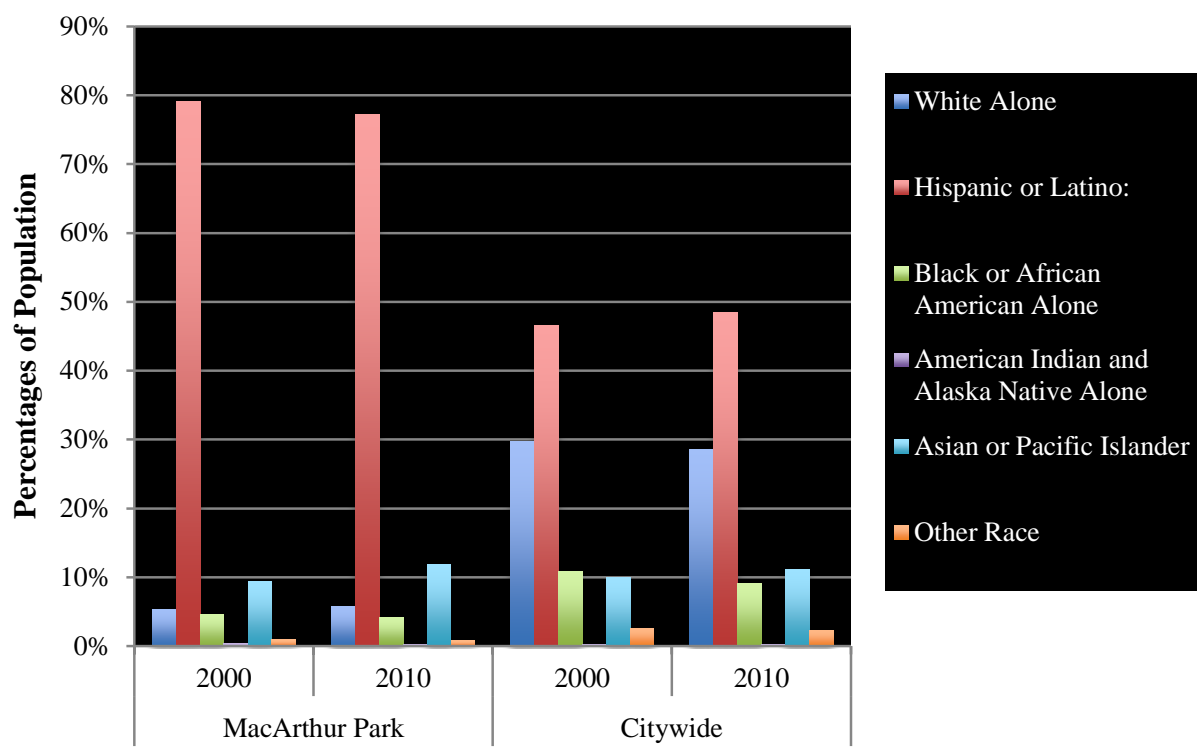

Source: U.S. Census Bureau (2000) Social Explorer fact sheet - Table SE: T15; U.S. Census Bureau (2010) Social Explorer fact sheet - Table SE: T55

\footnotetext{
4 MacArthur Park (Study Area Census Tracts): 2087.20; 2088; 2089.02; 2089.03; 2089.04; 2094.01; 2094.02; and 2094.03
} 
Figure 3: Income Disparities between MacArthur Park and the City of Los Angeles

\section{Income}

MacArthur Park vs. City of Los Angeles, 2000 to 2009 Census

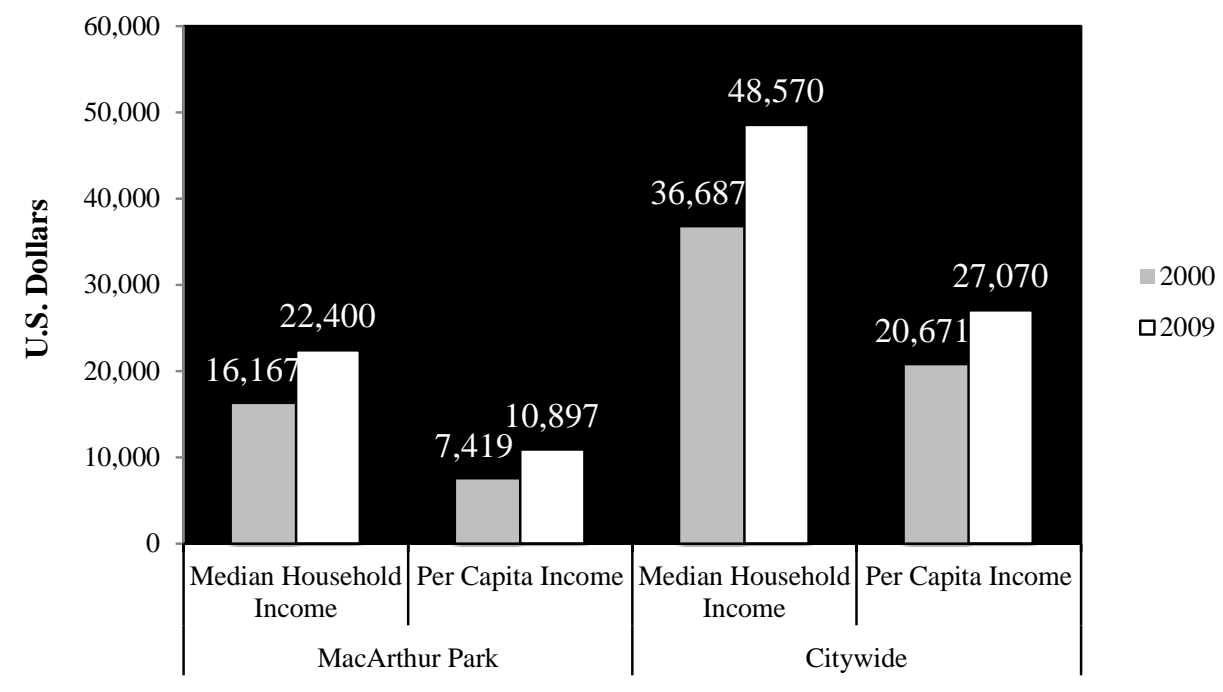

Source: U.S. Census Bureau (2000) Social Explorer fact sheet - Table SE: T93, Table SE: T145; U.S. Census Bureau (2009) Table B19013, Table B19301

Figure 4: Percentages of the Population Above and Below Poverty Level for MacArthur Park and the City of Los Angeles

\section{Poverty Status}

MacArthur Park vs. City of Los Angeles, 2000 to 2009 Census

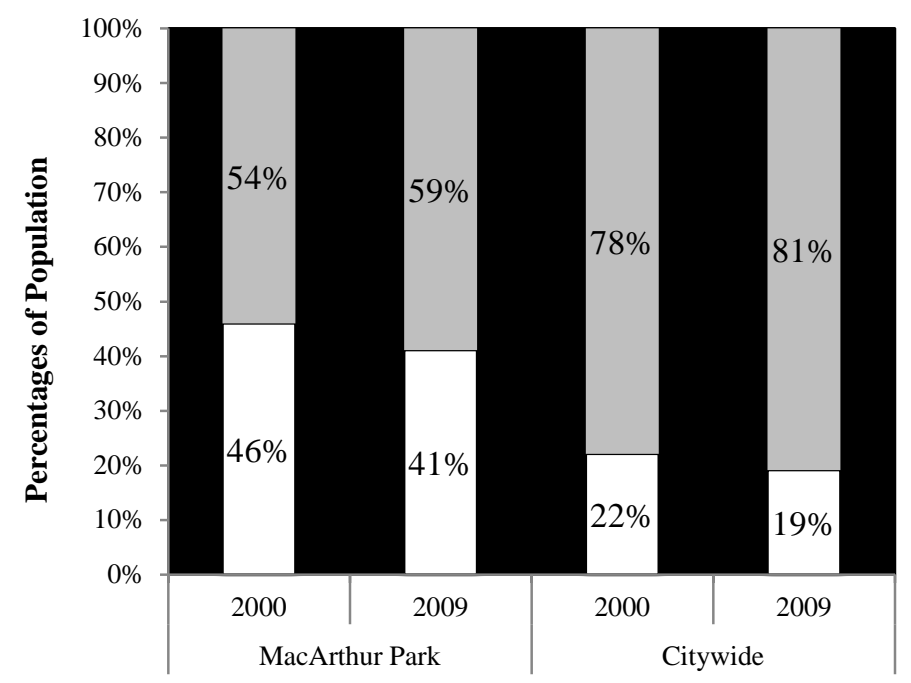

$\square$ Above Poverty Level

$\square$ Below Poverty Level

Source: U.S. Census Bureau (2000) Social Explorer fact sheet - Table SE: T183; U. S. Census Bureau (2009) Table B17001 
Figure 5: Percentages of U.S. Native and Foreign-Born Residents in MacArthur Park and the City of Los Angeles

Nativity in the United States

MacArthur Park vs. City of Los Angeles, 2000 to 2009 Census

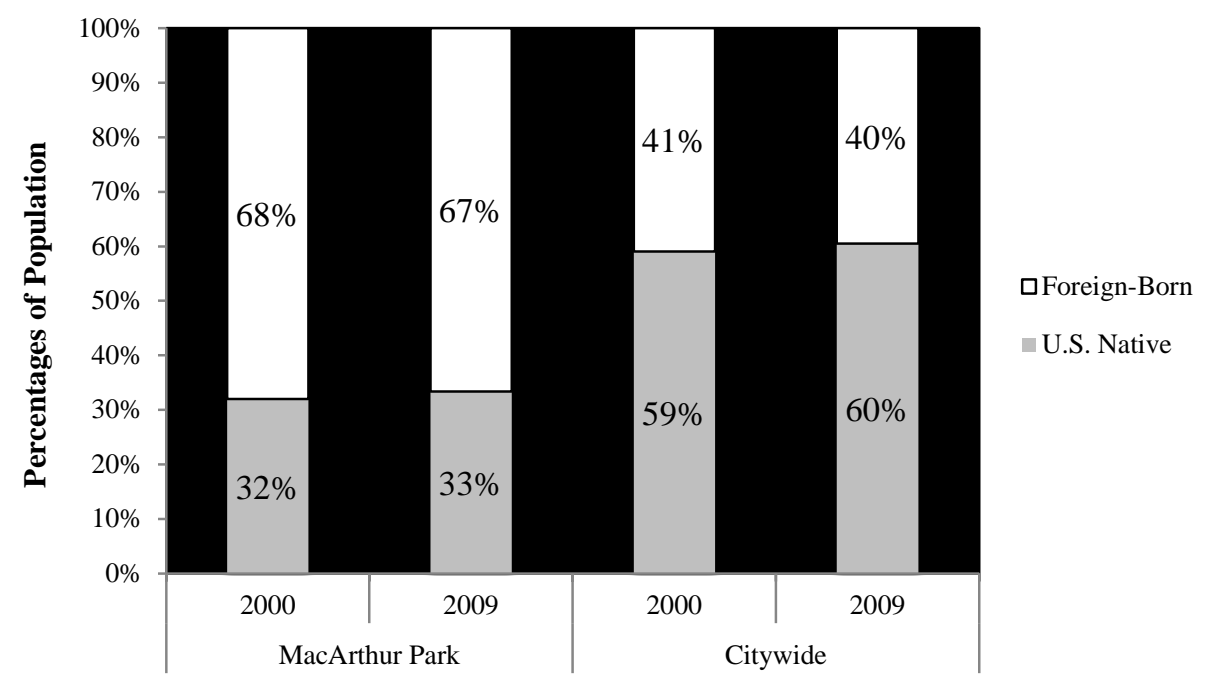

Source: U.S. Census Bureau (2000) Social Explorer fact sheet - Table SE: T201; U.S. Census Bureau (2009) Table B05012

Figure 6: The Years of Arrival in the U.S. of Immigrants in MacArthur Park and the City of Los Angeles

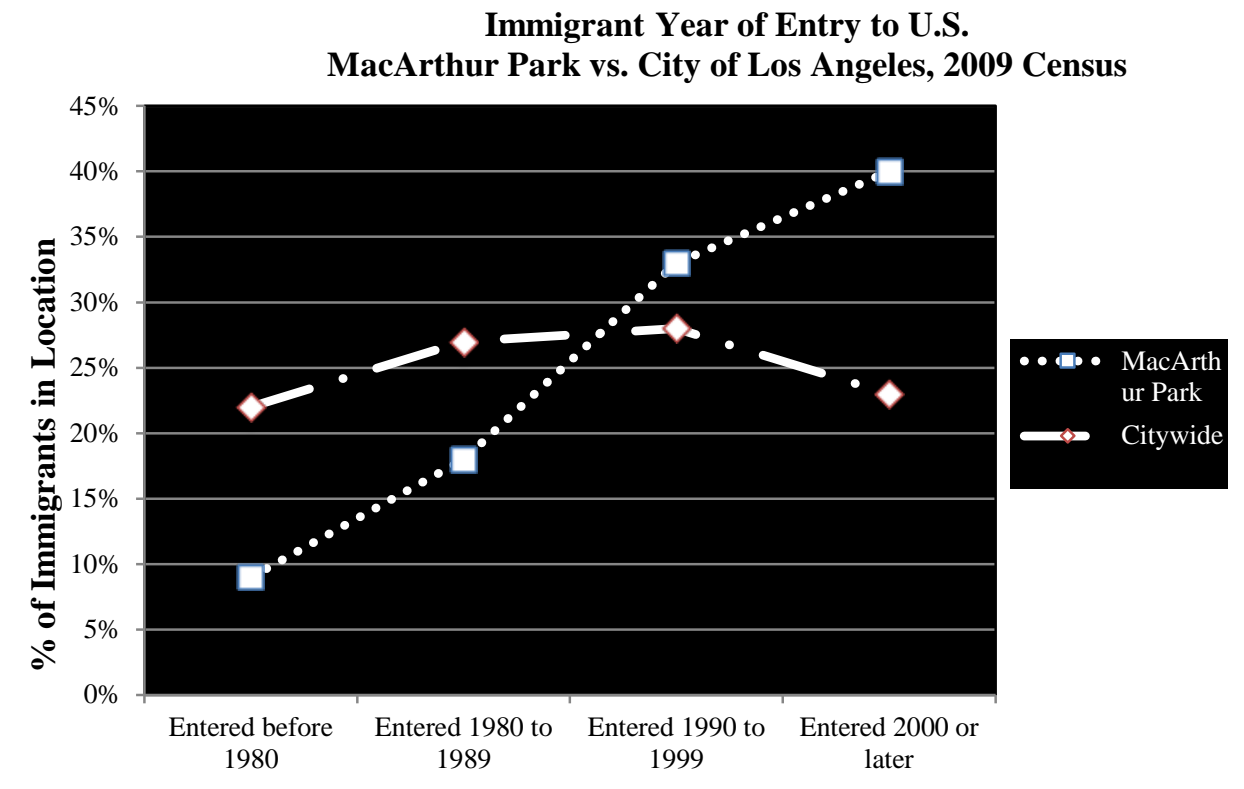

Source: U.S. Census Bureau (2009) Table B05005 
Figure 7: Affordability of Rents in MacArthur Park, Compared with the Entire City of Los Angeles

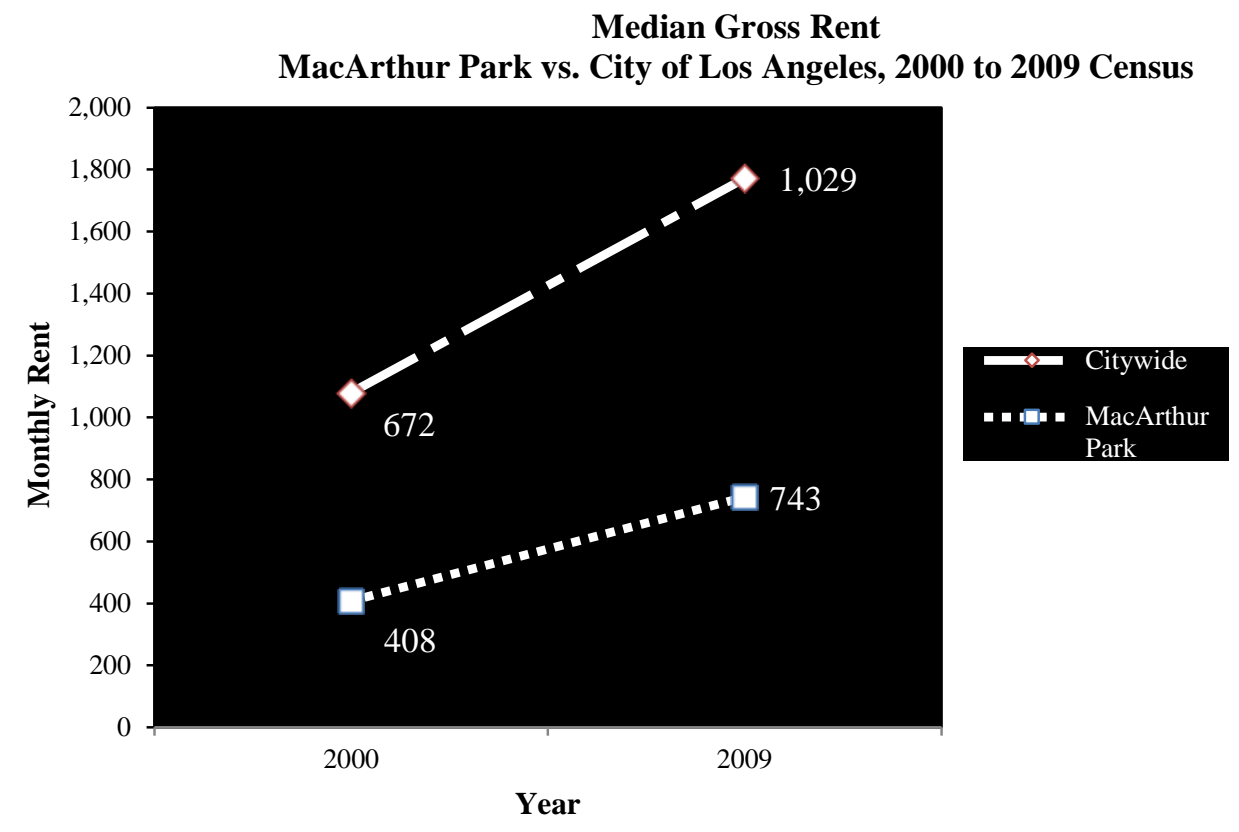

Source: U.S. Census Bureau (2000) Social Explorer fact sheet - Table SE: T167; U.S. Census Bureau (2009) Table B25064

Figure 8: Distribution in Rents Between MacArthur Park and the City of Los Angeles

\section{Cash Rent}

MacArthur Park vs. City of Los Angeles, 2000 to 2009 Census

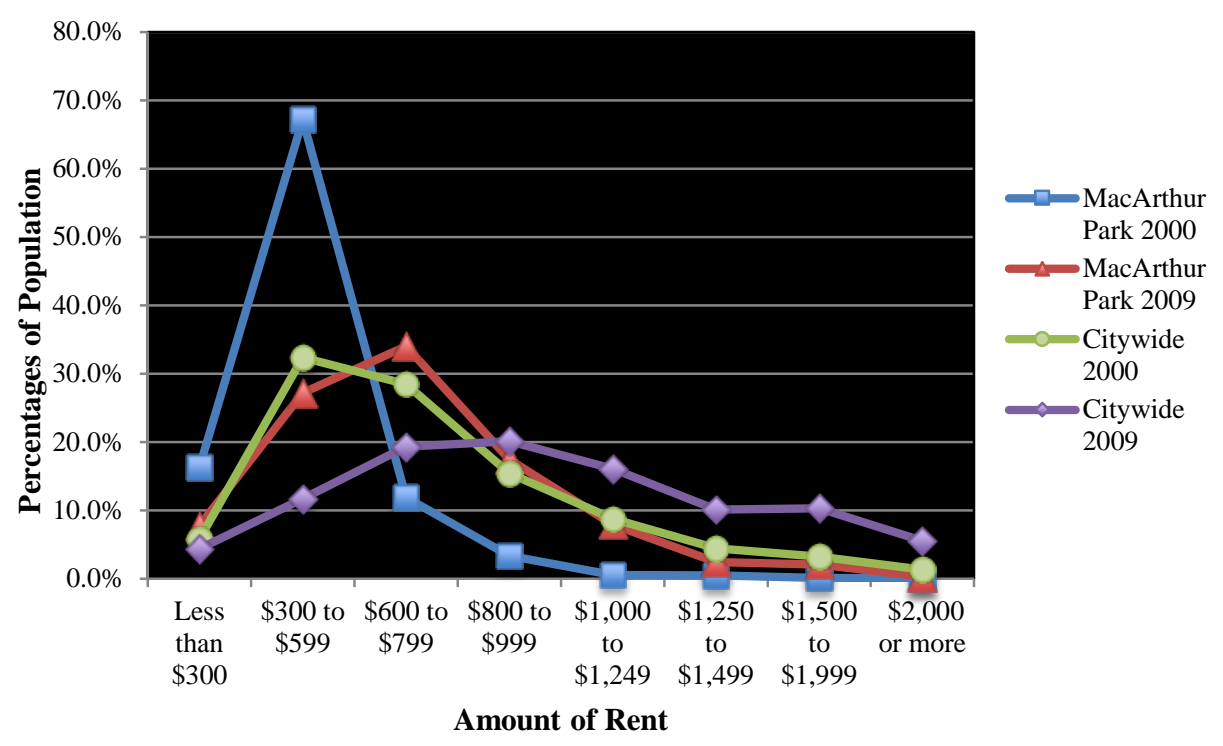

Source: U.S. Census Bureau (2000) Social Explorer fact sheet - Table SE: T165; U.S. Census Bureau (2009) Table B25056 


\subsubsection{Story of Project}

The story regarding MacArthur Park’s TOD really begins in the late 1980s when the Los Angeles County Metropolitan Transportation Authority (METRO) announced a typical, topdown, large, infrastructural revitalization plan that aimed to change the neighborhood instead of integrating into it. It called for a large commercial development around a planned subway station and had no provision for affordable housing. It aimed to build on the METRO property, but also encompassed a two-block area from Alvarado Street to Bonnie Brae Street and Wilshire to $7^{\text {th }}$ Street. METRO owned about half of that property, and the plan called for purchasing the rest of those buildings and tearing them all down to make room for the new commercial development around the subway station. The plan also called for building a large parking structure underneath the commercial complex and did not propose anything regarding the park itself; rather, it maintained all of its activities west of Alvarado.

By that time, the neighborhood had undergone some important demographic changes. The neighborhood had evolved into an immigrant, low-income community with high levels of poverty. Another important change in the neighborhood reflected a development occurring in LA politics as a whole. In the late 1980s, Richard Alatorre became the first Mexican-American elected to the city council in 23 years. Such a change in political representation was important for development projects because, in LA, councilors are elected by district and, in practice, are arbiters of development in their districts and control land use zoning changes. After Richard Alatorre's office redrew the city's First Council District in 1988-89 (with the help of a Voting Rights lawsuit), MacArthur Park residents elected Gloria Molina to represent the community. MacArthur Park, for the first time, had a councilor designated to represent it as its' own Latinodominated district, and that person was a Latina whose background was one of community activism. Thus, in the late 1980s, the stage was set for a dramatic confrontation; the park area was increasingly populated and dominated by a low-income, immigrant, Latino community, with a newly appointed Latina councilor. And yet, METRO was unveiling a revitalization plan in which it chose to completely ignore the new realities existing in the neighborhood.

From the beginning, Councilwomen Molina opposed the commercial development METRO had planned for the subway station. She was concerned that the investments in the area were not going to meet the needs of the community. The opposition to the large, new revitalization plan did not just come from the councilor's office, but also from community-based organizations already in the neighborhood. A strong and growing network of these organizations already existed in the neighborhood, and when the plan was unveiled they worked together to oppose its implementation. METRO's and the developers' apparent lack of concern or serious effort regarding community participation led to their having no community support for the project. From that point forward, however, every proposed plan has paid careful attention to the cultural capital in the area. From the early 1990s to early 2000, two additional plans ${ }^{5}$ were proposed, which both shared a vision of creating a "village center" type of neighborhood.

${ }^{5}$ These plans included: (1) Conceptual Master Plan for the Westlake/MacArthur Park Red Line Station Area, 1992; (2) Plaza de Las Americas, 1996. 
The newest plan (approved in early 2009) for the development of the METRO-owned subway station area was developed by McCormack Baron Salazar, a firm that specializes in building affordable housing and mixed-use development around transit stops. The project's stated goal was to "build multifamily affordable housing above the METRO Redline MacArthur Park station which would help address the community's need for safe and decent housing.” The project consists of two phases (A and B). In phase A, 90 affordable apartments catering to large families, 15,000 square feet of commercial retail space, and 249 parking spaces (100 commuter car parking spaces) were built. It was completed on June 18, 2012. During phase B, 82 affordable rental units, 17,000 square feet of retail space, and 83 residential parking spaces will be constructed. Phase B is estimated to be completed sometime in 2015. LA's former Community Redevelopment Agency sees the community benefits of this project as building affordable housing units, encouraging transit-oriented development, creating jobs through local hiring practices, and increasing retail services in the neighborhood.

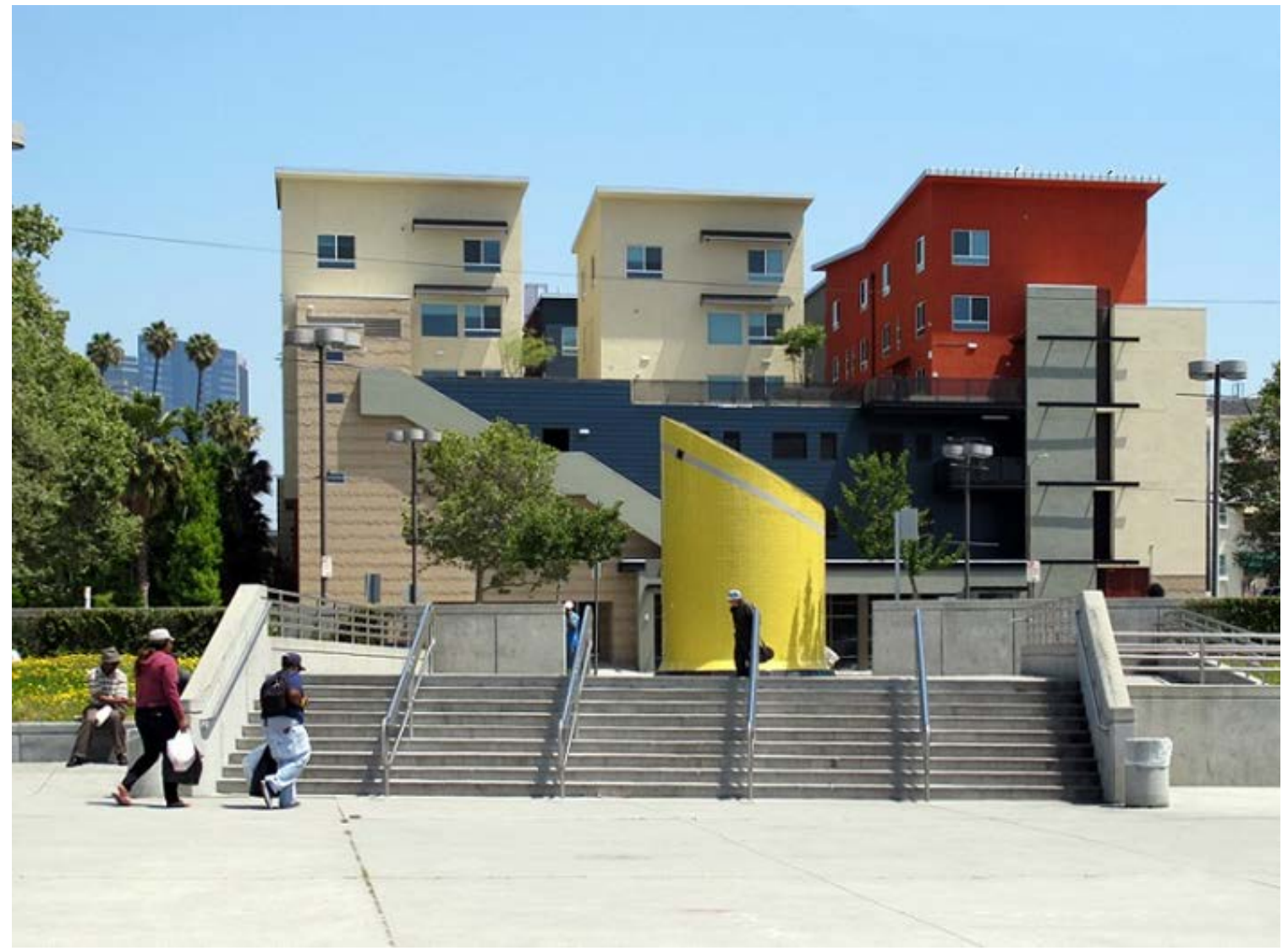

Figure 9: The MacArthur Park TOD 
The MacArthur Park Apartments (TOD) development invoved a process where Latino politicians took over the council district and pressured other city institutions to pay more attention to the area. It also encompassed the efforts of networked community-based organization's that pressured local politicians and engaged residents in revitalization efforts. Most importantly, this revitalization process depended upon the financial and cultural capital that emerged from this transnational immigrant community.

\subsection{FRUITVALE TRANSIT VILLAGE}

The Fruitvale Transit Village idea was first proposed in 1992 by community members who opposed BART's announcement of plans to build a multilevel parking facility at the Fruitvale station. Led by the Unity Council, an alternative plan was developed using Community Development Block Grant funds given to the council from the City of Oakland. Construction on the Fruitvale Transit Village began in 1999 after years of collaboration and support from several agencies such as the University of California at Berkeley's National Transit Access Center, the U.S. Department of Housing and Urban Development, and the Federal Transit Administration.

Today, the Village consists of 257,000 square feet of mixed-use development. There are 47 mixed-income residences, and 114,000 square feet of community services such as a City of Oakland library, La Clinica (a community health clinic), a senior center, a Head Start center, and a charter high school. Neighborhood retail, including shopping and dining, occupy 40,000 square feet of the Village. Also, to accommodate its visitors and Park-\&-Ride transit users, a 150-car parking garage and BART parking structure were built. The paseo (pedestrian way), which lies in the Village's center, is lined with palm trees and fountains that create a colorful and vibrant environment for both residents and visitors (see Figure 10). 


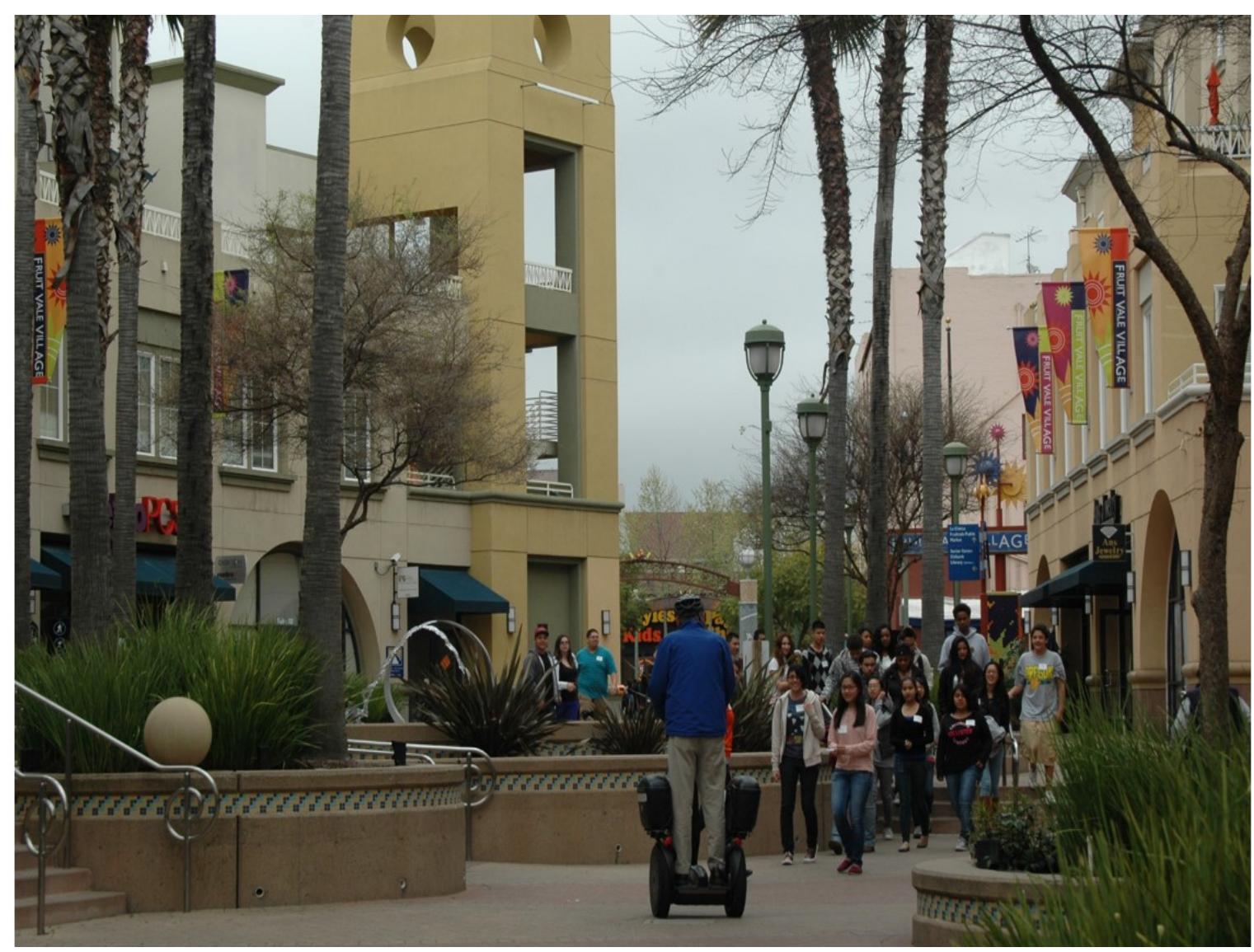

Figure 10: Fruitvale Transit Village Paseo (Pedestrian Way)

\subsubsection{Local Context}

Since WWII, Fruitvale has increasingly served as a hub for the region's growing Latino population, and the Latino community has flourished there (Kirkpatrick, 2007). The district has also provided jobs for many newcomers such as African Americans, Asians and Pacific Islanders who travel to the area in search of these opportunities. "Fruitvale is hailed as one of the most diverse districts in Oakland. Its residents have said that the district's diverse cultural community makes it an ideal place to live and raise children. It is a place where people work together,” (Alameda County Public Health Department, 2001). ${ }^{6}$

More recently, however, Fruitvale (once known as the city's "second downtown” because its orchards formed the base for a fruit canning industry, contributing to thriving commercial and manufacturing sectors) deteriorated as "businesses, jobs, and middle-class homeowners left the

${ }^{6}$ Alameda County Public Health Department 2001, op. cit. 
neighborhood" and relocated to more affluent suburbs. As the businesses left and the manufacturing base eroded, Fruitvale began to suffer from problems typical of neighborhoods in decline - vacant storefronts, joblessness, poverty and crime. The area continued to be troubled into the 1990s, with a reported retail vacancy rate of 40 to 50 percent, and the second-highest crime rate in the BART system at the Fruitvale station. ${ }^{7}$

In 1998, the district of Fruitvale was incorporated into two of the city's "Redevelopment Areas." Kirkpatrick argues that local signs of "socio-economic distress" remain high. In 2000, 49 percent of households in Fruitvale earned less than $\$ 30,000$, compared to 26 percent for households throughout Alameda County, while 34 percent of neighborhood residents participated in state welfare programs, compared to only 9 percent in the county.

Eventually, what emerged in 2004 was a $\$ 100$ million mixed-use project located on the site of the BART system's Fruitvale station. The Fruitvale Transit Village is located in the Fruitvale district (pop. 51,000), separated from downtown Oakland by Lake Merritt and the Chinatown and San Antonio neighborhoods. The project is said to fulfill several broad functions, including breathing economic life into the area by "priming... [it] for a blast of new development," (Kirkpatrick, 2007).

Today, Fruitvale is home to many recent immigrants. Over half of all families in the area speak a language other than English at home. Spanish, Chinese and Vietnamese are typical first languages. One-fifth of the households in the Fruitvale community live under the poverty line. ${ }^{8}$

${ }^{7}$ Silver Medal Winner. Fruitvale Village; Oakland, California

${ }^{8}$ Silver Medal Winner. Fruitvale Village; Oakland, California 


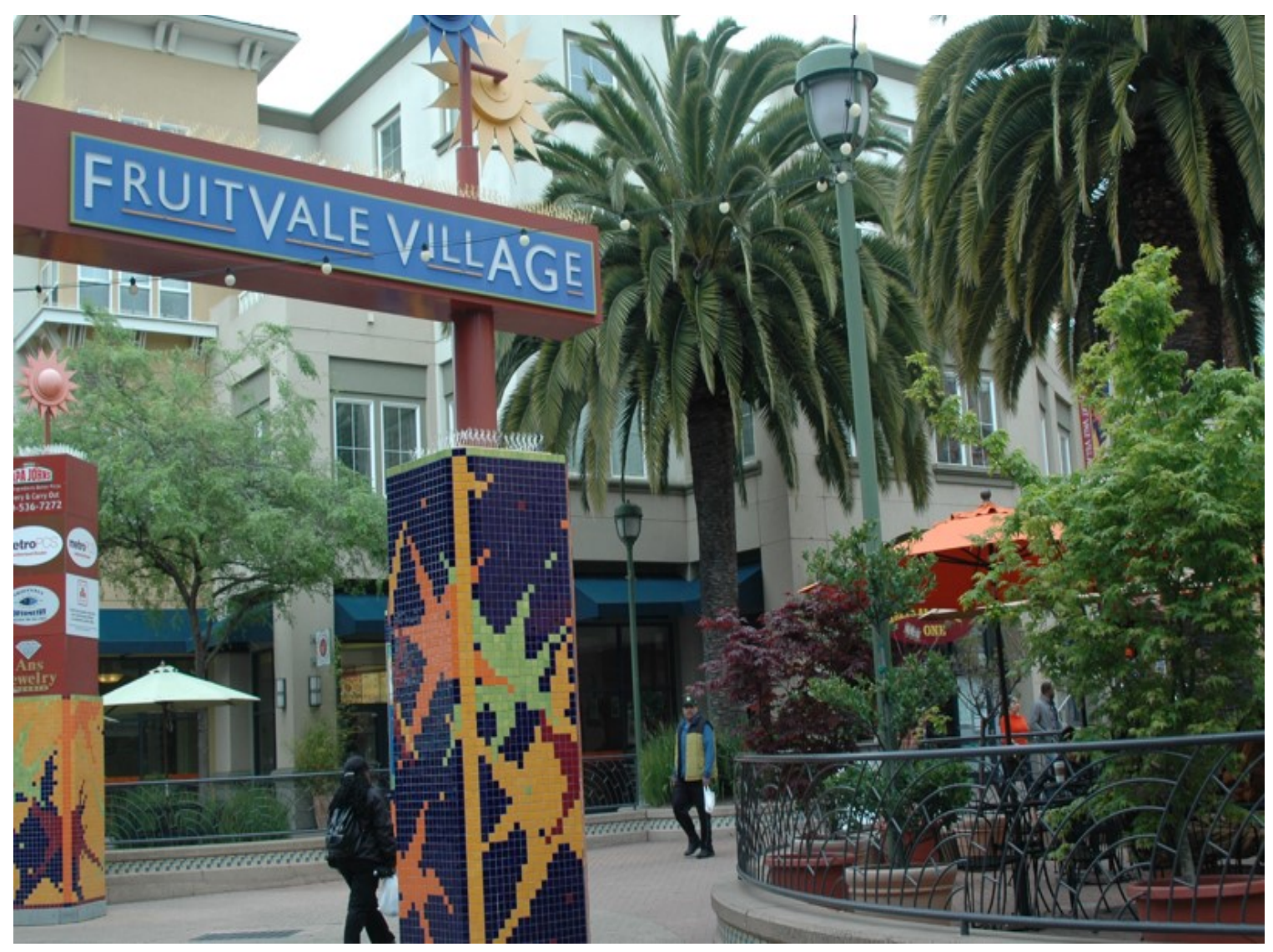

Figure 11: The Fruitvale Transit Village

\subsubsection{Demographics}

The following section describes the demographic characteristics of the neighborhood. The demographic characteristics in the Fruitvale community are strikingly similar to those in MacArthur Park. Fruitvale is a low-income, Latino, immigrant community that is also experiencing increased rent pressures. These increased rent pressures, however, are also being experienced by residents throughout the city of Oakland. In the past 10 years, Latinos have actually increased in terms of the percentage of the neighborhood's population. On the other hand, the percentage of immigrants living in the neighborhood, as well as the percentage of the neighborhood's population living under the poverty line, has not changed significantly. 
Table 2: Total Population for Fruitvale and the City of Oakland

\begin{tabular}{|l|r|r|r|r|}
\hline & \multicolumn{2}{c|}{ Fruitvale } & \multicolumn{2}{c|}{ Citywide } \\
\cline { 2 - 5 } & $\mathbf{2 0 0 0}$ & $\mathbf{2 0 1 0}$ & $\mathbf{2 0 0 0}$ & $\mathbf{2 0 1 0}$ \\
\hline White Alone & 4,593 & 4,443 & 93,953 & 101,308 \\
\hline Hispanic or Latino: & 25,405 & 24,503 & 87,467 & 99,068 \\
\hline American Indian and Alaska Native Alone & 11,817 & 8,900 & 140,139 & 106,637 \\
\hline Asian or Pacific Islander & 321 & 279 & 1,471 & 1,214 \\
\hline Other Race & 11,941 & 11,927 & 62,259 & 67,208 \\
\hline Total Population & 1,645 & 1,224 & 14,195 & 15,289 \\
\hline
\end{tabular}

Source: U.S. Census Bureau (2000) Social Explorer fact sheet - Table SE: T15; U.S. Census Bureau (2010) Social Explorer fact sheet - Table SE: T55 ${ }^{9}$

Figure 12: Hispanic or Latino by Race—Percentages of Population for Fruitvale and the City of Oakland

Hispanic or Latino by Race

Fruitvale vs. City of Oakland, 2000 to 2010 Census

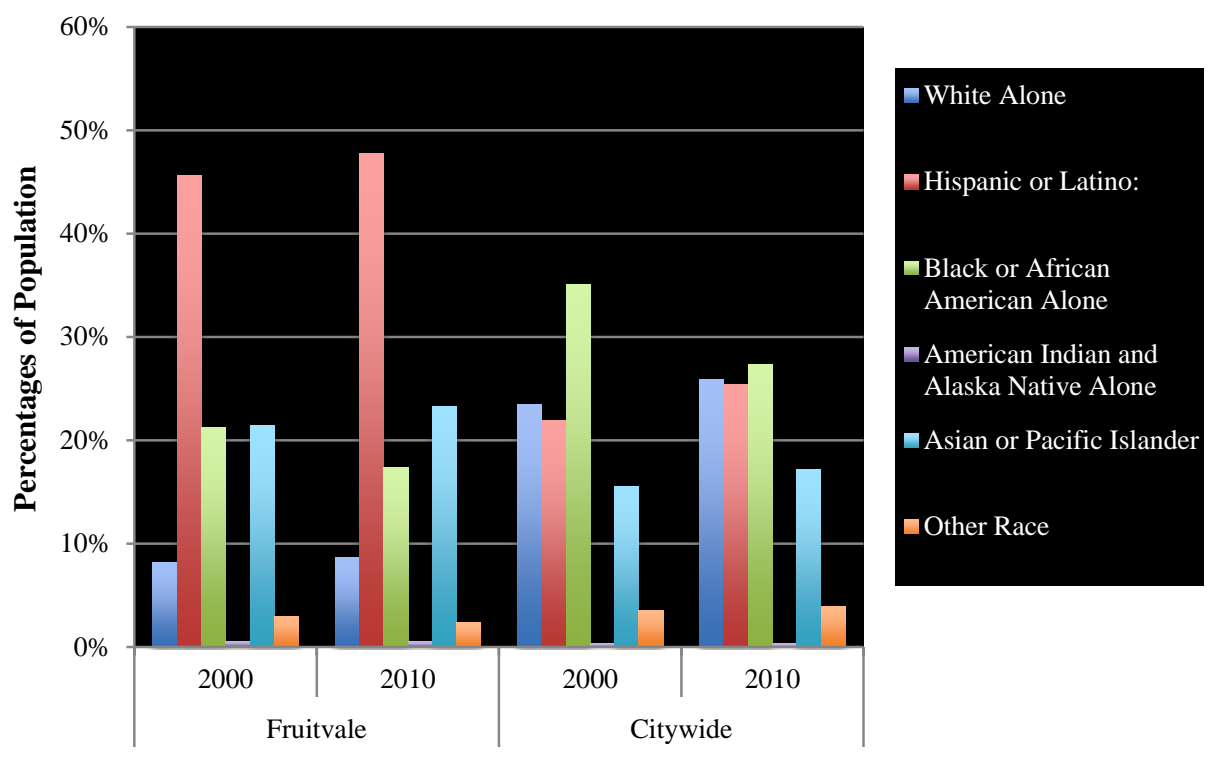

Source: U.S. Census Bureau (2000) Social Explorer fact sheet - Table SE: T15; U.S. Census Bureau (2010) Social Explorer fact sheet - Table SE: T55

9 The Fruitvale (Study Area Census Tracts): 4061; 4062.01; 4062.02; 4063; 4065; 4066; 4070; 4071; and 4072 
Figure 13: Income Disparities Between Fruitvale and the City of Oakland

\section{Income}

Fruitvale vs. City of Oakland, 2000 to 2010 Census

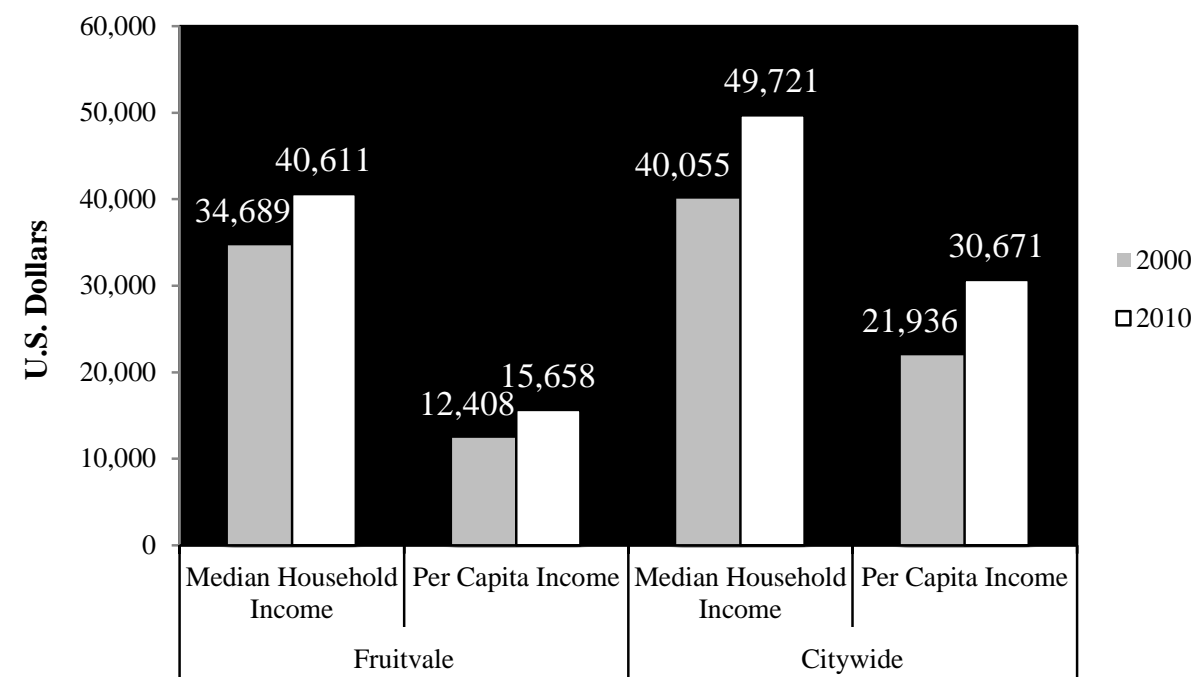

Source: U.S. Census Bureau (2000) Social Explorer fact sheet - Table SE: T93, Table SE: T145; U.S. Census Bureau (2010) Table DP03

Figure 14: Percentages of the Population Above and Below Poverty Level for Fruitvale and the City of Oakland

\section{Poverty Status}

Fruitvale vs. City of Oakland, 2000 to 2010 Census

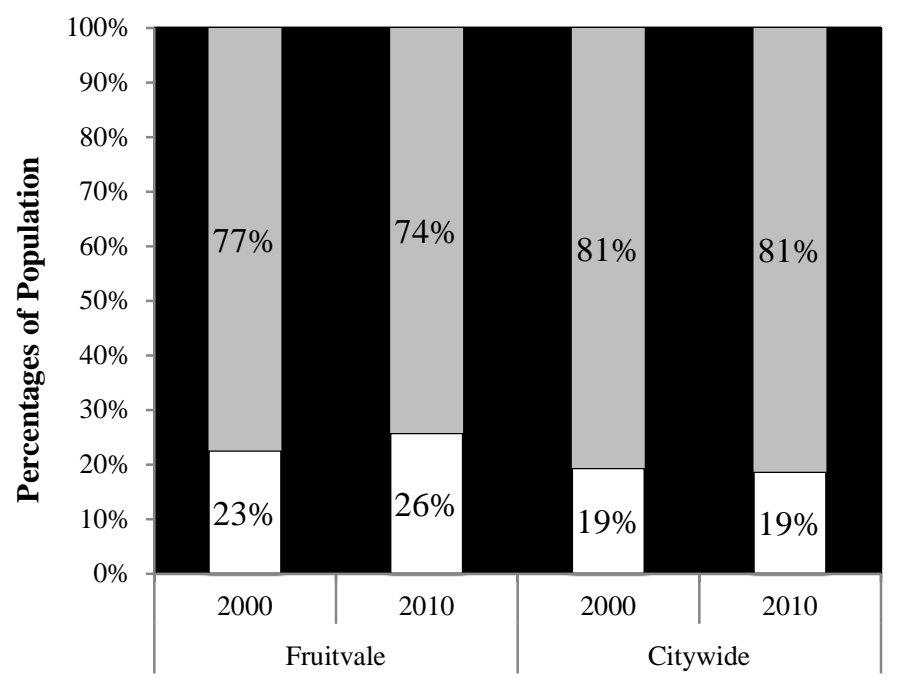

Above Poverty

Level

口Below Poverty

Level

Source: U.S. Census Bureau (2000) Social Explorer fact sheet - Table SE: T183; U. S. Census Bureau (2010) Table B17001 
Figure 15: Percentages of U.S. Native and Foreign-Born Residents in Fruitvale and the City of Oakland

Nativity in the United States

Fruitvale vs. City of Oakland, 2000 to 2010 Census

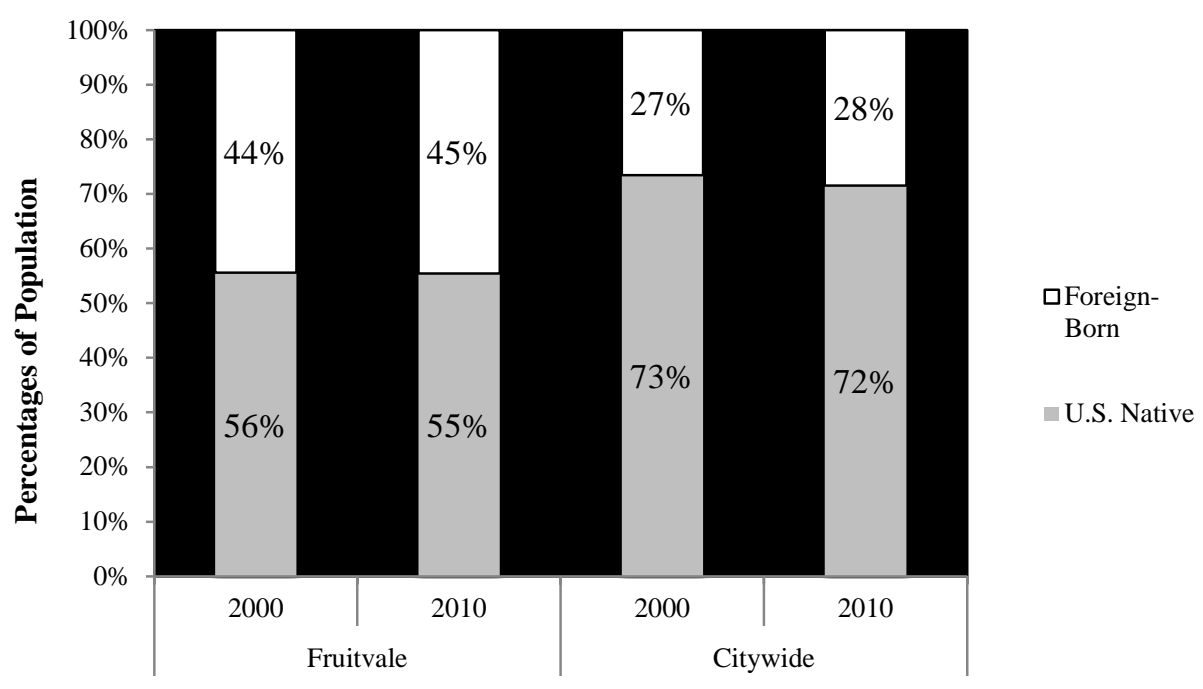

Source: U.S. Census Bureau (2000) Social Explorer fact sheet - Table SE: T201; U.S. Census Bureau (2010) Table B05012

Figure 16: The Years of Arrival in the U.S. of Immigrants in Fruitvale and the City of Oakland

Immigrant Year of Entry to U.S. Fruitvale vs. City of Oakland, 2010 Census

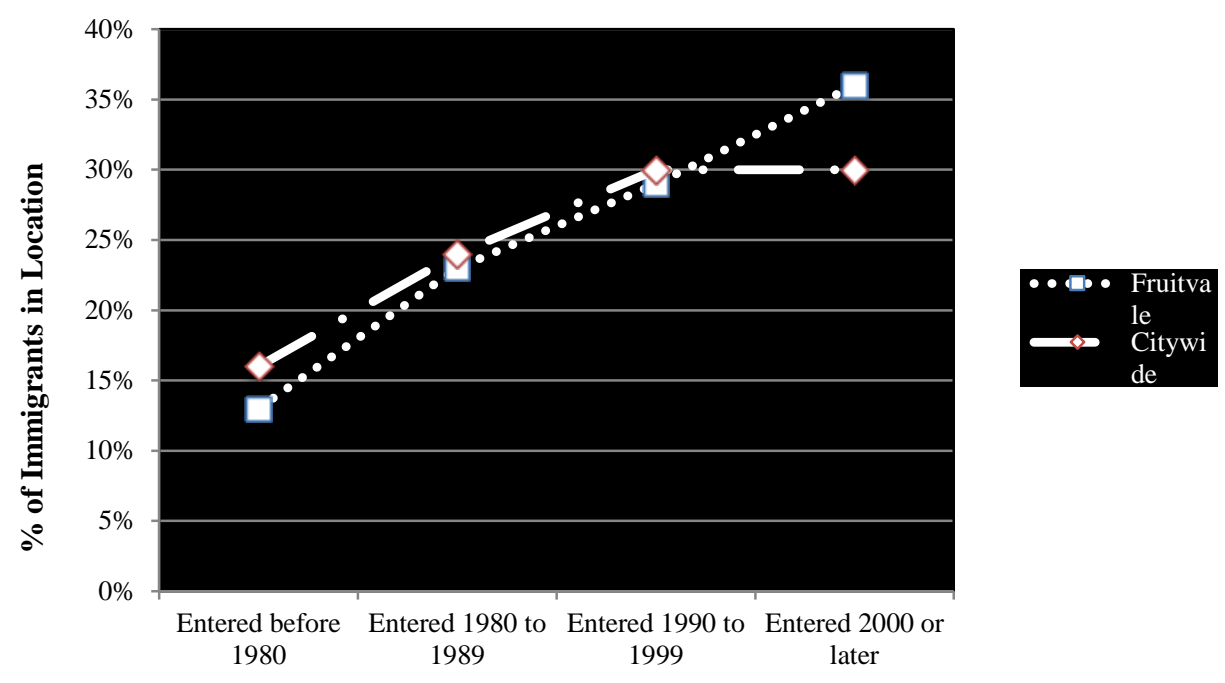

Source: Source: U.S. Census Bureau (2010) Table B05005 
Figure 17: Affordability of Rents in Fruitvale, Compared with the Entire City of Oakland

\section{Median Gross Rent}

Fruitvale vs. City of Oakland, 2000 to 2010 Census

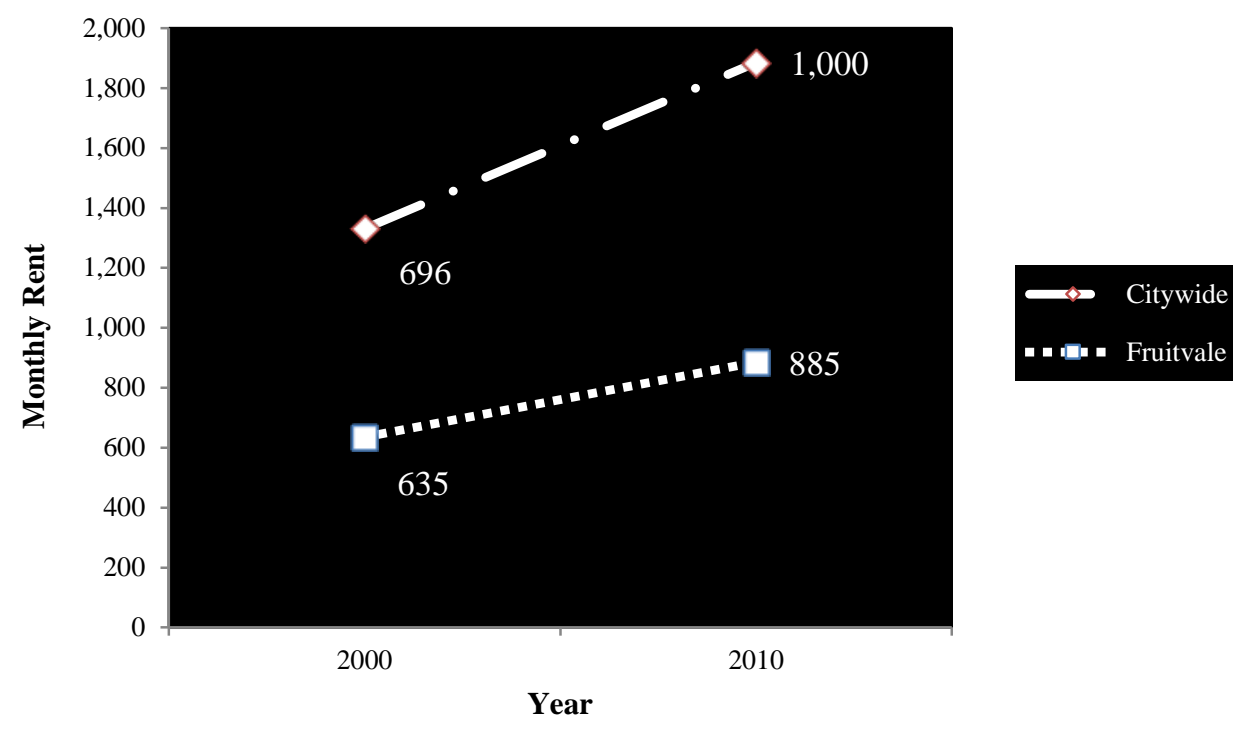

Source: Source: U.S. Census Bureau (2000) Social Explorer fact sheet - Table SE: T167; U.S. Census Bureau (2010) Table B25064

Figure 18: Distribution in Rents between Fruitvale and the City of Oakland

\section{Cash Rent}

Fruitvale vs. City of Oakland, 2000 to 2010 Census

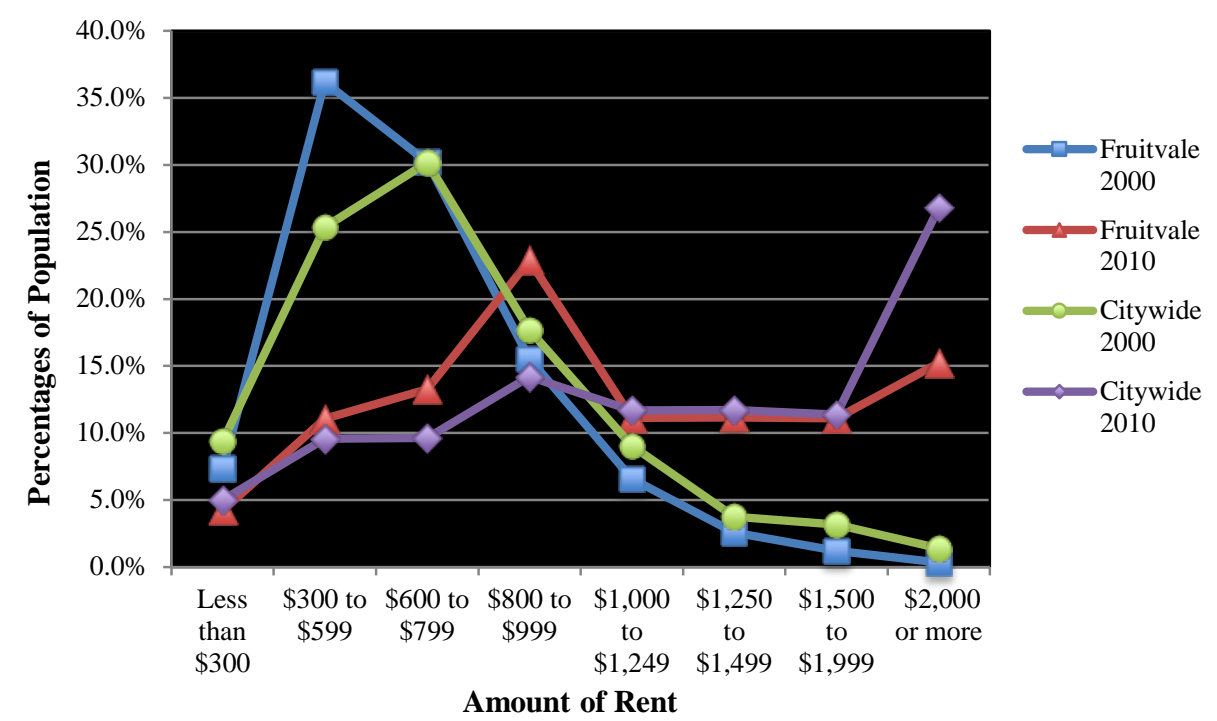

Source: U.S. Census Bureau (2000) Social Explorer fact sheet - Table SE: T165; U.S. Census Bureau (2010) Table B25104 


\subsubsection{Story of Project}

In 1991, BART unveiled construction plans for a multistoried parking structure at its Fruitvale station. Community forces erupted as a "spontaneous neighborhood protest" over the proposed addition that would physically and symbolically isolate the neighborhood from the surrounding city and region while increasing traffic, pollution and crime in the area. Because of the opposition to the proposal, BART agreed to work with the community to develop an alternative. ${ }^{10}$ Eventually, the Unity Council would assume all of the responsibilities of a nonprofit real-estate developer, but initially, it served only as a conduit for community concerns. According to one official, the city and BART "never thought they'd find an organized...voice in a lower-income community,” (Kirkpatrick, 2007).

From the beginning, the Unity Council was concerned with incorporating the community into the redevelopment process. As a result, the Unity Council successfully secured federal and state grants totaling $\$ 655,000$ for workshops designed solely to gauge community concerns about BART's proposed development. As one observer notes, “Typically, either city officials or private developers represent the driving force behind large-scale development projects. In this case, however, the Unity Council's leadership...helped ensure that the community's own vision [would] serve as a guiding principle.”

The success of the Unity Council in representing the "firestorm" of grassroots opposition to the proposal, and importantly, in crafting an alternative vision, stopped the BART proposal. From the very beginning, the City of Oakland realized that the Unity Council was positioned to become the natural medium for community participation. Hence, it awarded the Unity Council a $\$ 185,000$ Community Development Block Grant to develop an alternative plan. The following year, based on the success of the initial process, the U.S. Department of Transportation Federal Transit Authority (FTA) awarded the Unity Council \$470,000 to continue and expand its planning process. In addition to conducting further workshops, the Council commissioned economic, traffic and engineering studies of the site. ${ }^{11}$

In 1994, the Unity Council, the City of Oakland and BART formed a partnership and created the Fruitvale Policy Committee. La Clinica de La Raza also participated in policy meetings between the three main players. That marked the first time BART utilized such an arrangement to plan the area around a station (95). ${ }^{12}$

Ultimately, the project received significant funding from more than 30 separate sources, "each with different eligibility requirements and restrictions [that] had to be coordinated.” The sheer complexity of the financing would have prompted most private investors to shy away from the project. As one board member noted, "for-profit people would have pulled the plug on that

\footnotetext{
${ }^{10}$ Silver Medal Winner. Fruitvale Village; Oakland, California

${ }^{11}$ Silver Medal Winner. Fruitvale Village; Oakland, California

${ }^{12}$ Silver Medal Winner. Fruitvale Village; Oakland, California
} 
project ten different times." And in fact, more than one potential investor "backed off, saying the project was too complicated and too difficult with too much uncertainty for returns.”

One of the most complicated aspects of the project was meeting BART's requirement that all surface parking that was taken away be replaced one-for-one. This required a structure to accommodate about 500 cars. While BART originally had funds earmarked for the station's parking garage, the community protest led to those funds being diverted to other stations. The Unity Council eventually had to find the funds to build a new, multistory parking structure, now completed on the west side of the BART system's elevated tracks. Remarkably, the Unity Council helped obtain a grant from the FTA for $\$ 7.65$ million for this purpose (96). ${ }^{13}$

To some extent, the Unity Council, BART and the City of Oakland make unusual collaborators. Each has its own mandates and interests. However, each apparently realized that they needed the others in order to achieve their own objectives. Thus, as the Fruitvale Policy Committee they helped overcome challenges related to the complicated funding aspects of the TOD. Each of the entities benefited from the arrangement: the Unity Council improved the community for its constituents (and increased its income and equity, as well as developing its capacity); BART increased ridership (estimated to be between 300 and 600 new daily riders) and improved safety at a problematic station; and the City increased property taxes, became more effective in delivering services, and reduced crime and other problems in a troubled neighborhood.

One of the reasons the Fruitvale project has attracted so much attention is the role played by local residents and community organizations during its conception and execution. The Unity Council formed out of the 1960s activism and was able to join together several separate groups under one pan-ethnic umbrella. Importantly, the leaders of the Unity Council have broken longstanding racial and gender boundaries that typically restrict access to the upper ranks of decision makers involved in urban development. For instance, the last two leaders of the Unity Council have been women of Latina descent, who boast of a long history of nonprofit work, political mobilization and government service. Thanks to the "visionary" efforts of these women, the Unity Council is a more female-dominant organization than the majority of its counterparts. The leaders of the Unity Council are thus culled from the world of public service and political activism, and derive their legitimacy from their activities in these realms (Kirkpatrick, 2007).

\subsection{FINDINGS}

We find that large-scale TOD projects have the possibility of contributing to equity outcomes and generative urban revitalization in low-income, Latino, immigrant communities IF they incorporate the various forms of sociopolitical, financial and cultural capital that exists in these communities into the planning and implementation of TOD projects. In this findings section, we first identify the specific forms of endogenous capitals that exist in these neighborhoods

\footnotetext{
${ }^{13}$ Silver Medal Winner. Fruitvale Village; Oakland, California
} 
(political, financial and cultural) and then demonstrate how built capital (in the form of TODs) served as catalysts for transforming and improving both low-income, Latino communities.

\subsection{POLITICAL, FINANCIAL AND CULTURAL FORMS OF CAPITAL IN THE NEIGHBORHOODS}

\subsubsection{Role CBOs Played in Transforming TOD Projects}

Community-based organizations (CBOs) and their activism in the neighborhoods played a key role in ensuring these top-down TOD projects took the community's well-being into consideration. Both Fruitvale and MacArthur Park have a long history of community activism and strong involvement of neighborhood leaders in community improvement efforts. However, the CBOs involved in each project differ in their approach and forms of influence.

In Fruitvale, the Unity Council is the key organization that not only spearheaded the TOD project but also serves as the most important community organization in the neighborhood. The Unity Council emerged from the Chicano movement in the 1960s to serve the community needs of Latinos in the neighborhood. They were established in 1964 and now the Unity Council is a community development corporation that has programs related to workforce development, Head Start childcare, services to support homeownership, youth leadership development, a senior center, a public market, and the Fruitvale Transit Village.

The Fruitvale Transit Village was conceptualized, its funding secured, built, and now managed by the Unity Council. Hence, the Transit Village would have not happened without the leadership coming from the Unity Council. The Unity Council's approach to making the TOD project happen was a combination of gaining community input and participation, collaborating with local government officials, and using its federal connections to help secure funding and support. Arabella Martinez was the president of the Unity Council, and through her strong leadership style she was relentless in developing a vision of the transit village and relying on her federal contacts, as she previously served in President Carter's Administration.

Through Mrs. Martinez’s strong leadership style, the Unity Council used a more top-down, community-driven approach because the organization not only stopped BART from building its initial parking structure, but it then created an alternative vision in the establishment of a community-led TOD project in the neighborhood. A Unity Council leader framed the stewardship role the Council played in establishing the TOD, and made sure the community's voice was heard in the process. "We were stewards of the community. This wasn't an outside developer [building a TOD]. It wasn't the government coming in. We, in fact, opposed BART in terms of what they wanted to do. We led that fight. We led the fight in terms of community policing too. We led the fight in terms of better recreational facilities and programs. So I think partly it has to do with that sort of stewards of the community mindset." This mindset gave the Unity Council a lot of power to influence the process of developing the TOD. Since they had 
been working in the community since the 1960s, they had established a great deal of trust and legitimacy in the area.

With the legitimacy the Unity Council had from the community, it helped create the image that the community was being transformed through a bottom-up effort. But in reality, it was more of a top-down approach lead by this well-connected community development corporation. This topdown approach did have a lot of community participation and residents' concerns were heard and taken into consideration, but the decision-making power was kept within the Council. A Unity Council staff person intimately involved in the process explained this relationship:

Interviewer: Who would make decisions regarding the transit village?

Interviewee: Not the community, it was the Unity Council. It was the Unity Council's project. Unless we knew there was potential for a grant and it was important for the community to speak on behalf of the project, then that is where they would be involved. But for the most part it was up to the Council.

The interviewee went on to say that community members really got involved when there were grant applications and the Council needed to demonstrate community support for the project. She was adamant in explaining that it was always, from the visioning to the groundbreaking, a Unity Council project. Another former staff member explains how Mrs. Martinez's leadership shaped the project and how the project depended on her connections: "The Transit Village would not have happened without Arabella Martinez's will. She would say, 'You are with me or not with me.' She promoted it and had a lot of say. She brought powerful people from DC to fund it, the Clinton Administration gave lots of funding. It came from community development block grants. But the process was not organic, bottom up. It's not a blueprint for other communities unless they also have all the [political and financial] connections.”

Even though it was a top-down oriented project, this does not mean it did not have the support of the local community or their best interest in mind. We want to make clear that we believe the Unity Council's primary goal was to improve the community because community concerns are reflected in the outcomes of the project. Constructing a large-scale TOD by a community development corporation is not a small feat. It took a lot of financial and political support from local government leaders, transportation and city planners, and federal officials. The Unity Council understood that their organizations' future very much depended on the success or failure of their transit village, and they took a very political approach to working with the various governance institutions influencing the project. Sometimes this approach was to aggressively oppose certain development plans, such as when they initially opposed the parking structure that would have cut International Boulevard from the BART station. A key Unity Council leader spoke to how this opposition provided an opportunity to do something different in terms of transportation in the neighborhood: "We essentially had an outsider come in to do something we thought was really bad. So we opposed that, we led that effort. But then we said, 'This is what we want done.' And it took us eleven years to build the transit village.” At other times, the Unity Council took a much more collaborative approach in working with city officials, BART, the 
housing authority, police and local planners. "We could not have done it alone, we needed help from key city agencies.”

Another key leader in the Unity Council stated that this top-down political model was necessary for pushing their agenda and getting the transit village approved. She felt that the community development model of having one key organization representing the community was very helpful and necessary. But that organization needs to have good leadership and a solid reputation of being effective both in working in the community and with city officials. "We had to be bulldogs and push for the transit village." She claims that the Unity Council was always running the agenda and this threatened other neighborhoods because they also wanted TOD funding. But it was necessary to have one key TOD project in the region that could showcase how TOD could work in a low-income community. Hence, the community-led, political, top-down model seemed necessary to make sure the project got implemented. She eloquently frames it this way:

The story is about how an organization can think big, execute big and succeed big. The true grit of a Latino organization that made something big like this happen and how it has secondary and third order benefits to people in the neighborhood.

In MacArthur Park, CBOs also played a critical role in ensuring that the TOD helped meet the needs and concerns of community members. Like in the Fruitvale neighborhood, MacArthur Park has very active CBOs that have a long history in the community. The organizations in MacArthur Park emerged during the 1980s as the community transitioned to a low-income Latino immigrant neighborhood, so they have a more recent history then the Unity Council. The CBOs in MacArthur Park initially started their activism work covering human rights abuses as the civil wars in Central America during the early 1980s to mid-1990s captured the attention of activists in the transnational neighborhood. After the civil wars in Central America ended, the CBOs in MacArthur Park started to turn their attention towards immigrant rights and local community issues.

In MacArthur Park there is not one organization that represents the interest of the entire community, but about 15 various CBOs that collectively advocate for immigrant rights and community development services in the neighborhood. These organizations range from The Central American Resource Center (CARECEN), which was founded in 1983 and focused on immigration and educational advocacy, to Mama's Hot Tamales, a more recent organization that worked to help formalize the street vendors in and around the park. An example of CARECEN's work is its day labor center located two blocks from the TOD site that helps educate day laborers on workers' rights, and also serves as an intermediary between day laborers and their contractors. Another key CBO in the neighborhood is the Salvadoran American Leadership \& Educational Fund (SALEF) that provides educational scholarships to students in the community. SALEF has also contributed to the Latino placemaking efforts in the neighborhood by spearheading the petition for the construction of a new Oscar Romero plaza across the street from the TOD site. This was an eight-year effort that serves as a key example of how CBOs in the neighborhood are networked and collaborate to place pressure on local officials in bringing direct benefits to the Latino community. 
The interactions between the local city councilman's office and these networked CBOs were extremely important in making sure the TOD and the revitalization of the neighborhood included specific community benefits. Like the Unity Council in Fruitvale, these organizations were well connected politically at city hall, and had sufficient community legitimacy to represent residents' interests. In fact, the progressive Latino councilmember made it a point to gain buy-in and even fund community projects via these networked CBOs. Staff members from the councilman's office said the role community organizations and activists played in the negotiations over the TOD were critical. The councilman's office purposely reached out to these CBOs because the organizations could put political pressure on other city entities that were not doing enough to improve the neighborhood. A former councilman for the district stated, "We started bringing community organizations into the city bureaucracy, they were great advocates, and we started forcing other city government services to listen to them. We started working with building and safety and police, and recreation and parks.” A different, and also former, city councilor of the area recalled how the councilman's office collaborated with these CBOs:

We were trying to empower the community. We had what we called More Advocates for Safe Homes, MASH units. They were small neighborhood groups that were basically fighting for their communities. And we worked with them to bring attention to issues in the community. There were immigrant organizations like Churlock, CARECEN, OneStop Immigration and we worked through them. I had a policy where I would not call a press conference, but I went to their press conferences and I supported them so that people would know who they were.

Even though there was this collaborative relationship between CBOs in MacArthur Park and the local councilman's office, some CBOs kept pressure on the office to make sure affordable housing was being implemented both in the TOD site and in other community revitalization efforts. One such group used activist/grassroots organizing techniques to maintain accountability from local officials. The group, Collective Action, was very aware of displacement pressures that might occur because of the new investments in the community, and they wanted to maintain close ties to the city's planning and transportation agencies. A community leader explained their rationale for placing political pressure on city officials and staff:

We want to create a plan that we can take to the Fair Housing members, or the zoning administrator and say, this is what we want. And also for developers, as more developers start coming in. Say, 'that's nice, your condo development looks great, but this is what we want.' For us it's a process because we are process based, how we influence developers and elected officials; how do we bring people to the table who know what they are talking about, who understand policy, because you know, it's not rocket science; it's just political.

The role CBOs played in the development of the TOD projects in Fruitvale and MacArthur Park was critical. In Fruitvale, the transit village would not have been built if the Unity Council had not provided both the vision and then the "bulldog" leadership necessary to secure funding and 
push for its development and construction. In MacArthur Park, the networked CBOs were responsible for the positive community benefits associated with the project, especially the amount of affordable housing units constructed on the TOD site. The Unity Council used a more top-down but community-focused political organizing model, and in MacArthur Park the networked CBOs used a more collaborative approach but also kept political pressure on key city institutions to ensure equity in the TOD project's development. These forms of endogenous political capital present in both neighborhoods helped them sustain the new transportation infrastructure projects brought to the neighborhoods.

\subsubsection{Local Latino Politicians as Champions}

The political capital in these neighborhoods is also exercised via the local Latino politicians who saw the benefits of revitalizing these neighborhoods via the TODs. Both neighborhoods had Latino city councilmen who fought for community benefits and improvements in the area. The Fruitvale district was represented by Ignacio De La Fuente, a progressive councilman who came out of the labor movement and had long ties to the neighborhood via work he had done with La Clinica, a key community health clinic that served as the TOD's anchor. One local politician described De La Fuente's role as an inside champion. He stated that “a complex project like this needs an inside champion to help in the regeneration. Someone who understands inside processes of government and maneuvers the political climate. Oakland is a tough place.”

De La Fuente was such a champion. He placed this project at the top of his "projects agenda." His decision to support and fund this project cost him politically as several other councilmembers did not appreciate that a lot of the city's funding was being spent in his district. But as someone involved in the process described it, "If you are an elected official and represent a district, you are put into a position where you have to fight, you have to do battle for your area. This project was not going to happen, without having the champion, without having someone doing the infighting, someone that has enough insight so that you know where the resources are, so that you know the different public resources and grants that you can use. Otherwise, the project would have been impossible."

De La Fuente developed a close relationship with the Unity Council leadership team. They both bounced ideas off each other and brainstormed ways to gain funding for the project. De La Fuente would be the insider at city hall and Mrs. Martinez would gain community support for the project. A Unity Council leader describes De La Fuente's relationship to the Fruitvale Transit Village as critical and also the Council's support for De La Fuente:

And an important person in this...you know, we elected in that time Ignacio De La Fuente as our city councilman. And then he later became the council president. You know, he was an enormously important actor...very supportive of what we did. Umm...and we supported him.

But interviewees describe the political battles that took place over funding and making way for the TOD as extremely politically difficult. One local politician described the contentious battles: 
"You need an inside champion or it won't happen. A lot of Latinos fail to think outside of the box. You cannot be afraid of people attacking you. The process is politically complex, especially when you are in communities of color, and there is not a balance of political power, it's tough.”

There was opposition from other community groups that were outside of the Fruitvale neighborhood, and they placed political pressure on other city councilmembers to not support the project. One story told to us by interviewees involved De La Fuente taking some of the leaders of these oppositional CBOs aside and convincing them to support the Fruitvale TOD with his publicly savvy persuasions. Before De La Fuente left office, he was able to secure \$6 million in funding for buying the land needed to start phase two.

MacArthur Park had similar Latino political champions that supported the TOD project and helped sustain the community's revitalization efforts. MacArthur Park belongs to LA's first district, which was developed in the early 1980s from community activists' efforts and lawsuits that advocated for more Latino political representation in LA. The Voting Rights Act of 1965 was used as the platform to create the first district, which has a high concentration of lowincome, Latino immigrants and poverty. A longtime city official described the history of its creation: "The Voting Rights Act gave us a platform by which to advocate for a new district of left over neighborhoods. The city council essentially threw away a bunch of neighborhoods and said, here, we don't want these, this is where the crime is, this is where the poor people live, this is where the infrastructure is broken, this is where no one wants to invest. That is the history of the first district."

Elected out of the first district was current Los Angeles Supervisor Gloria Molina. Mrs. Molina came out of the Chicano movement and was a community activist. It was through her leadership that the initial top-down TOD project in the neighborhood was opposed and transformed (Sandoval, 2010). This initial, large-scale TOD plan called for the neighborhood's transformation. The TOD plan had no affordable housing allocation, called for high-end retail and condominium units, and was disconnected from the community. Gloria Molina describes her initial impression of the large-scale TOD project (Sandoval, 2010):

There were just so many issues at the same time, so when they put this on the table and they are talking about this shiny new thing; I was like, yeah, yeah, but we have all these things to take care of. So this was proceeding and we were concerned about it; the biggest concern was who they were going to attract. The community wanted a market and they were saying, no market will come in, we want to do this; and I said no, the community wants a market, they don't have a market to go to, so could we find a way so that we can do some sort of market there. Everything was what the developer wanted, not what the community wanted. I wasn't on the MTA then so I didn't have as much influence, they were kind of moving along on their own. The project that they initially wanted was too dense for the area. When they first presented it to the community, it wasn't built for the community, it was built for the people that were going to go through there; the park and ride and creating the parking. If you are going to have commercial development you have to think, what is the benefit for the community? If they want a market and you are saying, 
no it doesn't fit, then you are not meeting their need. The entire project was built for the commuter, the person that would go through the system; create a little coffee shop for them, it was really bizarre. I thought they were very arrogant; they didn't have a good understanding of the community. They weren't opening up the process. Like the simplicity of the market; instead of trying to figure out how does this all work; their attitude was it doesn't work, so we are not going to do that.

Hence, Mrs. Molina was worried about the potential issues of displacement and the lack of community input into the initial TOD project. But it was not until she became county supervisor and she formally sat on the MTA committee that she was able to stop the project, force the transportation planners to go back to the drawing board, and also provide more community input into the TOD plan's development (Sandoval, 2010).

The councilmember under whose watch the current TOD project developed was Ed Reyes. Mr. Reyes was a trained urban planner with a master's degree from UCLA. Interestingly, Mr. Reyes worked for two years for the Unity Council in Fruitvale after finishing his graduate work in planning, and then moved back to Los Angeles to work for the city's urban planning department. Mr. Reyes championed two key projects as the first district's councilmember. One was the cleanup and regeneration of the Los Angeles River, and the other was the revitalization of MacArthur Park. According to a former staff member, Mr. Reyes focused on building community capacity and local leadership in his district:

We hire people because they came from the neighborhood. We want to see the improvements. Gloria [Molina] hired people from the neighborhood, Mike [Hernandez, another former councilmember] hired people from the neighborhood, and Ed [Reyes] hires people from the neighborhood. And we are educated Latinos, we understand right from wrong. We understand the injustices, but we also understand how to make it right. Now with Antonio [Villaraigosa] as Mayor, [we had] another tremendous opportunity.

With the councilman's planning background and his focus on neighborhood development, Mr. Reyes was able to advocate for many affordable housing projects in the neighborhood. In fact, his staff stated that every project that wanted to change a zoning ordinance had to go through review by the council office, and Mr. Reyes would use that opportunity to advocate for affordable housing. This was also the case specifically in supporting the TOD development.

The role local Latino politicians played in the TOD project's development cannot be understated. They were the link between the community organizations, residents, merchants, and the city's organizations involved in the process. They used their political capital to advocate for the TODs. This ensured that the process would move forward, that key funding would be available, and that the community's needs were being addressed.

\subsubsection{Supporting Latino Small Businesses in Revitalization Efforts}


The biggest impact the Fruitvale TOD has had on the community is the revitalization that occurred on International Boulevard. All the interviewers agreed that International has seen much revitalization and now is a vibrant commercial corridor. As a community leader recognizes, “The Unity Council wanted to revitalize Fruitvale and International Blvd's potential vibrancy was key [to that revitalization]. International Blvd serves the community and is now a very vibrant shopping district." The TOD opened up pedestrian access to International from the BART station and this has positively improved Latino retail businesses. A local politician explained the impact: "The Transit Village Project was a catalyst that took store fronts and businesses along International Boulevard from 40 percent occupied to 98 percent today." According to a Unity Council staff member who focuses on economic development, the Fruitvale neighborhood now generates the second highest sales taxes in all of Oakland. But ironically, the initial opposition for the Fruitvale Transit Village came from the businesses along International that thought the TOD would lead to their displacement. As one politician involved in the process explained, "It was a challenge for the Unity Council to have hundreds of meetings with the businesses to convince them that there would not be displacement, that it would be a catalyst and good for businesses, it would increase foot traffic."

The efforts to help Latino small businesses on International were part of the Unity Council's revitalization efforts from the beginning. They understood that International was the center of the Fruitvale community because that was where the activities and vibrancy of the area existed. Its diverse mix of Mexican and Central-American businesses is what gave Fruitvale its “international” identity. A key Unity Council leader explained the original goal that linked International to the TOD project:

We had a very clear vision about what we were about. We were about community revitalization, and we had a very clear and simple strategy that was easy to understand. Not only were we going to be place-based, and in a very narrow space in terms of blocks. But we were going to concentrate our resources around International Boulevard because one of the things we said was that if we don't do something about the retail businesses in the Fruitvale we're not going to survive [as a community]. Fruitvale isn't going to survive...it's going to get worse and worse and worse. And we said... whenever we're going to build something, we're going to build it so that it helps the economy...the International Boulevard retail economy and the Fruitvale economy.

This is the key reason the Unity Council so adamantly opposed the initial construction of the BART station parking structure. The large parking structure was going to be located between International and the BART station, and there are two blocks separating International from the station. Before the Fruitvale Transit Village investments took place, International and its small retail businesses were in bad shape. There was violence in the neighborhood, similar to MacArthur Park, and gangs controlled the streets. The area was not well taken care of, which lead to trash and graffiti being familiar sights around the neighborhood. A community leader explained that the small stores had "security guards and metal guards, and so forth. And the stores that were remaining were not really the types of stores people wanted to shop at. The quality wasn't so good either and the prices weren't so good. They weren't necessarily very clean. 
And so people literally, and I'm talking about the residents, would go out of the area to shop because they just didn't feel comfortable shopping on International Boulevard.”

The original idea for the transit village actually emerged from a retail leakage study that UC Berkeley Professor Ed Blakely of the City and Regional Planning Department conducted with his students. Their study revealed that a lot of the residents were shopping outside of the neighborhood, and his idea was to create a connection though street design from International to the BART station to encourage more people riding BART to shop on International. This gave Arabella Martinez the initial idea of creating a paseo between both spaces.

Because of this need to revitalize International Boulevard, the Unity Council was interested in creating two programs: Their Business Improvement District (BID) and the Fruitvale Village Paseo, which would link International to the BART station. In 1996, the Unity Council organized business merchants on International and started a litter and graffiti abatement program.

According to one staff member, the social fabric was deteriorating in the neighborhood and had to be rebuilt; hence, their initial efforts were focused on a façade improvement program that was actually a part of a National Mainstreet Urban Commercial Neighborhood Initiative grant. Fruitvale's BID was the first organized in the city of Oakland.

The key Unity Council staff person responsible for engaging the community through public participation efforts took the lead in organizing Latino merchants on International. The BID started in 2000, and every five years merchants and business owners vote whether or not they favor renewing it. Their initial focus was on International and making sure businesses received support, facades were being improved, and local business owners could eventually buy their properties. Merchants have voted three times to continue the district. The merchants taxed themselves by paying a percentage that is based on the square footage of their business. The BID currently has a yearly budget of $\$ 325,000$. These funds are used for graffiti removal and cleanup, power washing building façades, street sweeping, flyer and poster removal, and collaborating with the police department on safety issues. The funds are coordinated through a Unity Council program called Peralla Corporation that now has about 100 employees who work for this BID and other areas throughout Oakland. The funds are also used to hire consultants who teach merchants best practices on accounting, marketing and developing business plans, and these consultants give specific advice to each business owner. They also work with the police, and collaborate closely with both the police chief and local police captain. Business owners can complain to the police about safety issues at community meetings, which take place at the senior center in the transit village. The Unity Council staff person in charge of both the outreach to Latino small businesses and the BID says that although rents have increased since the TOD has opened, there has been no displacement of local Latino businesses on International Boulevard. 


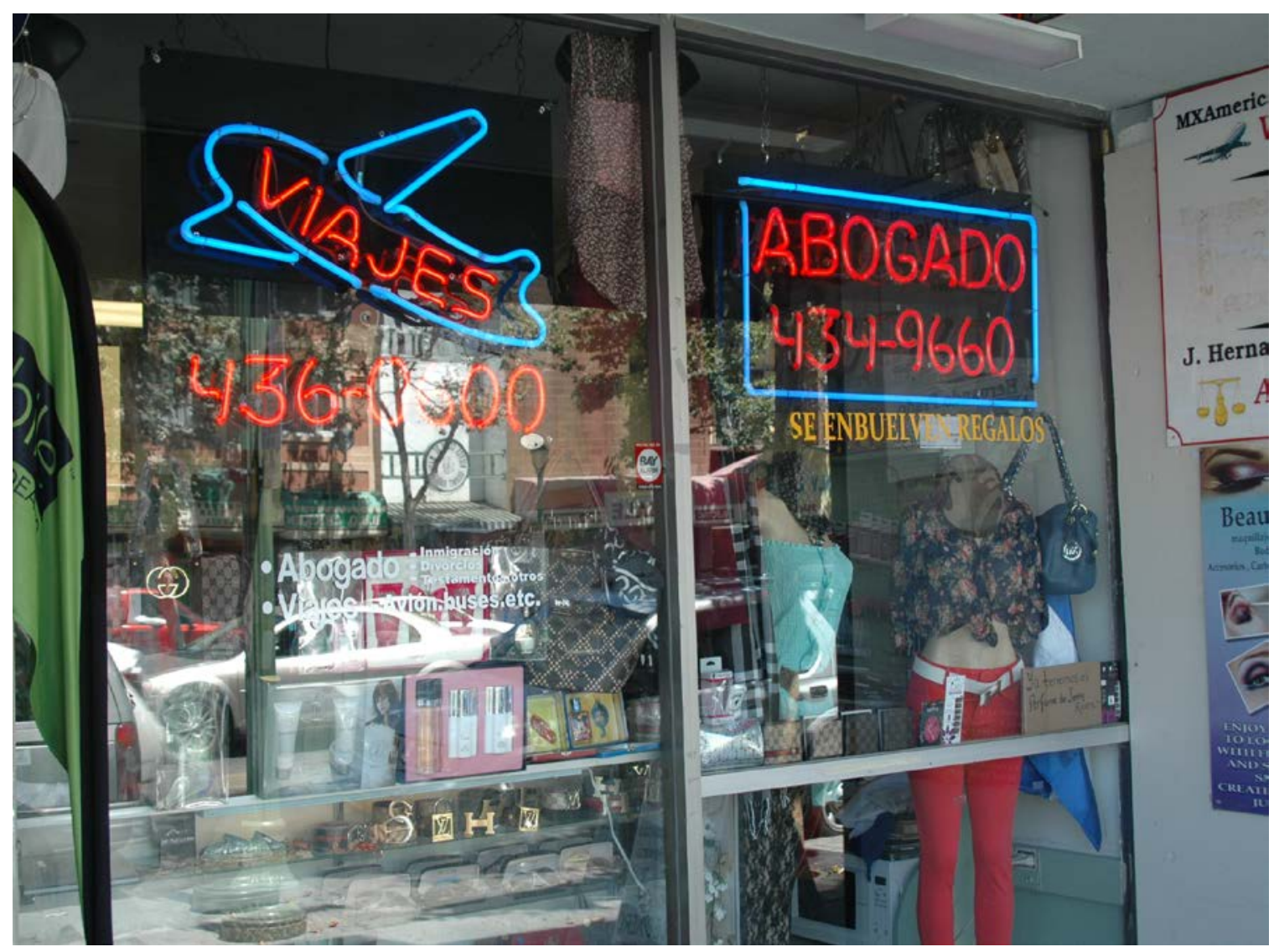

Figure 19: International Blvd.'s Latino Small Businesses have Benefitted from the TOD

The reason everything associated with International became such an important part of the project was because the project's handlers wanted to link the transit village to the rest of the community. As one former Unity Council staff person explained it, the area's revitalization had to go beyond the TOD. "The Latino Oasis [Transit Village] had to bleed outward. This incredible little oasis could not just be its own little thing, whatever the improvement, it had to bleed outward and everyone had to be a beneficiary of it and the business improvement district is a great example of that."

The paseo (a nicely designed streetscape from the BART station to International) was a key design element of the TOD because it linked the station to the TOD and International. The Fruitvale Village Paseo was the original idea ever since Arabella Martinez had taken Professor Ed Blakely on a walk between the BART Station and International in the early 1990s. Allan Jacobs, another UC Berkeley faculty in City Planning, had designed the median on International and played a role in helping to design the paseo. A Unity Council staff person in charge of helping to manage the TOD explained that many people complain about the TOD plaza as a badly designed public gathering space, but the true purpose of that design was to serve as this paseo, not a public gathering place. The Metropolitan Transportation Agency funded both the 
median on International and also the paseo. It's critical to understand how the paseo has helped connect these three nodes of interaction in the neighborhood. Without this current synergy, the development would not be as vibrant and active with the public. It was a good strategy to help bring more business to the merchants on International.

Street vending is another type of Latino small business in these neighborhoods. This is most obvious in the MacArthur Park case, where city officials tried to harness the informal financial systems that existed in the community. These informal economic systems included the hundreds of street vendors that sold their goods illegally in and around the park, and especially next to the subway station. The street vendors sold food that catered to the Mexican and Central-American community, such as tamales, corn, etc. They also sold medicine from Mexico that residents were familiar with, as well as electronic products, clothing, movies, and other products that directly catered to the low-income, Latino community. The usual response to street vending by the city is to try to end those activities by either ticketing or arresting individuals, which usually ends up displacing vendors. In MacArthur Park, the response by local officials was different.

The local councilman at the time, Mike Hernandez, decided to start the first legitimate streetvending district in Los Angeles. His staff viewed street vendors in a positive light instead of viewing them as criminals. One street-vendors program participant, who worked for a non-profit organization that provided business training assistance to informal street vendors, stated:

We didn't want to change the community so we did a couple of things. One was to recognize that there was a large informal economy there, that there were tamaleros there, so those folks were inspiring entrepreneurs and they could do better if they could get some financing. We would partner with micro-entrepreneurs and we could train them with a business plan and show them how to do marketing, showing them how much to charge. Then we would send them to Mama's Hot Tamales and there they would do actual practical hands-on experience, they would be expected to work in the restaurant, they would have to wait tables, and run the cash registers and kitchen. By the time they got out of there, they would know the different parts to running a restaurant and they could get out and start their business. This was about education and empowerment with the help of some capital.

The street-vendors program started by Councilman Hernandez and continued by Councilman Reyes relied on a community-based organization, Mama's Hot Tamales, to be the mediator between the city and the street vendors (Sandoval, 2010; Kelly and Sandoval, 2014). Mama's Hot Tamales served as a kitchen incubator where the street vendors would cook their food and it could be regulated by the city. The councilman's office was giving these informal activities a chance to thrive because it understood how important informal financial capital is in the neighborhood. A key politician explained why these informal financial activities were critical to the community's growth. He stated that his "approach was not based on real estate, it was based on the flow of capital as defined by small wallets. That's the MacArthur Park way. That's every city in the Third World. I've been to El Salvador and all these cities that have all these intense informal activities.” He recognized that street vendors, day laborers, informal medical clinics, 
miqueros who sell false identification papers, and some swap meet activities are all part of the economic engine driving these types of neighborhoods. And if you try to get rid of those activities, you will also be contributing to the displacement of the Latino, low-income, immigrant community in general because they are interlinked and interdependent on each other.

Another councilman staff person acknowledged the importance of informal financial capital in the community as he gave the research team a tour of a new project they were working on in the neighborhood. "The informal economy is the formal economy for this community." The council district is collaborating with three community organizations on developing a "mercado," a type of community market where street vendors could sell their goods and not be worried about being harassed by police officers or city officials. In fact, the market is located in front of the neighborhood's police station. City officials are encouraging street vendors to move from neighborhood alleys to this mercado where they could be better regulated. Hence, both the councilman's office and key community organizations in MacArthur Park are demonstrating how important forms of financial capital, even though they might be informal, can still be supported and encouraged to maintain some form of regulation.

Supporting endogenous forms of financial capital in revitalization efforts via large-scale TODs is critical to maintaining important community economic activities such as local businesses. The Fruitvale case demonstrates that linking the TOD physically via design and programming (through the BID) had very positive outcomes for Latino small businesses on International Boulevard. There was initial concern by business owners on International that the TOD's retail would harm International's retail by either providing direct competition or changing the retail market and displacing merchants. Both of these concerns were addressed via a public participation process that helped create the BID that ultimately helped businesses on International. The MacArthur Park case demonstrates that informal Latino businesses also play an important role in neighborhood revitalization. The construction of the subway station accentuated the street vendors in particular. City officials were able to think outside the box and develop innovative responses to regulate those activities and not just displace the vendors. That was critical because those informal financial activities are directly tied to forms of financial capital in the neighborhood that should be built upon and not destroyed.

\subsubsection{Latino Placemaking as Community Anchor}

Every community needs some form of local resource to anchor its revitalization. In both the Fruitvale and MacArthur Park cases, it was a form of cultural capital that manifested itself from the Latino community's placemaking practices. Latino placemaking views the transformation of the built environment as a response to cultural preferences, lifestyles and economic needs (Rios et al., 2012). This form of placemaking based on cultural preferences and attributes is a form of cultural capital present in both Fruitvale and MacArthur Park, which played a key role in the TOD's transformation.

The design of Fruitvale's TOD had to make a big splash. It had to showcase the project as something different and be a welcoming design for BART users and local residents. Since it was 
a catalyst project, the design had to also be eye-catching and represent something unique in the region. A Unity Council leader explained the rationale for the design: "You need to start with a big vision because funders and politicians are not going to rally around a small vision. They are going to rally around a big vision and that is what motivates people and gets people going. And then when you get there, here is the big secret, you don't know what you are going to get." Even though the design had this large vision, there was much community input via charettes and other public participation tools to make sure the community's perspective was incorporated into the design. An architect who worked on the design commented that the TOD had to be a destination for the region.

Latino cultural features were also incorporated into the design. The paseo had Spanish architectural features, the public plaza space incorporated indigenous Latino features, and the housing unit's bright pastel colors resembled those commonly found in other Latino neighborhoods. Designers who worked on the project said that cultural diversity and sensitivity played an important role in designing the project's architectural features. They even wanted a direct sightline into St. Elizabeth's Cathedral, the Catholic church that serves as the neighborhood's key religious/cultural icon and where a lot of the anti-violence/anti-gang organizing was centered. If you stand on the BART platform, you have a straight line of view from the BART station, through the TOD and paseo, to the cathedral. According to one of the architects who worked on the TOD design, the goal was to create a welcoming context, one "of having an international cultural experience.” 


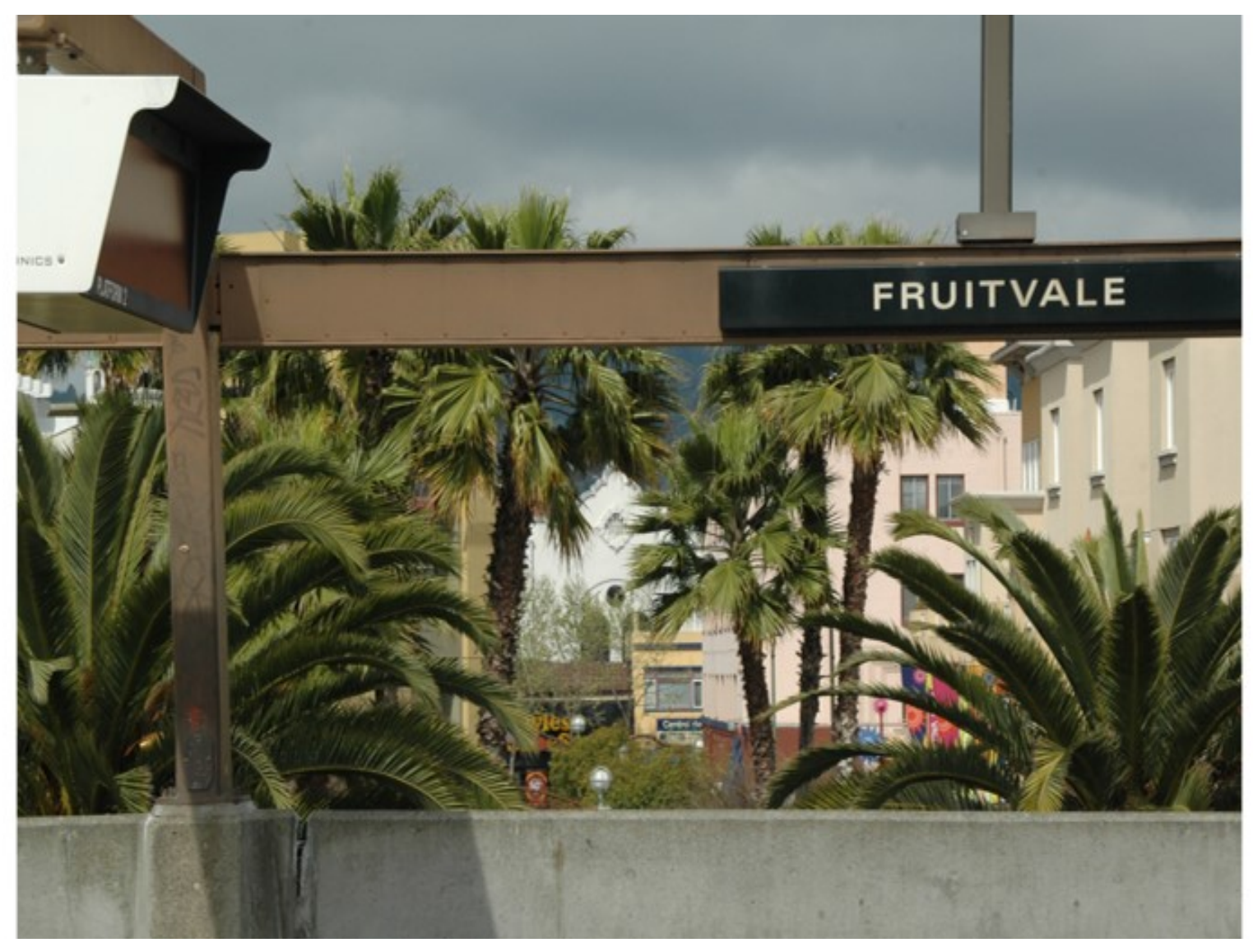

Figure 20: Located in the Center of the Image, this View of the Cathedral was Designed into the TOD Project (image was taken from BART's platform)

The Unity Council also uses the TOD site to organize important cultural festivals for the community. One of the largest festivals in Oakland is the "Dia De Los Muertos" (Day of the Dead), which takes place in November. The festival brings in thousands of people and is located along $12^{\text {th }}$ Street to $37^{\text {th }}$ Avenue in the Fruitvale District. The festival builds cultural capital because it brings in dance troupes and musicians, and allows community members to culturally express important values (individuals create altars and memorials to commemorate the dead).

Another form of cultural capital is expressed via the food available both at the TOD site and along International. For example, it is very difficult to find Guatemalan tamales in the United States. Mexican tamales are easily available and can be found in most Mexican restaurants, but Guatemalan tamales are only sold in restaurants that cater specifically to Guatemalan clientele. And one can find Guatemalan tamales in MacArthur Park and along International in Fruitvale. This is yet another indicator of the strong cultural capital that exists in these neighborhoods. A Fruitvale community leader nicely summarizes the benefits of incorporating cultural capital into the project: "The success is that the Unity Council not only built the transit village, but it improved the greater community. From a cultural perspective, from a façade improvement perspective along East 14th, from the senior to childcare facilities. And you typically don't get 
that, especially from a housing developer, they will come in and just do housing. They don't take the cultural roots in the neighborhood in mind.”

The Latino placemaking in MacArthur Park is occurring through the establishment of Latino businesses and their changing façades, the transformation of the park (from being a passive park to being an active park), the informal activities present around the TOD, and the neighborhood's cultural events. However, in contrast to Fruitvale, there is not one key CBO organizing a lot of this cultural capital but instead a mixture of organizations and residents expressing their cultural rights. One key example of how cultural capital has contributed to the revitalization of the neighborhood is the park itself that has been transformed from an aesthetic passive park (which is how historic preservationists would like to keep it) to an active space filled with Latino kids playing in new playgrounds and informal soccer leagues, which host tournaments that are usually attended by hundreds of spectators. Establishing the soccer field was not an easy task as the council district had to formally designate the field a "meadow" to appease historic preservation activists. Hence, both the soccer fields and goal posts are not permanent and the soccer fields transform back to meadows on a daily basis. A community leader explained that process:

Daniel is the leader of the informal soccer leagues. I meet him in the late 1990s and I would tell him to hang in there because we are going to change this. But the historic preservationists did not want to change the use of the park. They wanted to keep the historic image of the 1950s and they moved to make the park a historic monument. It was their way of keeping the immigrant kids out of the park. We said we would make it into a meadow. We would make it an artificial turf because we did not stripe in the soccer fields or establish the goals. With Daniel's help, as well as working with all the families, we raised the money through Prop $\mathrm{K}$ and the community redevelopment agency. We designed it with the immigrant kids in mind. So the band shell, the meadow (the soccer field) and all the functional areas you see today, we brought them in, so that we would keep the historic character of the park. We never used the word soccer field. We knew that the natural forces of the community were going to take it over anyways and we weren't going to police that takeover. We weren't going to arrest the kids. 


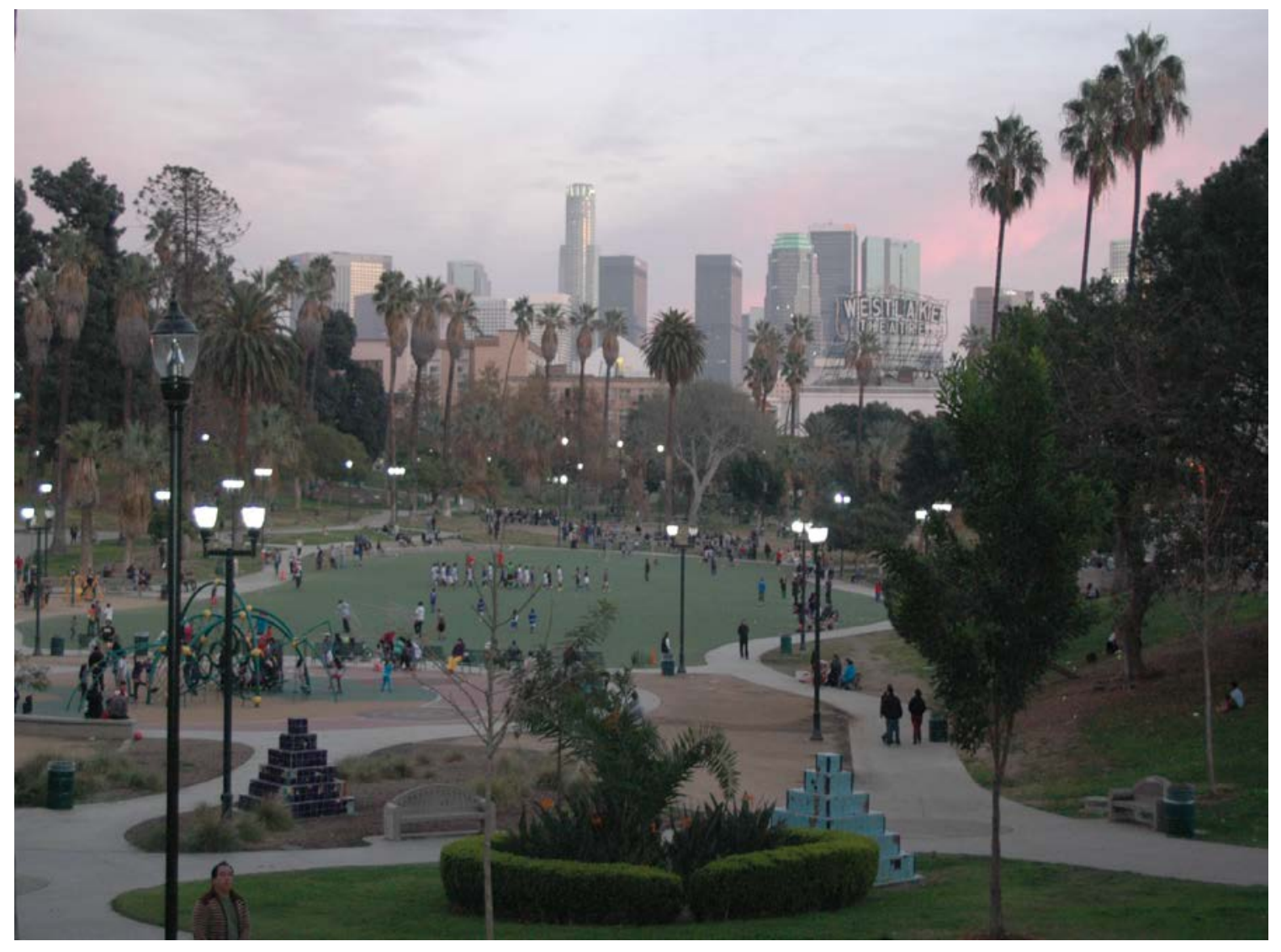

Figure 21: Youth Soccer Fields in MacArthur Park, Which as a Collective are Officially Considered a Meadow

The other expression of cultural capital in the neighborhood is similar to the cultural festivals and celebrations that are organized in Fruitvale. Both Feria Agostina (an annual El Salvadoran celebration in early August) and a Central-American Independence Day celebration and parade (celebrated on September 15) are important cultural celebrations that take place in the park. As Kelly Main (who wrote her dissertation on MacArthur Park) describes:

The events provide an opportunity for park-goers to experience both traditional and hybrid culture. Feria Agostina takes place around the time of Las Fiestas Agostinas and la bajada, when thousands of Salvadorans gather in the streets of San Salvador to celebrate the transfiguration of the Divine Savior of the World, El Salvador's patron. On Central American Independence Day, Costa Ricans, Salvadorans, Guatemalans, Hondurans, and Nicaraguans celebrate their independence in MacArthur Park. Together, these events are attended by thousands, as food and information booths, bandstands for music, carnival rides, and speeches fill the segment of Wilshire Boulevard that cuts through MacArthur Park (Main and Sandoval, 2014). 
These types of cultural celebrations help to anchor an ethnic group to a community via their cultural capital. Another example of how cultural capital is used as an anchor to establish community and contribute to revitalization can be seen in the establishment of the Monsignor Oscar Romero Plaza, across the street from the TOD. Monsignor Romero was a Catholic archbishop assassinated in El Salvador during its civil war because he spoke out against human rights violations. The Salvadorian community wanted to celebrate his legacy by dedicating a statue in his honor. The Central American Roundtable, a coalition of various neighborhood CBOs, led the eight-year effort to commemorate the Catholic bishop. In November 2013, the El Salvadorian community celebrated the construction of the plaza. This was a form of Latino placemaking and another example of how cultural capital serves as an anchor for revitalizing neighborhoods. The first thing people see directly across the street as they exit the MacArthur Park METRO subway platform is the statue of Romero.

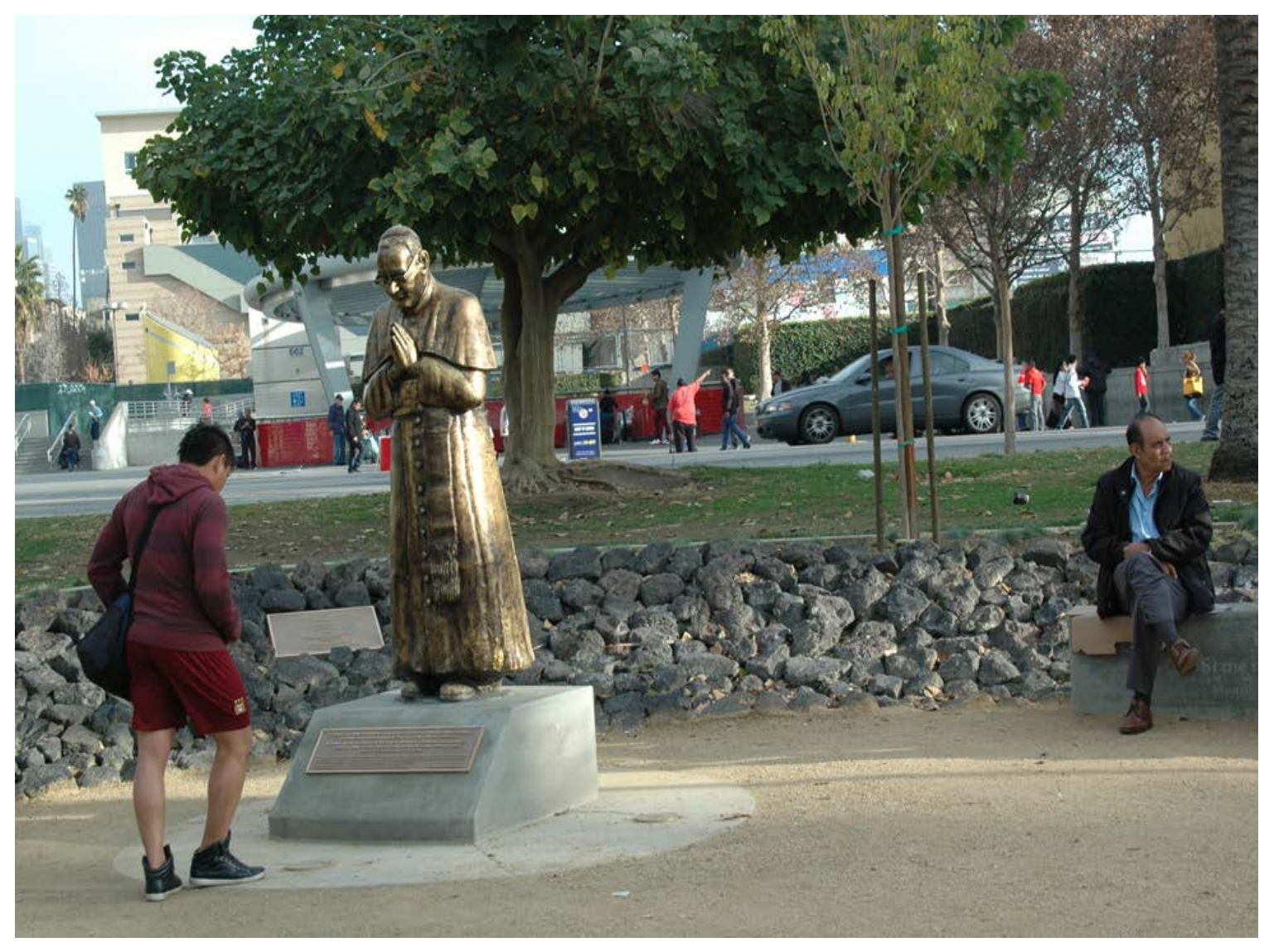

Figure 22: The New Monsignor Oscar Romero Plaza Across the Street from the TOD 


\title{
6.2 EQUITY PROCESS AND OUTCOMES OF TOD PROJECTS
}

\author{
6.2.1 Redefine Equity and Latina Participation \\ We knew we were beautiful and wanted the rest of the world to know that. \\ Former Unity Council Director
}

TOD projects are the built form of capital that can have the potential to serve as catalysts for neighborhood revitalization. But not much is known about the equitable outcomes of TOD projects in low-income communities of color. Philosopher Iris Marion Young views equity as making institutional amends to communities of color for previous discriminatory policies by government (Young, 2011). At the core of this framing are issues of power and decision-making around resources, and these two case studies demonstrate that communities of color played key roles in redefining the TOD projects and in decision-making. Interestingly, some of the key players involved with these TOD cases viewed equity as providing access and opportunities in neighborhood revitalization. It is very useful to review their framing because, in an important way, it dictated their activism and goals around how the TODs would contribute to the revitalization of their respective communities. One key player in the Fruitvale case described equity the following way:

I'm trying to broaden your definition of equity. Like, for example, equity is having wonderful facilities for poor people. Equity is having really good parks and recreation facilities. Okay? Equity is about having your streets clean regularly. And, so in terms of commercial and retail, it means that people have more...a greater diversity of goods and services and there's more competition because there are more stores. They don't have to go out of the neighborhood to shop. And many of these are minority-owned establishments.

So if kids can play in the park instead of the streets, because before it was safer for them to play in the streets than in the parks [because of gangs], that's equity.

So you have new parks, you have new schools, you have new medical facilities, new senior centers, new childcare facilities...you name it. And, umm...that has not resulted, at least as far as I can see, in people being pushed out of the Fruitvale. And the other part of it, I guess people are safer. I mean, not only are the streets cleaner...but they're safer. There's still crime, but Oakland is full of crime in the flatlands. So, umm...so I think on balance I would say on the equity situation, I think we did very well.

People involved in the Fruitvale case mentioned how the TOD project helped provide access to social services and made the area cleaner and more beautiful. A community leader comments that, "The Fruitvale previously looked like a typical Latino community that had not been cared for, had eroded itself, didn't have an identity, but the transit village changed that perception.” One of the key outcomes the Fruitvale Transit Village has had is that it opened up the 
neighborhood to the region. It is a destination and a link to International Boulevard and the neighborhood.

The other theme around equity that is important to analyze has to deal with the participatory process and decision-making related to the TOD. What you see is that those leading the charge were Latina women with a very strong and effective leadership style. County Supervisor Gloria Molina almost single-handedly stopped the initial large-scale TOD project that had threatened the neighborhood. Many of the CBOs in MacArthur Park were also led by women who had direct access to city officials and the police. For example, Sandi Romero, executive director of Mama's Hot Tamales, which spearheaded the street-vending program, had direct access to the LAPD's chief. In Fruitvale, Arabella Martinez called most of the shots when it came to making direct decisions on the Fruitvale Transit Village's development. Mrs. Martinez had access and connections to federal and local politicians and staff members. A male staff person who worked on the design of Fruitvale Transit Village called her "La Coronela" and thinks a large-scale project like the village needs someone like her to get things done. "A project like that needs a Godmother.” Another key leader within the Unity Council commented on the gendered relationships and sometimes the conflicts that emerged with the male Latino business owners on International Boulevard.

Between Arabella and me, Latinas, and most of the businesses along International Boulevard are Mexicanos. So you have the big mouth Latina leading the organization and you have the Mexicanos [accentuating the "os," for males]."

Ha, ha, ha, ha, capital OS, right, so there was quite a bit of tension there. I didn't have time to play the subordinate Latina. Right away they wanted to criticize.

In an interview, a UC Berkeley professor, who had been involved in the project from a distance, commented that she believed the project was successful because of Arabella Martinez and her strong leadership style and connections. The participation of strong women and their access to decision-making processes affecting different parts of the TOD projects was also a factor that we believe contributed to the equitable outcomes of both projects. 


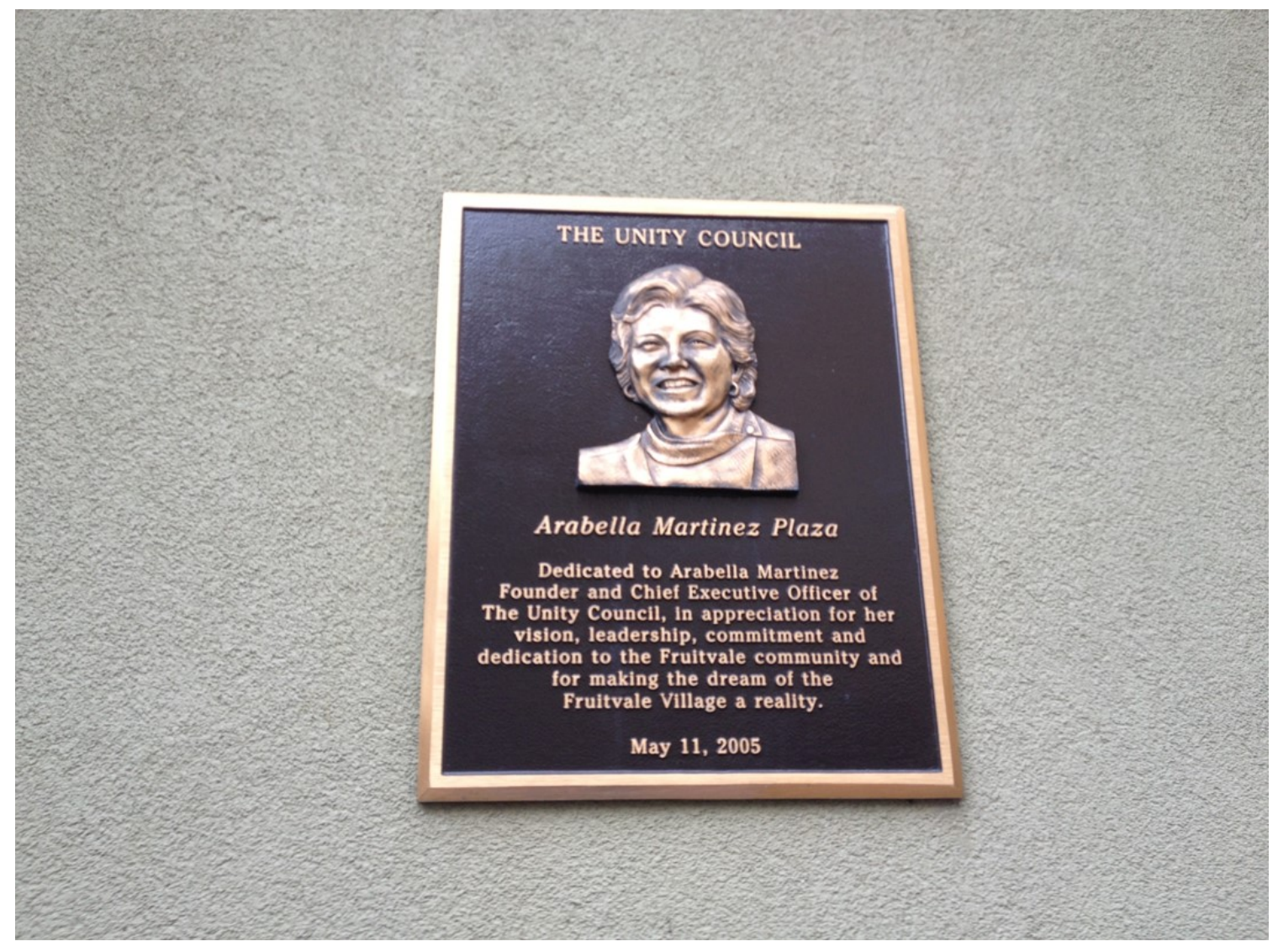

Figure 23: Arabella Martinez’s Plaque at the Fruitvale TOD Site is a Reminder of her Leadership and Contribution to the Project

\subsubsection{Equity Outcomes in the Neighborhood}

When people think about TOD, they think about dollars and cents. But if you think of it from an equity perspective... having access to a high school, having access to education and transportation, those are really important and good resources.

Fruitvale Community Organizer

The two large-scale TOD projects contributed to equity outcomes in the neighborhood by proving increased access to regional public transportation and affordable housing; encouraging diverse local small businesses; and improving social services provision in the neighborhood, such as medical and educational services. Indicators such as ridership numbers show that ridership has been increasing in both Fruitvale Station and MacArthur Park. In both neighborhoods, bus lines have been re-routed to link up as transit hubs with the TODs. In MacArthur Park, residents of the new housing development are even given a monthly METRO pass (a subsidy that both the housing developers and METRO help allocate). This is the only type of program that exists like this in the LA METRO system. 
Each household gets one monthly free pass on transit. It's a local program, but passes come from METRO. Residents pay $\$ 20$ when the true market cost is $\$ 70$ for the pass. METRO has these types of programs with businesses, so the question was whether they could do this with housing. And they did. This public transportation pass voucher actually helped the housing developers receive state tax credits because it was an innovative project that linked housing and transportation costs.

The TOD's affordable housing units have had a large impact on the overall affordability of rents in the neighborhoods and ameliorated the risks of displacement. All of the units within the TOD projects are affordable housing units. The councilman's office in MacArthur Park made affordable housing one of its primary areas of concern. Mr. Reyes encouraged his staff members to pressure new housing developers that were interested in coming into the neighborhood, and needed a rezoning permit, to address the affordable housing issue. Both TOD projects were awarded to developers who were experts in affordable housing and actually had experience working in low-income, Latino communities. In Fruitvale, MVE Architects, Inc. were the architects in charge of designing a community-oriented and culturally appropriate TOD project. In Los Angeles, McCormack Baron and Salazar where the developers who had extensive experience building and managing affordable housing projects throughout the country. In retrospect, former Unity Council leaders feel that they should have initially focused more on affordable housing instead of building the retail services and only 90 units. Their second phase is all affordable housing with about 300 units. A key leader in the organization explained their mistake:

What should we have done differently? Well, I mean it's hard to say what one would do different. I think one thing I might have done differently if I had...we probably should have built phase 2 as phase 1 because that was going to be the affordable housing component. And the housing in phase 2, plus the one in phase 1 would have supported the retail more.

The affordable housing component needs to be included because the new built capital will most likely increase the value of the neighborhood, since there has been an increase in new amenities and access to regional transit. MacArthur Park is a case in point because it has all the urban amenities that urbanists crave yet even though the TOD came in, the community was not displaced because of the key role affordable housing advocates played in its development. A non-profit business organizer summarized the point:

MacArthur Park should be an example for the rest of the country. It's important to maintain the neighborhood, it's a mile from downtown, a lot of jobs are there, a lot of access to transit, medical services, and a beautiful public space. A perfect place for new urbanists. "It all fits together." Equity in terms of TOD is providing more affordability and access because of the link to affordable housing and transportation, but the affordable housing has to be there. 
Another outcome related to equity in these TOD projects relates to the TOD projects encouraging diverse, local small businesses. The Fruitvale Transit Village accomplished this by bringing more foot traffic onto International and by directly supporting the BID's establishment. The Unity Council understood from the beginning that Latino small businesses were interdependent with the success and failure of the Fruitvale Transit Village. They did not want to directly compete with them and, in fact, wanted to find ways to collaborate and support them. Interestingly, the vision Unity Council leaders had for the project's initial retail was to incorporate higher-end retail similar to that found in BART's Rockridge station. They felt that that type of retail would provide a more mixed-income presence in the neighborhood without necessarily displacing any of the existing Latino businesses. Their strategy failed, however. The transit village's commercial properties remained vacant for a few years. But now all their commercial properties are occupied. They were able to fill a lot of space by placing service agencies instead of retail, which actually serves more of an equity function.

The entire boundary of MacArthur Park is surrounded by Latino small businesses. The TOD project did not directly support these small businesses, but one can make the argument that the increase in foot traffic, which was spurred by the subway station, has directly benefitted the businesses that are located within walking distance of the METRO station. Where the TOD project did directly support Latino business owners, however, is that it was the catalyst behind the street-vendors program. Here one can argue that the METRO station helped to increase the number of street vendors (at times, there are approximately 50 vendors surrounding the exits of the subway station) that are located both adjacent to the METRO station and in the park. The street-vendors program, for example, was responsible for formalizing many of the informal business relationships that existed in the neighborhood. Two of the area's councilmembers were instrumental in supporting those activities.

The Fruitvale TOD's effects on the community's social services make it stand out in terms of equity impacts. Fruitvale Village is an entire package that has a health care facility, a childcare center, a public library, a senior center, and a charter high school. While the MacArthur Park TOD does not have any of these social services, they are located in the neighborhood within walking distance of the TOD.

Fruitvale Transit Village has found a way to package all these social services under one project. The village has a library that was funded by the City of Oakland. It also has a charter school, Arise Charter High School, where 90 percent of students are Latinos recruited from the local area. The school's primary focus is on college preparation. The TOD's Head Start program has a long waiting list. It also has a senior center that, according to a local politician, "is one of the most successful senior centers in the city and is always packed. Not once a week, but if you go every day of the week you will see Latino, Asian and black seniors that spend most of their time there. If you look at the library, if you go at any time after 3 o'clock you see more kids using those resources than any other library in the city. So when it comes to social equity, are you kidding me, affordable housing, what else can you want in one project!” 
The transit village's largest draw is the community health clinic, La Clinica, which brings thousands of clients into the village each year. The Unity Council's strategy was to build social services by targeting La Clinica as the development's anchor. La Clinica is a well-established and well-respected community health center that has been in Oakland since the 1970s. La Clinica has 32 sites, and in 2012 served over 80,000 patients and handled approximately 370,000 patient visits. It is the largest community health clinic in the state of California. Hence, it was critical for Arabella Martinez to convince La Clinica's leadership to relocate into the Fruitvale Transit Village to serve as the anchor tenant and add credibility to the TOD project. BART was also very interested in having La Clinica as part of the project. At 40,000 square feet, La Clinica's space in the transit village is the largest facility in its system, which provides medical, pharmaceutical, laboratory, behavioral health treatment, and dental services. The TOD has also helped increase the number of clients for La Clinica in the Fruitvale neighborhood. 


\subsection{CONCLUSION}

We hope we are catalysts in TOD for Los Angeles. Catalysts for future development. If you are looking at the TOD being a quarter of a mile from the station, we are the pin at the center, so our project can help catalyze other projects.

LA Metropolitan Transportation Agency TOD Staff

Catalyst projects need to be linked to other commitments, to ensure that low-income families have an opportunity to benefit from those catalysts, not just have catalysts change and gentrify those communities.

Non-profit business leader in MacArthur Park

We are celebrating this model that the rest of the country should be looking to. Putting housing close to transit is part of President Barack Obama's Climate Action Plan.

HUD Secretary Shaun Donovan, after touring the MacArthur Park TOD, 2012

\subsection{CATALYSTS FOR TRANSFORMING AND IMPROVING LOW- INCOME, LATINO COMMUNITIES}

The Fruitvale Transit Village and METRO’s MacArthur Park TOD project (as HUD Secretary Donavan commented on MacArthur Park) are models of how TOD projects should be constructed in low-income neighborhoods. In many ways, these neighborhoods are the areas in cities that could really benefit from large-scale transportation investments linked to housing, retail and community services. TOD projects that incorporate the community context and demand authentic public participation can ameliorate past discriminatory transportation policies that disrupted and even destroyed low-income communities of color. Hence, these projects have the potential to make amends for historical injustices and serve as vehicles for advancing equity (Young, 2011).

Contemporary TOD projects have the opportunity, depending on the process and the context of the neighborhood, to really make an important contribution towards the revitalization and improvement of low-income neighborhoods. Through this research project, we uncovered why the Fruitvale Transit Village and MacArthur Park TOD were different from the historical norm of detrimental, large-scale transportation projects, and how they contributed to the revitalization of both neighborhoods. Via two in-depth qualitative case studies, we traced the reasons why these projects were different. Both cases contributed to neighborhood revitalization because each neighborhood possessed strong endogenous forms of political, financial and cultural capital. These forms of capital, in turn, influenced the development of the TOD projects. We answered our main research question by closely analyzing the context and dynamics within each neighborhood and understanding how those dynamics influenced the TOD's outcomes. Hence, our research question: 
How might low-income, Latino communities benefit from large-scale TOD projects? What are the risks to these neighborhoods if TODs are linked to neighborhood revitalization? And what are the neighborhood characteristics that exist within Latino communities that can help mitigate those risks and create more equitable outcomes?

Large-scale TODs can help serve as catalysts for low-income neighborhoods by paying attention to and building upon three important factors in these neighborhoods:

1) Support the endogenous forms of cultural, political, financial and built capital that exist in these neighborhoods.

2) Encourage more bottom-up participatory forms of decision-making and activism in neighborhoods.

3) Incorporate and support increased access to:

- Regional public transportation

- Affordable housing

- Diverse local small business networks

- Social services provisions like medical and educational facilities

- Authentic public participation methods

\subsubsection{Support Endogenous Forms of Cultural, Political, Financial and Built Capital that Exist in these Neighborhoods}

If transportation planners are indeed interested in increasing the equitable outcomes in lowincome communities via their TOD projects, they need to pay attention to the assets that already exist in these neighborhoods. Transportation planners cannot view all neighborhoods as being clean slates. Each neighborhood has a particular history and its own form of community-based assets. These assets need to be viewed as forms of capital that neighborhoods can build upon so that they are not gentrified. Both in Fruitvale's and MacArthur Park's TOD projects, these endogenous forms of capital were critical to ensuring that the projects contributed to equitable outcomes.

The political capital in the neighborhood was sustained by local Latino politicians who saw it in their best interest to make sure the TOD projects would not displace the existing Latino lowincome population. Politicians such as Gloria Molina, Mike Hernandez, Ed Reyes (and Mr. Reyes' Chief of Staff Jose Gardea), who represented District 1 in Los Angeles, advocated for community-oriented design measures during critical points in the project's decision-making process. Because of this, the project was better incorporated into the existing neighborhood's context. They maintained important ties to local CBOs and also tried to get them involved in the TOD planning process. CBOs were especially involved in advocating for increasing affordable housing in the area which helped mitigate gentrification concerns. Ed Reyes' staff also clearly understood the important role informality played in the neighborhoods' economic health. A key 
staff member even commented that "the informal economy is the formal economy for [the MacArthur Park] community.” They established a mercado where informal vendors could legitimately sell their goods, and also played a key role in establishing the city's first streetvendors district. In Fruitvale, Ignacio De La Fuente relied on his reputation and political capital to ensure that Fruitvale's TOD was financially and politically supported by the city council. He collaborated with other government institutions in the region such as BART, the regional MPO, and the Oakland Planning Department to ensure the project was supported.

Community-based organizations in the area also played a key role in developing the necessary political capital to ensure the TOD projects had community benefits. Without the Unity Council in Oakland, the Fruitvale Transit Village would most likely not have been envisioned, funded or built. The TOD project was the Unity Council's key project for almost a decade, and Arabella Martinez's key leadership helped sustain its process. The Unity Council's role was critical because it served in an intermediary role between the government's efforts to build a TOD and the community's needs. Mrs. Martinez had strong connections with federal, regional and local funding agencies that were able to provide the necessary resources to finish the project. The Unity Council also had strong community-based connections because of its 20-year history of providing important social services in the neighborhood. Hence, they were able collaborate with local businesses that initially opposed the TOD (because they viewed increased competition as a barrier to their continued success). The Unity Council was extremely effective in getting key community leaders on board to create a community vision for the TOD. They also had the needed political capital to oppose BART's initial plans to build a parking structure that would have cut International Boulevard off from the BART station.

In MacArthur Park, the neighborhood's CBOs also had a long history of community activism, which dated back to the early 1980s when they focused on human rights issues tied to Central America's civil wars. In other words, the CBOs were networked and united around transnational immigrant rights issues. And since the neighborhood's CBOs were powerful, the local council office understood it was important to collaborate with them on important issues such as affordable housing, policing and the park's improvement. The political influence local CBOs have in a neighborhood is critical to consider when implementing large-scale TODs. The political capital they possess can make or break a project. If CBOs are on board and feel that a TOD project will contribute to community benefits, they can help garner local support for the project and open up dialogue with residents and local business owners. But if CBOs think a TOD project will just lead to more displacement and neighborhood turnover, they can oppose the project via community protest or litigation, which could complicate the process or even stop the project.

Building on the financial capital that exists in these neighborhoods helps reframe these communities from marginalized areas to more vibrant communities where entrepreneurs are contributing to the neighborhood's revitalization. The merchants along International Boulevard served a very important role in the neighborhood's revitalization. They collaborated with the police department, and provided the "eyes on the street" that were necessary to create a safe area. The merchants were also organized by the Unity Council during key community participation 
efforts, which demonstrated that there was community support for the TOD project. The informal economic activities in MacArthur Park were not destroyed, which is usually the case when large-scale development projects are built in disinvested areas. Instead of displacing these informal activities, like the street vendors, local government officials decided to try and regulate them by legitimizing their businesses. This was difficult to do and the strategy saw mixed success. The street-vendors district provided opportunities for some vendors to get training via Mama's Hot Tamales because they were able to start their own formal restaurants through that training. The district, however, was ultimately discontinued because of the level of bureaucracy the vendors had to maneuver, and the competition that remained from informal vendors that undercut the regulated vendors' prices (Sandoval, 2010). These informal activities are an important part of low-income Latino neighborhoods, and creating strategies to support their regulation in a way that brings them out of the shadows can also be considered an equity outcome.

Cultural capital played a key role in the revitalization of the neighborhoods, and the TOD's design measures also benefited from a Latino cultural framing. The Fruitvale TOD was designed to take into consideration Latino placemaking practices expressed via physical attributes. This is why a paseo, a public plaza, a mercado, and other Latino cultural architectural attributes were designed into the physical structure of the TOD project. The MacArthur Park TOD also incorporates Latino placemaking features. However, these features were incorporated only after the TOD project transitioned from a top-down to bottom-up process. MacArthur Park's Oscar Romero Plaza, for example, represents an important placemaking cultural icon in the Salvadorian community. Its location in one of the largest public spaces for Latinos in LA is directly across the street from the TOD project and is in tune with Latino placemaking practices (Main, 2012). The availability of culturally specific food in both neighborhoods - the cultural celebrations and parades in both communities and the physical reminders of home (Mexico and Central America) that immigrants feel when they are walking through the neighborhood - are all cultural expressions of capital within the neighborhood (Main and Sandoval, 2014). The success of both of these TOD projects, in a large way, can be attributed to the savvy way stakeholders were able to communicate the positive expressions of the cultural capital within these communities.

\subsubsection{Encourage More Authentic Bottom-Up Participatory Forms of Decision-Making and Activism in Neighborhoods}

Mechanisms for authentic public participation need to be incorporated into TOD projects, especially those where there are gentrification risks. This participation needs to go beyond what is legally mandated and also go beyond unauthentic forms of public engagement so that decisions that have already been made by transportation planners are not the driving force behind large-scale transportation projects. Although both the Fruitvale and MacArthur Park neighborhoods have very similar demographic characteristics and both initially opposed topdown TOD projects, the public participation process in each case was very different.

The Fruitvale Transit Village project was developed through a top-down political process by a well-established and well-connected community development corporation (the Unity Council). 
Key Latino leaders who had contacts at the federal, state, regional and city levels led the project. The Unity Council had decision-making power regarding the project's development, and controlled both the vision and how the project should be developed. They did, however, provide many public participation opportunities, such as when they engaged local residents during community workshops and organized local merchants. There were even instances where they went directly to gang members in the community and got them involved in the process by asking them how they would like to see their community improved. Since they had been working in the neighborhood since 1964, the Unity Council had strong connections with local churches, service agencies, schools, politicians, businesses, other CBOs and key community leaders in the neighborhood. These connections are very important in public participation processes. Transportation planners working on equity issues need to either establish these types of connections or rely on CBOs that are well-connected in the community and have already built high levels of trust. In other words, transportation planners can connect to important community leaders through experienced liaisons (CBO staff members). Even though the Unity Council used a top-down political process model for accomplishing its goals, these community connections ultimately helped them sell the project as a community-driven, urban revitalization, TOD project.

The MacArthur Park TOD emerged as a top-down process that eventually broke down. In its resurrection, a more organic process emerged that was supported by the local councilman's office and key CBOs in the neighborhood. METRO had a "get anything built at the TOD site" agenda, which provided the city councilman's office an opportunity to build something that would address the Latino community's needs. The MacArthur Park TOD was a standalone project that was focused on providing affordable housing and retail (but no social services). But the TOD project eventually impacted other forms of businesses and social services in the neighborhood, and through the sum of its parts helped contribute to other forms of neighborhood revitalization.

The CBOs and activists in MacArthur Park played an important role in re-creating the TOD project and revitalizing the neighborhood. They were savvy about working with the councilman's office and placing needed pressure when appropriate. Most of their activism centered on gentrification concerns and focused on making sure there were adequate amounts of affordable housing constructed in the neighborhood. They feared that the TOD project would bring additional forms of investment into the area and change both the retail and housing character of the neighborhood, which would ultimately lead to neighborhood turnover. Some of these neighborhood organizations had been working together for approximately 20 years, so they trusted one another and believed in each other's work. The was one key difference in MacArthur Park and Fruitvale, as it relates to CBO participation: In MacArthur Park a network of CBOs represented the community's well-being, while in Fruitvale there was one organization that was primarily responsible for representing the neighborhood's interests. The process, however, was similar in terms of the amount of energy each CBO exerted, and how they influenced local politicians and development agencies to address local needs. 


\subsubsection{Support Increased Access to Equity Outcomes}

Both the Fruitvale and MacArthur Park TOD projects need to be seen as more than standalone TOD projects. They should be viewed as catalyst projects that helped initiate or contributed to the neighborhood revitalization of low-income, Latino communities. Both projects contributed to neighborhood-based equity outcomes in terms of providing access to regional transportation and affordable housing; supporting local businesses; and increasing access to social services. Fruitvale Transit Village became a social service hub for the neighborhood and opened up regional mobility to people in the community. The MacArthur Park TOD became a national example for linking affordable housing to transportation and mobility.

In Fruitvale, La Clinica eventually relocated to the TOD site and now also operates an important regional community health clinic there. The city located a public library (paying 20 years of advanced rent to help secure more financing for the TOD). The TOD's senior center is a vibrant multicultural activity center that draws seniors from across the entire neighborhood. Arise, a charter school that relocated to the TOD site, recruits neighborhood youth and prepares them with the tools they will need to be successful in college. The majority of their students are Latinos. The Head Start program, located in a beautiful facility at the TOD site, has a long waiting list because it serves the local neighborhood's low-income population. Initially, the Unity Council had a difficult time finding tenants for its commercial retail spaces because highend commercial entities were reluctant to locate their businesses in a low-income, Latino community. This conflict was further exacerbated after local merchants, who were located on International Boulevard, opposed the Council's retail efforts. Today, however, there seems to be a healthy amount of synergy between the businesses located on International and those in the village.

One of the most important outcomes associated with Fruitvale's TOD project was how the neighborhood's geographic center (International Boulevard) was incorporated into BART's regional transportation hub. This was accomplished via the paseo. The paseo was always the goal, not to build a plaza or a public space, but to connect International to the BART station. The other key outcome was how businesses on International benefited from the TOD project. At first, merchants on International were opposed to the project. However, after the development of a business improvement district (BID), these merchants furthered their community's revitalization efforts by providing feedback on how they should complement the retail located in the transit village. In fact, the merchants on International were given priority access to the transit village's new retail spaces. Overall, the top-down political strategy that Arabella Martinez used to accomplish her vision of creating a TOD in a low-income Latino neighborhood improved the neighborhood.

The MacArthur Park revitalization needs to be viewed in a more organic and holistic manner. The key was affordable housing as a tool to mitigate gentrification concerns. Building new affordable housing was a primary goal of both the local council's office and key CBOs in the neighborhood. The councilman's office also encouraged developers to create mixed-income housing, essentially forcing developers to set aside about 20 percent of their units for affordable 
housing. The councilman's office encouraged three links to any new housing development: 1) paying attention to design, 2) providing affordable housing, and 3) improving access to public transportation. The councilman's office was interested in increasing affordable housing in the neighborhood, so it used its leverage to accomplish this goal. LA's City Council has discretionary zoning powers, which means it can regulate land use patterns, and thus can either accommodate or deny developers who are interested in changing zoning requirements that do not allow for their particular developments. Hence, the council office placed pressure on developers to create projects that would incorporate the neighborhoods' current low-income, Latino immigrant population.

MacArthur Park's local small businesses were also supported by the TOD project. The new affordable housing units will provide new markets for businesses, but more importantly, the construction of the subway station opened up the neighborhood to a larger and more regional market. The redevelopment agency, with the assistance of the councilman's office, also helped organize a BID in MacArthur Park (located within the TOD site). This BID has focused on street design and litter cleanup. The MacArthur Park neighborhood is also home to a large number of social services. But instead of being located under one package (the TOD), they are scattered throughout the neighborhood. They are still located within walking distance from the TOD site, however. MacArthur Park is also a regional hub for medical services, which specifically cater to low-income, Latino immigrants. There are dozens of small medical clinics in the neighborhood. At these clinics, medical providers speak Spanish, work mostly through a cash economy, and serve a large amount of patients without health insurance. The formal medical practices that are provided by these clinics are regulated by the state. They provide a very important service to the neighborhood.

\subsection{FUTURE RESEARCH ON TODS IN LATINO NEIGHBORHOODS}

The purpose of the study was to better understand how TOD shaped the revitalization efforts occurring in two low-income Latino communities where TOD was a major factor in revitalization efforts. We were particularly interested in the relationship between TOD and neighborhood revitalization related to equity concerns. It is critical to understand how these projects contributed to community revitalization because of the dismal history that large-scale transportation projects have had on low-income communities of color. This research has demonstrated that TOD projects can contribute to equity outcomes and generative urban revitalization in low-income, Latino, immigrant communities by incorporating the various forms of sociopolitical, financial and cultural capital that exists in these communities into the planning and implementation process of these projects. These endogenous forms of capital intermix with the new investments in built capital and create opportunities for community investments that can contribute to neighborhood revitalization opportunities.

The Community Capitals Framework helped uncover the various forms of capital that existed in the neighborhoods (political, financial, cultural and built), and how those forms of capital intermixed to create the specific equity outcomes we identified. Our comparative case-study approach allowed us to recognize important conceptual relationships as well as to understand 
how certain equity outcomes were tied to specific forms of capital within the neighborhoods. In order to further explore the study's emerging findings on TODs in low-income, Latino neighborhoods, the next step in this research is to expand and continue conducting more replication case studies of TOD projects in similar neighborhoods. Conducting more case studies in low-income, immigrant, Latino neighborhoods that have seen TOD investments will help answer our primary conceptual question, which asked how the institutional, social, cultural and political context of Latino, low-income, immigrant communities helps them reshape large-scale redevelopment projects in a more equitable and generative fashion. We aim to understand how the process and outcomes are similar or differ in other neighborhoods and explain the distinction.

Two new case studies have been identified to further explore the study's emerging conceptual questions and framework, and shed more light on the effects TOD projects have in terms of equity outcomes in low-income, Latino communities. Each case study will focus on a key aspect of the emerging conceptual question, and will ultimately lead to the creation of typologies of TODs in Latino neighborhoods. The case sites are the following: (1) Pico/Aliso METRO Gold Line Rail Station in East LA, located in an area with a high amount of affordable housing; and (2) the Barrio Logan San Diego Trolley station near Chicano Park, a node of activism for Latinos in the region. These two new case studies will build on the findings in this report to generate typologies of TOD projects in Latino neighborhoods and the various equity outcomes generated by each project.

This future research will examine how TOD projects in Latino neighborhoods are different (related to affordable housing, social services, retail, community activism, and placemaking) from traditional TOD projects (R. Cervero et al., 2002; Carlton, 2007; J. Jacobson and A. Forsyth, 2008). It also will explore how this difference needs to be understood by transportation planners and decision-makers when they are intervening in these neighborhoods. For example, some planners might view these areas as blighted and consider TOD projects as being the important interventions or catalysts needed to "improve" the character of the community. However, this type of approach (especially when it is coupled or guided with a meager understanding of important community drivers) can lead to displacement and gentrification. This research project will build upon the findings of this report, and identify how communities and transportation planners can create more equitable transportation systems by building on the endogenous characteristics found throughout Latino neighborhoods. We will specifically identify strategies and tools to help ameliorate gentrification concerns because of the new capital investments.

The Fruitvale Transit Village and MacArthur Park TOD case studies help us better understand how TOD projects can be more inclusive, generative and community-based. They help us recognize the importance of working within the context of a neighborhood. In both cases, for example, we see the important role neighborhood dynamics play in contributing towards equity outcomes in low-income, Latino, immigrant neighborhoods. These two cases also shed light on the important role transportation planners play in supporting more equitable outcomes by building on the endogenous forms of capital that exists in these neighborhoods, and by creating opportunities for authentic public participation were community members have some power to 
shape the process. TOD projects can provide opportunities for improving low-income communities, and both the Fruitvale Transit Village and MacArthur Park TODs are exemplary examples of how these equity outcomes can be accomplished. 


\subsection{REFERENCES}

Atkinson, Rowland (2002) Does Gentrification Help or Harm Urban Neighborhoods?: An Assessment of the Evidence-Base in the Context of the New Urban Agenda. In ESRC Centre for Neighbourhood Research. CNR Paper 5.

Avila, Eric (2014) The Folklore of the Freeway: Race and Revolt in the Modernist City. Minneapolis, MN: University of Minnesota Press.

Avila, Eric (1998) The Folklore of the Freeway: Space, Culture, and Identity in Postwar Los Angeles. In Aztlan: A Journal of Chicano Studies 23 (1), pp. 15-31.

Benn, Howard P. (1995) Bus Route Evaluation Standards: A Synthesis of Transit Practice. With assistance of The Federal Transit Administration. TCRP Synthesis 10. Washington, D. C.

Bernick, M. and R. Cervero (1997) Transit Villages for the $21^{\text {st }}$ Century. New York: McGrawHill.

Blackwell, Angela (2000) Promoting Equitable Development. In Indiana Law Review 34 (4), pp. 1273-1290.

Boarnet, M. and R. Crane (1998) L.A. Story: A Reality Check for Transit-Based Housing. In Journal of the American Planning Association 63 (2), pp. 189-204.

Bullard, R. D. (1996) Introduction: Environmental Justice and Transportation. In Environmental Justice and Transportation: Building Model Partnerships. Clark Atlanta University.

Bullard, R. D. and Glenn S. Johnson (eds.) (1997) Just Transportation: Dismantling Race and Class Barriers. Gabriola Island, B. C.: New Society Publishers.

Calthorpe, P. (1993) The Next American Metropolis: Ecology, Community, and the American Dream. New York: Princeton Architectural Press.

Cartlon, Ian (2007) Histories of Transit-Oriented Development: Perspectives on the Development of the TOD Concept. With assistance of the Institute of Urban and Regional Development. University of California, Berkeley. Working Paper 2009-02.

Cervero, Robert (1998) Transit Villages in California: Progress, Prospects, and Policy Reforms. With assistance of the Institute of Urban and Regional Development. University of California, Berkeley. Working Paper 98-08.

Cervero, Robert (2004) Transit-Oriented Development in America: Contemporary Practices, Impacts, and Policy Directions. With assistance of the Institute of Urban and Regional Development. Paper prepared for International Planning Symposium On Incentives, Regulations, and Plans.

Cervero, Robert et al (2004) Transit-Oriented Development in the United States. Experiences, Challenges, and Prospects. With assistance of the Transit Cooperative Research Program. TCRP Report 102. Washington, D.C.

Cervero, Robert; Ferrell, Christopher; and Steven Murphy (2002) Transit-Oriented Development and Joint Development in the United States: A Literature Review. With assistance of the Transportation Research Board of the National Academies. Research Results Digest 52.

Cohen, Adam (2000) Los Angeles. Gangsta Cops. In Time 155, 3/6/2000 (9), pp. 30-34. Available online at http://content.time.com/time/magazine/article/0,9171,996265,00.html.

Crane, Randall and Lisa Scweitzer (2003) Transport and Sustainability: The Role of the Built 
Environment. In Built Environment 29 (3), pp. 238-252.

Dittmar, Hank and Gloria Ohland (eds.) (2004) The New Transit Town: Best Practices in Transit-Oriented Development. Washington, D.C.: Island Press.

Flora, Cornelia and Jan Flora (2013) Rural Communities: Legacy and Change. Boulder, CO: Westview Press.

Furth, Peter (2000) Data Analysis for Bus Planning and Monitoring: A Synthesis of Transit Practice. With assistance of The Federal Transit Administration. TCRP Synthesis 34. Washington, D.C.

Gleason, J. M. and Darold T. Barnum (1982) Toward Valid Measures of Public Sector Productivity: Performance Measures in Urban Transit. In Management Science 28 (4), pp. 379-386.

Hartman, Ronald et al. (1994) The Role of Performance-Based Measures in Allotting Funding for Transit Operations: A Synthesis of Transit Practice. With assistance of The Federal Transit Administration. Washington, D.C.

Hodge, D. (1980) Inner City Revitalization as a Challenge to Diversity? Seattle. In Laska, S. B. and D. Spain (eds.), Back to the City: Issues in Neighborhood Renovation, pp. 187-203. New York: Pergammon Press.

Jacbonson, Justin and Ann Forsyth (2008) Seven American TODs: Good practices for urban design in Transit-Oriented Development projects. In Journal of Transport and Land Use 1 (2), pp. 51-88.

Kennedy, Maureen and Paul Leonard (2001) Dealing with Neighborhood Change. A Primer on Gentrification and Policy Choices. With assistance of The Brookings Institution Center on Urban and Metropolitan Policy.

Kirkpatrick, L. O. (2007) The Two "Logics" of Community Development: Neighborhoods, Markets, and Community Development Corporations. In Politics \& Society 35 (2), pp. 329-359.

Kittelson \& Associates, Inc. (2003) A Guidebook for Developing a Transit PerformanceMeasurement System. With assistance of Federal Transit Administration. TCRP Report 88. Washington, D.C.

Lee, B. L. (1997) Civil Rights and Legal Remedies: A Plan of Action. In Bullard, R. D. and G. S. Johnson (eds.), Just Transportation: Dismantling Race and Class Barriers to Mobility. Gabriola Island, B. C.: New Society Publishers.

Lefaver, Scott (1997) Public Land with Private Partnerships for Transit Based Development. With assistance of San José State University. IISTPS Report 97-1. Sacramento, CA.

Levinson, H. S. (2004) The New Transit Capacity and Quality of Service Manuel: Tour of the Expanded Guide for Transit Planners and Operators, $2^{\text {nd }}$ Edition. With assistance of the Transportation Research Board of the National Academies. TR News 232. Washington, D.C.

Litman, Todd (2002) Evaluating Transportation Equity. In World Transport Policy \& Practice 8 (2), pp. 50-65.

Loukaitou-Sideris, Anastasia (2000) Revisiting Inner-City Strips: A Framework for Community and Economic Development. In Economic Development Quarterly 14 (2), pp. 165-181.

Machell, Erin et al (2010) Building Support for Transit-Oriented Development: Do Community- 
Engagement Toolkits Work? With assistance of the University of California

Transportation Center. Berkeley, CA.

Main, Kelly (2012) Public Space Attachments for Latino and Immigrant Communities: A Case Study of MacArthur Park. In Rios, M. and L. Vasquez (eds.) Dialogos: Placemaking in Latino Communities. New York: Routledge, pp. 83-97.

Main, Kelly and Gerardo Sandoval (2014) Placemaking in a translocal receiving community: The relevance of place to identity and agency, Urban Studies 52 (1), pp. 71-86.

Mohl, R. A. (2008) The Interstates and the Cities: The U.S. Department of Transportation and the Freeway Revolt, 1966-1973. In Journal of Policy History 20 (2). 193-226.

Myers, Dowell (2007) Demographic Futures as a Guide to Planning: California's Latinos and the Compact City. In Journal of the American Planning Association 67 (4), 383-397.

Nakanishi, Yuko (1997) Big Performance Indicators: On-Time Performance and Service Regularity. With assistance of the Transportation Research Board. Washington, D.C.

Newman, Peter and Jeffrey Kenworthy (1999) Sustainability and Cities: Overcoming Automobile Dependence. Washington, D.C.: Island Press.

Renne, John and Peter Newman (2002) Facilitating the financing and development of 'Smart Growth.’ In Transportation Quarterly 56 (2), pp. 23-32.

Renne, John and Jan Wells (2004) Emerging Europeanstyle Planning in the USA: TransitOriented Development. World Transport Policy \& Practice 10 (2), pp. 12-24.

Rios, Michael et al (2012) Dialogos: Placemaking in Latino Communities. New York: Routledge.

Salvesen, D. (1997) Promoting Transit-Oriented Development. In Urban Land 55 (7), pp. 31-35.

Sandoval, Gerardo (2010) Immigrants and the Revitalization of Los Angeles: Development and Change in MacArthur Park. Amherst, New York: Cambria Press.

Soursourian, Matthew (2010) Equipping Communities to Achieve Equitable Transit-Oriented Development. In Community Investments 22 (2), pp. 22-45.

Still, T. (2002) Transit-Oriented Development: Reshaping America’s Metropolitan Landscape. In On Common Ground Winter, pp. 44-47.

Stolz, R. (2002) Transportation Equity and Environmental Justice. In Planners Network Magazine. Fall. Available online at http://www.plannersnetwork.org/2002/10/transportation-equity-and-environmentaljustice/.

Tobar, Hector (2000) The Tattooed Soldier. New York: Penguin Books.

Wander, Madeline (2008) An Equity Agenda for Transit-Oriented Development: Planning for Sustainable Growth in Los Angeles' Inner City. With assistance of Robert Gottlieb, Martha Matsuoka. Urban and Environmental Policy Senior Comprehensive Paper.

Wellman, Gerard C. (2012) Community Empowerment and Public Transportation Agencies: A Case Study Analysis of Transit Agencies' Community Development Initiatives. In Community Development Journal 43 (4), pp. 512-526.

Young, Iris Marion (2011) Justice and the Politics of Difference. Princeton, New Jersey: Princeton Press. 


\section{APPENDIX I: LETTER TO INTERVIEWEES}

\section{Dear Participant:}

I am a faculty member at the University of Oregon in the Department of Planning, Public Policy and Management. I am working on a research project that is designed to compare and contrast the development and community and equity impacts of three large transit-oriented development (TOD) projects in low-income Latino immigrant communities: MacArthur Park subway station in Los Angeles, Fruitvale Transit Village BART station in Oakland, and a light rail station in Hillsboro, OR. I will be interviewing metropolitan transportation staff, redevelopment staff, city planning staff, local city council members, politicians, and leaders of community based organizations in these three cities. Additionally, I will be interviewing community leaders, residents in the neighborhood, and other users of the transportation systems who have specific knowledge related to this topic.

These interviews will help me better understand how the transit oriented development transportation projects transformed these Latino immigrant communities. I will be evaluating the impacts of the TOD on these communities and how community members responded to these impacts. For example, I will evaluate whether the TOD projects lead to higher density land-use patterns in these neighborhoods, with minimum cases of displacement. The research will be shared with the academic community and will include policy recommendations related to policy and planning work, and specifically offer suggestions for how to implement large-scale transportation improvements in vulnerable low-income Latino communities. Please note that this research is funded by a grant from the National Institute for Transportation and Communities (NITC). I hope to learn about your role in these important issues, your knowledge of the topic area, and any insights regarding how Latino immigrants are shaping planning efforts related to TOD projects.

With your permission, I will be recording your interview. I will also be taking careful notes. These notes will be strictly confidential and stored in a secure location. All the interview notes shall be secured in a locked safe in my office and I will be the only person with access to that information.

This interview is voluntary and we can end them at any time you request. You are also free to refuse to answer any questions in these activities. There is no penalty or loss of benefits for not taking part in the research or for stopping your participation. The estimated time for the interview is approximately 1 hour. Again, your participation is voluntary and every effort will be made to keep your responses confidential. Completion of the interview indicates your willingness to participate in this project and that you are over the age of eighteen.

I am confident that this research will benefit city planners, transportation agencies, government officials, community agencies, and others working in immigrant neighborhoods as all can learn more about incorporating immigrants to large scale transportation infrastructural planning efforts. 
Please note, this project has been reviewed and approved by the Institutional Review Board (Committee for the Protection of Human Subjects) at the University of Oregon. If you have any questions about the rights of research subjects or research-related injury, please contact the IRB Administrator at (541) 346-2510.

If you have any questions about the project or interview or want more information before the interview, please feel free to contact the project advisor, Professor Gerardo Sandoval, at 541 346-8432.

Gerardo Sandoval, $\mathrm{PhD}$ 


\section{APPENDIX II: EXAMPLE OF INTERVIEW GUIDE}

1) Where did the idea for the project come from? What was the original goal?

2) What changes have you seen in the neighborhood before and after the TOD project? After the community revitalization efforts?

3) Who were the key players in the community, city, and other agencies that were involved in the TOD project?

4) How did you use your political capital as a resource to advocate for the project?

5) How did you get support to finance the project?

6) What mechanisms of public participation were incorporated into the project?

7) To what do you attribute the success or failure of the project?

8) Particularly, what were some of the characteristics within the community that contributed to the project?

- Social

- Cultural

- Political

- Financial?

9) What have been some unintended outcomes or challenges associated with the TOD project?

10) Have there been any worries of displacement in the community? How have they need addressed?

11) Compare and contrast to MacArthur Park/Compare and contrast to Fruitvale....

12) If you would have done anything different in the project, what would that have been?

13) Could this project be replicated in other communities? What would it take?

14) Anything else you consider important? 